\title{
Draft Function Allocation Framework and Preliminary Technical Basis for Advanced SMR Concept of Operations
}

Jacques Hugo John Forester David Gertman Jeffrey Joe Heather Medema Julius Persensky April Whaley

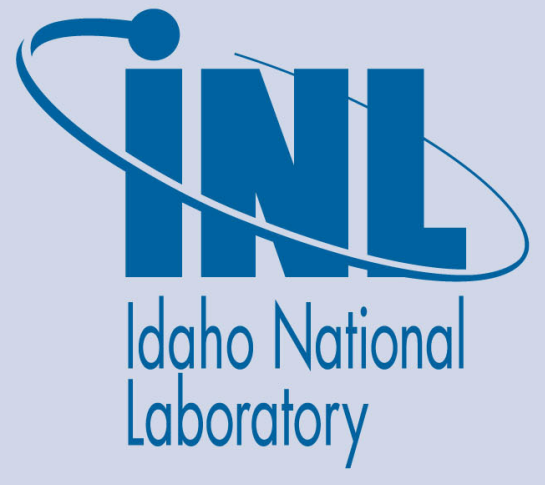

April 2013

The INL is a U.S. Department of Energy National Laboratory operated by Battelle Energy Alliance 
INL/EXT-13-28601

\title{
Draft Function Allocation Framework and Preliminary Technical Basis for Advanced SMR Concept of Operations
}

\author{
Jacques Hugo \\ John Forester \\ David Gertman \\ Jeffrey Joe \\ Heather Medema \\ Julius Persensky \\ April Whaley
}

April 2013

\begin{abstract}
Idaho National Laboratory
Human Factors, Controls and Statistics Department

Idaho Falls, Idaho 83415

http://www.inl.gov
\end{abstract}

Prepared for the U.S. Department of Energy Office of Nuclear Energy Under DOE Idaho Operations Office

Contract DE-AC07-05ID14517 


\section{DISCLAIMER}

This information was prepared as an account of work sponsored by an agency of the U.S. Government. Neither the U.S. Government nor any agency thereof, nor any of their employees, makes any warranty, expressed or implied, or assumes any legal liability or responsibility for the accuracy, completeness, or usefulness, of any information, apparatus, product, or process disclosed, or represents that its use would not infringe privately owned rights. References herein to any specific commercial product, process, or service by trade name, trade mark, manufacturer, or otherwise, does not necessarily constitute or imply its endorsement, recommendation, or favoring by the U.S. Government or any agency thereof. The views and opinions of authors expressed herein do not necessarily state or reflect those of the U.S. Government or any agency thereof. 



\section{EXECUTIVE SUMMARY}

This report presents preliminary research results from the investigation into the development of new models and guidance for Concepts of Operations in advanced small modular reactor (aSMR) designs. aSMRs are nuclear power plants (NPPs), but unlike conventional large NPPs that are constructed on site, aSMRs systems and components will be fabricated in a factory and then assembled on site. aSMRs will also use advanced digital instrumentation and control systems, and make greater use of automation. Some aSMR designs also propose to be operated in a multi-unit configuration with a single central control room as a way to be more cost-competitive with existing NPPs. These differences from conventional NPPs not only pose technical and operational challenges, but they will undoubtedly also have regulatory compliance implications, especially with respect to staffing requirements and safety standards.

For example, the impact of aSMR designs on operational and regulatory considerations, such as workload, situation awareness, human reliability, staffing levels, and the appropriate allocation of functions between the crew and various plant systems that are likely to be highly automated is largely uncertain and will remain uncertain until empirical research data become available to support the development of sound technical bases. Experience with aSMRs outside of the US Navy is limited, existing human factors and systems engineering design standards are not current in terms of human interaction basics for automated systems, and there is a lack of a good functional allocation and staffing model that takes into account static or dynamic allocation.

Given these uncertainties and other issues, new Concepts of Operations models must be researched and developed for aSMRs. Concepts of Operations describes the characteristics of a proposed system from the viewpoint of an individual who will use that system. It is used to communicate the quantitative and qualitative system characteristics of the plant to all stakeholders, provides the basis for procedures, and serves as input to Human Factors analyses. New Concepts of Operations models are developed by conducting an in-depth analysis of the characteristics and attributes of the concepts of operations of future aSMR. By doing this, insights into how the role and function of humans in the plant might be affected by advanced aSMR technologies, and, conversely, how the operation of these plants might be influenced by the need to integrate human factors principles in the design are revealed.objective of this research is to establish the technical bases for non-traditional concepts of operations for aSMRs (i.e., Develop new models and guidance for Concepts of Operations), with the goal of addressing specific human factors challenges related to non-traditional concepts of operations, and the associated changes in the allocation of functions to human and system agents. This includes the development of functional allocation principles as one of the primary decision criteria for staffing design and HSI design.

In support of this objective and goal, three important research areas were included: (1) operating principles of multi-modular plants, (2) function allocation models and strategies that are affected by the development of new, non-traditional concept of operations, and (3) the requirements for human performance, based upon work domain analysis and current regulatory requirements. The major findings and key observations to date are that while there is no aSMR operating experience that informs Concepts of Operations, a considerable amount of conceptual design information in published literature is available, along with operating experience from predecessor plants, such as the Experimental Breeder Reactor-II (EBR-II). Given these sources of information, this research effort has been able to make significant preliminary progress in developing models of Concepts of Operations for aSMRs. This Concepts of Operations project has laid out the framework for and has begun to define the operational strategies and requirements that establish the functions and staffing requirements aspects to aSMR concepts of operations, which are essential to informing the allocation of functions and the collaboration of humans and automation within the aSMR operating context. 
This report summarizes the progress to date on our efforts to outline potential functions, including the theoretical and operational foundations for the development of a new functional allocation model and the identification of specific regulatory requirements that will influence the development of future concept of operations. The report also highlights changes in research strategy prompted by confirmation of the importance of applying the work domain analysis methodology to a reference aSMR design. It also describes how this methodology will enrich the findings from this phase of the project in the subsequent phases and helps in identification of metrics and focused studies for the determination of human performance criteria that can be used to support the design process. 


\section{Acknowledgements}

The success of this project depends upon the experience, knowledge and insights of several highly respected individuals. Among these there can be little doubt that Julius "J" Persensky was a giant among human factors experts. His years at the NRC and his more recent work as part of the Idaho National Laboratory Human Factors, Controls and Statistics department made an indispensable contribution to this project; his extensive knowledge and experience in Human Factors, nuclear power, and the regulatory environment was unsurpassed, and he was critical to the success of this project in his role as mentor and expert. It was therefore with shock and sadness that the team recently learned that $\mathrm{J}$ had passed away after a difficult struggle with cancer.

This report is dedicated to the memory of $\mathrm{J}$ and his sterling efforts to contribute to this project and this report during trying times. The project team will miss him and know that the nuclear industry has lost another human factors pioneer. 


\section{CONTENTS}

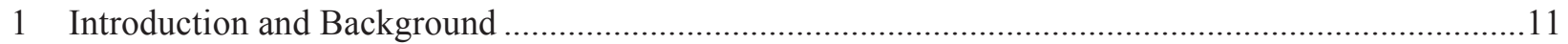

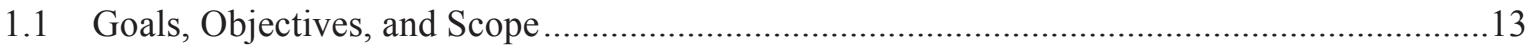

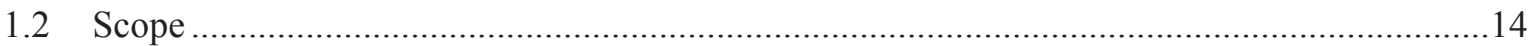

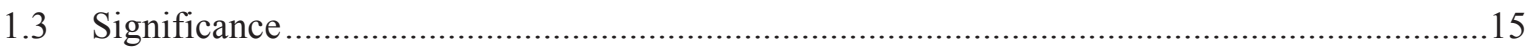

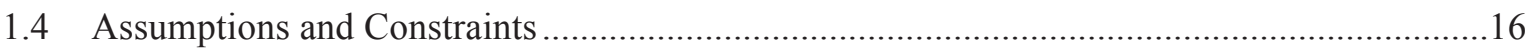

2 Methodology

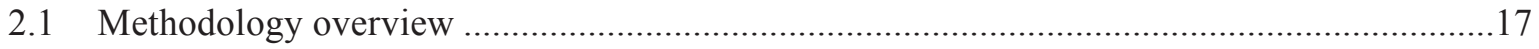

2.2 Literature reviews of Scientific and Technical reports ....................................................17

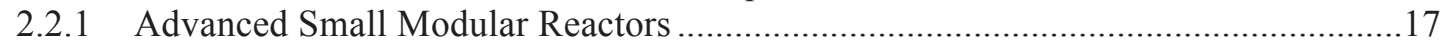

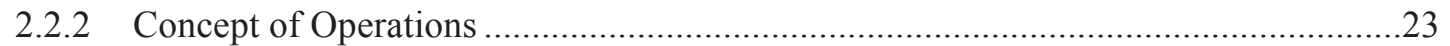

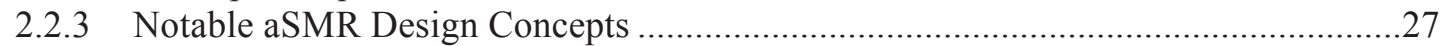

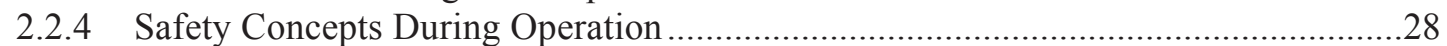

2.2.5 Operational Issues with Sodium Cooled Reactors.....................................................

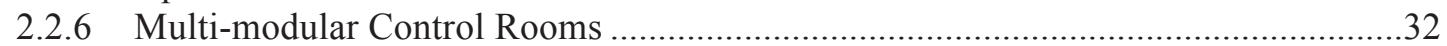

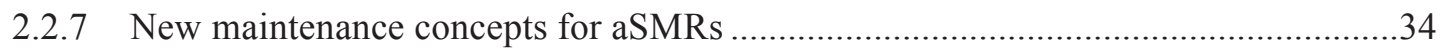

2.2.8 Concept of Operations: Advanced Diagnosis and Prognosis. .....................................35

2.2.9 Beyond Design Basis Accidents for non-LWRs ..........................................................

2.2.10 The Relationship between Systems Engineering, Human Factors Engineering, and Concept of Operations ................................................................ 37

2.2.11 Development of ConOps documents in the Nuclear Industry ..................................39

3 Development of a Function Allocation Model for aSMR ConOps ...................................................42

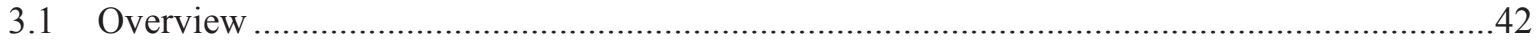

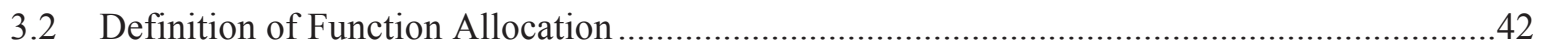

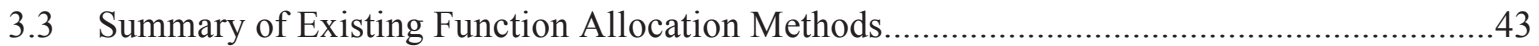

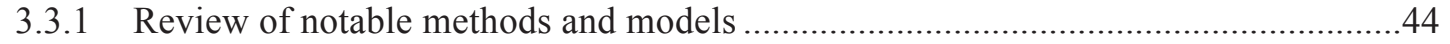

3.3.2 Strengths and weaknesses associated with current function allocation

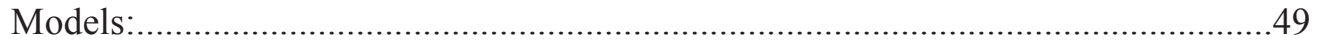

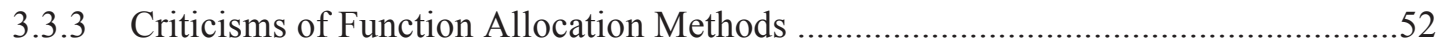

3.4 General principles for the development of a dynamic function allocation model ..................55

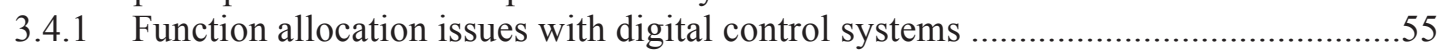

3.4.2 Role of Function Allocation in the NRC review process ..........................................57

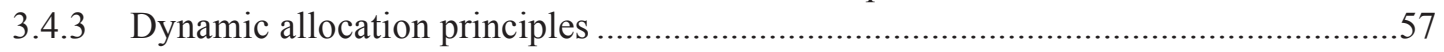

3.5 Proposed new foundational function allocation model and process to support the

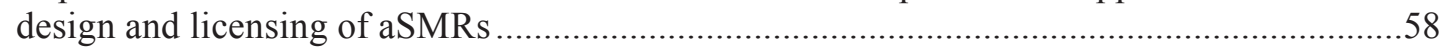

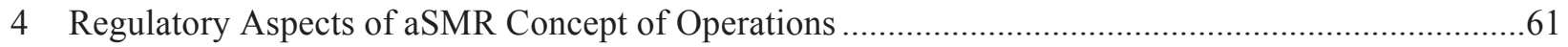

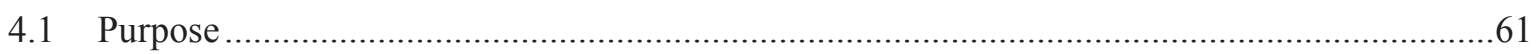

4.2 Overview of Concept of Operations-Related Issues .........................................................61

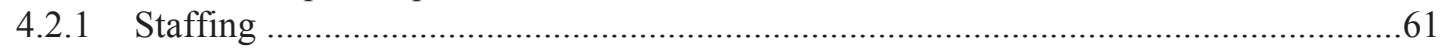

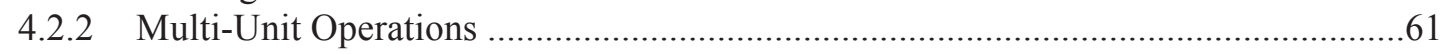

4.3 Current Regulatory Basis and Guidance for SMR Designs ..............................................63

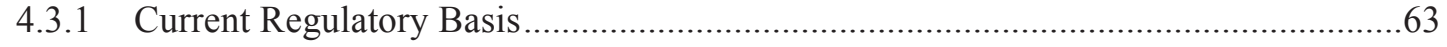

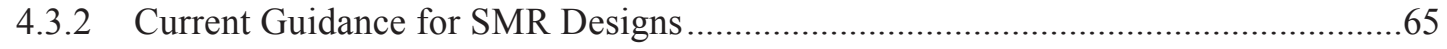




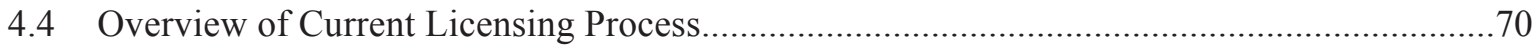

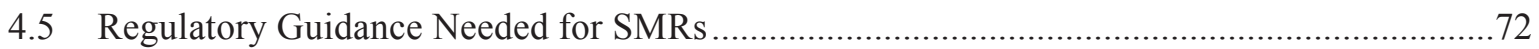

4.6 Guidance for Working Within Current Regulatory Framework .............................................73

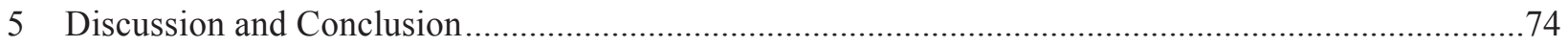

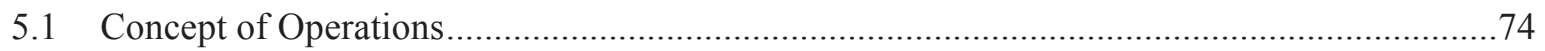

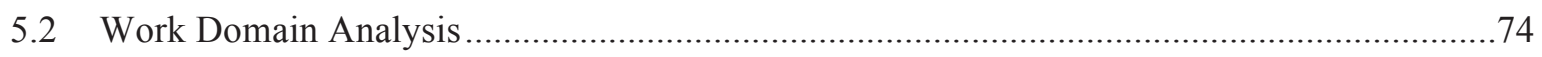

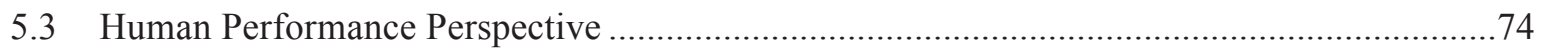

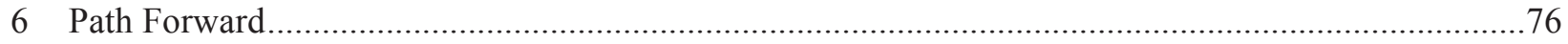

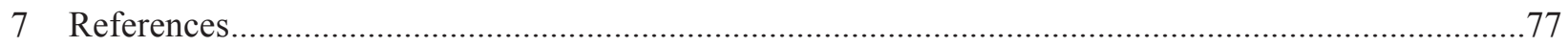

\section{FIGURES}

Figure 1: Integration of HFE with Systems Engineering and Licensing Processes.................................. 37

Figure 2: The Concept of Operations Document and its relationship to other engineering

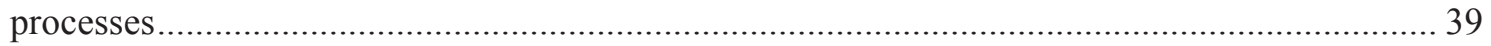

Figure 3: Process Flow Diagram (Hugo, 2009, adapted from NUREG/CR-3331) ................................. 46

Figure 4: Broad-based methodology for allocation of functions (Nemeth, 2004) ................................... 47

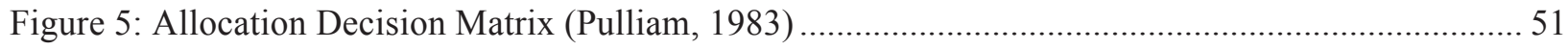

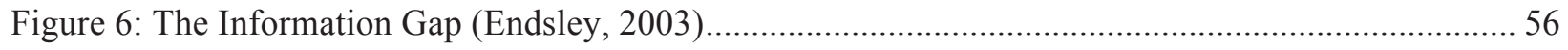

\section{TABLES}

Table 1: Operational and Human Factors impact of aSMR design concepts ........................................ 18

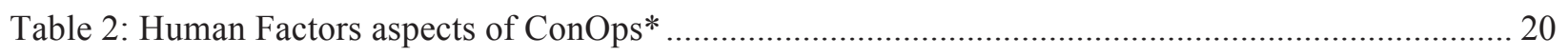

Table 3: Comparsison of current-generation plant safety systems with potential SMR design* .............. 28

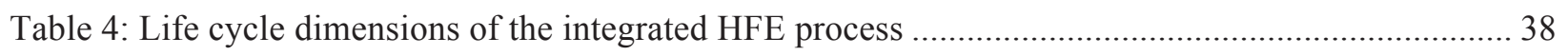

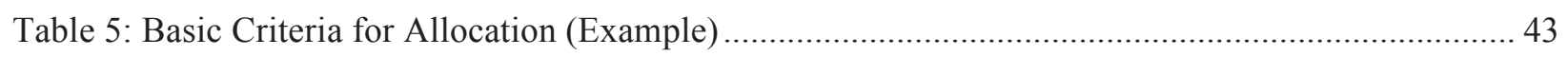




\section{ACRONYMS}

$\mathrm{AC} \quad$ Alternating current

AIAA American Institute of Aeronautics and Astronautics

ANS American Nuclear Society

ANL Argonne National Laboratory

ANSI American National Standards Institute

AOO Anticipated operational occurrence

AOP Abnormal operating procedure

aSMR Advanced small modular reactor (non-light water reactor technology)

ATWS Anticipated transient without scram

BNL Brookhaven National Laboratory

BOP Balance of plant

CBP Computer-based procedure

CFR Code of Federal Regulations

COL Combined License (NRC)

ConOps Concepts of operations

COSS Computerized operator support system

CNRA Committee on Nuclear Regulatory Activities

CSNI Committee on the Safety of Nuclear Installations

DC Direct current

DCD Design control documents

DiD Defense-in-Depth

DOE U.S. Department of Energy

EBR Experimental Breeder Reactor

ECCS Emergency core cooling system

EOF Emergency operations facility

EOP Emergency operating procedure

EPR European Pressurized Reactor

ESBWR Economic Simplified Boiling Water Reactor

FA Function allocation

FBR Fast breeder reactor

FRA Functional requirements analysis

FSAR Final Safety Analysis Report

GE General Electric 
HFE Human factors engineering

HRA Human reliability analysis

HSI Human-system interface

HTGR High-Temperature Gas-cooled Reactor

HVAC Heating, ventilation, and air conditioning

I\&C Instrumentation and control

IAEA International Atomic Energy Agency

ICHMI Instrumentation and Control and Human-Machine Interface

ICU Intensive Care Unit

IEEE International Electrical and Electronics Engineers

IIRP Issue Identification and Ranking Program

INCOSE International Council on Systems Engineering

INL Idaho National Laboratory

INPO Institute of Nuclear Power Operators

IPWR Integral Pressurized Water Reactor

LMR Liquid metal reactor

LWR Light water reactor

MCR Main control room

MWe Megawatts electricity

NEA Nuclear Energy Agency

NOP Normal operating procedure

NPP Nuclear power plant

NRC U.S. Nuclear Regulatory Commission

NSSS Nuclear steam supply system

O\&M Operations and maintenance (costs)

OCC Outage control center

OCD Operational concept document

OECD European Organization for Economic Co-operation and Development

ORNL Oak Ridge National Laboratory

PCS Process control system

PCU Power conversion unit

PPE Personal Protective Equipment

PRA Probabilistic risk analysis

PSER Pre-application safety evaluation report

PWR Pressurized water reactor 


$\begin{array}{ll}\text { RFI } & \text { Request for information } \\ \text { RPS } & \text { Reactor protection system } \\ \text { SAMG } & \text { Severe Accident Management Guideline } \\ \text { SEMP } & \text { Systems Engineering Management Plan } \\ \text { SEP } & \text { Systems Engineering Process } \\ \text { SMR } & \text { Small modular reactor (based on light water reactor technology) } \\ \text { SPDS } & \text { Safety Parameter Display System } \\ \text { SSC } & \text { Structures, systems, and components } \\ \text { TAREF } & \text { Task Group on Advanced Reactor Experimental Facilities } \\ \text { TMI } & \text { Three Mile Island } \\ \text { TRP } & \text { Technical Review Panel } \\ \text { TSC } & \text { Technical support center } \\ \text { TSS } & \text { Task Support System } \\ \text { UAS } & \text { Unmanned aircraft system } \\ \text { WANO } & \text { World Association of Nuclear Operators } \\ \text { WDA } & \text { Work domain analysis }\end{array}$




\section{Advanced SMR Concepts of Operations:}

\section{Draft Function Allocation Framework and Preliminary Technical Basis}

\section{Introduction and Background}

The U.S. Department of Energy (DOE) and the nuclear power industry are exploring alternatives to meet the future energy demands of the United States. As part of this mission, they are examining an emerging category of nuclear power plant (NPP) designs: small modular reactors (SMRs). Unlike the current NPP fleet that may generate over 1,000 Megawatts electricity (MWe) per plant, SMRs generate far less MWe per reactor, some producing less than 100 MWe per reactor. The U.S. DOE divides SMR designs into two major technology categories: (1) SMRs, which include designs based on existing light water reactors (LWRs), such as integral pressurized water reactors (IPWRs); and (2) advanced SMR (aSMR) designs, which are not based on existing LWR technology. aSMR designs use fuels other than uranium oxide (such as metallic or triso fuels), and/or rely on a coolant other than water (such as helium, lead-bismuth, or molten salt).

As U.S. energy demands increase and coal plants are retired in the upcoming decades, the DOE envisions that SMRs and aSMRs may be an attractive option to fill the void in energy production. Greenwire, March 2013 reports that "DOE's effort is aimed at establishing an industry that would manufacture as many as 50 SMRs a year by 2040 or sooner, said Rebecca Smith-Kevern, the director of light water reactor (LWR) technology at the department's Office of Nuclear Energy, which oversees the licensing of tiny nuclear plants. "We have a vision of having a whole fleet of [small modular reactors] produced in factories," Smith-Kevern told a regulatory conference in Bethesda, Maryland. "We envision the U.S. government to be the first users." Smith-Kevern also stated that the administration was looking for ways to reduce the oil dependence for military bases in place such as Guam and Hawaii. She stated that these could be some of the first sitings for SMRs. (Northey [77]).

SMR and aSMR designs offer several advantages over traditional large NPP designs. SMR designs can carry out other critical functions in addition to energy generation, including hydrogen production and industrial process heat applications such as water desalination and purification, and production of liquid transportation fuels and petrochemicals. SMR designs also offer advanced safety and proliferationresistance features. Additionally, as noted above, a major advantage of SMR and aSMR systems is that they can be fabricated in a factory and then assembled on site, in contrast with conventional large reactors that are constructed on site. Because of this, construction time for SMRs will be greatly reduced compared to current larger-scale reactors.

Economy of scale (i.e., total cost defrayed against a larger electrical output) is a key advantage for the operation of large reactors, but their capital cost and operations and maintenance costs (O\&M) are very high. SMRs and aSMRs lose the benefit of economy of scale due to the lower electrical output per reactor; instead, they compensate with lower capital cost due to smaller components and standardized, relatively mass-produced components and systems. It is expected that additional modules can be added as the need arises to comprise a larger complex consisting of multiple modules. Economic research to date is incomplete, but it is assumed that the initial outlay for the first couple of SMR modules would be significantly less than construction costs for some of the newer large reactors such as the Areva-NP Olkiluoto EPR (European Pressurized Reactor) currently under construction in Finland.

For SMRs and aSMRs, O\&M costs are a key consideration. This includes the normal production management activities such as scheduling, procedures, and work control and optimization. It also includes the maintenance activities such as routine, preventive, predictive, scheduled and unscheduled actions aimed at preventing equipment failure or decline with the goal of increasing efficiency, reliability and 
safety $^{1}$. Since SMRs and aSMRs do not compete on output against total cost, it could be argued that loss of economies of scale is the key driver. In order to be competitive, SMRs and aSMRs need to compensate by achieving operations economy through innovative concepts of operations. It is a well-known fact that a large part of O\&M cost is consumed by labor; in fact, most utilities report that more than $70 \%$ of O\&M costs are labor-related. Kuznetsov (2008), cited in a 2008 report by the European Organization for Economic Co-Operation and Development (OECD), stated that "On-going low operating costs $(<20 \%$ of total costs) and high availability factors (85-90\%) are needed to maintain cost competitiveness. This means that SMRs and aSMRs must have fewer systems requiring ongoing maintenance and more designed-in automatic controls. Standardization of systems designs and broad deployment can help to achieve learning curves approaching 80\%." [63].

All SMR and aSMRs designers are aware that competitiveness will only be achieved by reducing O\&M costs and are working towards reducing this critical cost component by improving efficiency through technology. However, efficiency will not be achieved only through technology. As indicated above, O\&M cost is an integral aspect of concepts of operations. Improved efficiency and productivity will only be achieved by considering all aspects of the way the plant and its systems are operated, including the use of advanced technologies, highly integrated automation, and innovative schemes for enabling human and system agents to collaborate in operating the plant. Current design concepts indicate the potential of aSMRs to be cost effective in terms of both O\&M factors by reducing the dependence on large operating crews that are common with large NPPs. One of the expected benefits of SMRs and aSMRs is that, due to their typical compact footprint, their high level of automation, and overall reduced complexity, it should be possible to reduce staffing for operations as well as maintenance. For example, it is potentially possible to simplify control room, local control station, and human-system interface (HSI) design through automation and the use of advanced technology. To date this is an unproven assumption, and this is where much research is needed. None of the concepts examined to date have considered any aspects of new concepts of operations, the changing role of humans in highly automated plants, or the dynamic relationship between humans and automation that would be required to achieve reduced O\&M costs.

Other design concepts anticipate efficiencies through deploying multiple units on the same site. Advantages that could be obtained from such a configuration would include enable sharing of non-power structures and related staffing because not all administrative and general expenses are directly related to the number of units in the plant. However, the implications of compliance with staffing requirements and safety standards set by the U.S. Nuclear Regulatory Commission (NRC) have not yet been fully evaluated. In addition, the impact on workload, situation awareness and human reliability is largely uncertain and will remain uncertain until empirical research data become available to support the development of technical bases for system design, technology selection and assignment of functions to humans and machines.

New equipment and components that can operate for longer periods without maintenance of major system components will also drive a need for new operational approaches. This will place more demand on online monitoring and diagnosis of the plant's condition. Because of this, safe and reliable operation of the plants will be greatly enhanced by advanced diagnostics and prognostics methods. In addition, the operation of multiple reactor modules with an increased number of shared components will require the development and validation of appropriate control systems and HSIs associated with higher levels of automation, which in turn would lead to a potential reduced staffing per module.

To realize fully the many perceived benefits of SMRs and aSMRs, designers must overcome a number of obstacles introduced by differences in the designs, technologies, and operational characteristics relative to

1 This is the annual cost associated with the operation, maintenance, administration, and support of a nuclear power plant. Included are costs related to labor, material \& supplies, contractor services, licensing fees, and miscellaneous costs such as employee expenses and regulatory fees. The average non-fuel O\&M cost for a nuclear power plant in 2011 was 1.51 cents / kWh. Nuclear Energy Institute, http://www.nei.org/resourcesandstats/nuclear_statistics/costs. 
existing plants. These plants are moving toward greater automation but will still rely on human interaction for supervision, system management, and operational decisions. More importantly, operators are still regarded as the last line of defense should failure of the automation system prevent automatic plant protective measures from actuating.

The U.S. DOE's Office of Nuclear Energy (NE) is sponsoring research and development (R\&D) on SMRs and aSMRs. Regardless of the specific reactor design, all SMR and aSMR designs will employ advanced digital instrumentation, controls, and human-machine interfaces (ICHMI), which consist of technology that is significantly more advanced than current analog systems in the LWR fleet. The DOE recognizes that ICHMI research, development, and demonstration are needed to address the specific technical challenges and technological gaps of ICHMI for SMR and aSMR designs. To address these issues, the DOE has established research programs for both SMR and aSMR designs. The aSMR Program has established a critical ICHMI research pathway, which consists of research projects in five technical areas (Wood, 2012 [171]):

- SMR assessment methods

- $\quad$ SMR ICHMI

- SMR materials, fuels, and fabrication

- SMR licensing support

- SMR advanced concepts evaluations.

A particular focus of the R\&D area in the aSMR ICHMI pathway is the area of human factors. There are a number of concerns about the impact of new and advanced technologies on human performance in aSMR plants. To address these issues, the DOE ICHMI research pathway includes several related research projects that investigate different aspects of the design considerations and consequences of highly advanced plants. The present research effort, the aSMR Concepts of Operations project, is part of this research program.

A plant's concept of operations is generally understood to be a high-level description of the plant, its systems and their functions, and how operating personnel will interact with the system to achieve the plant goals. aSMR plants will require defining new concepts of operations to address the unique operating scenarios that aSMRs will involve. The purpose of the aSMR Concepts of Operations project is to investigate the impact of new operational concepts on human performance and the implications for aSMR plant operations and safety. This report serves to document research performed to date; the focus of the current phase of research is to address the specific human factors challenges related to non-traditional concepts of operations, with the associated changes in the allocation of functions to human and system agents.

\subsection{Goals, Objectives, and Scope}

One of the more challenging aspects of the introduction of aSMR into the nuclear fleet involves the appropriate allocation of functions between the crew and various plant systems that are likely to be highly automated. This is challenging because operating experience with SMRs outside of the U.S. Navy is limited, existing human factors and systems engineering design standards are not current in terms of human interaction basics for automated systems, and there is a lack of a good function allocation (FA) and staffing model that takes into account static or dynamic allocation.

The primary objective of the present phase of the project is to conduct an in-depth analysis of the characteristics and attributes of the concepts of operations of future aSMRs, how the operation of these plants might be influenced by the need to integrate human factors principles in the design, and, conversely, how the role and function of humans in the plant might be affected by advanced technologies as part of the need to reduce O\&M costs.

These objectives are pursued in this project through the following activities and tasks: 
1. Conduct an extensive Work Domain Analysis (WDA) based upon a selected reference design or generic aSMR design and completed to the extent made possible by available information. This analysis includes an overview of the basic operational concepts of known designs (e.g. molten salt reactor) and how these proposed concepts (e.g. staffing design and advanced HSIs) would contribute to reducing operating and maintenance costs.

2. Develop definitions and criteria for human performance for aSMRs and their contribution to the development of Concepts of Operations. In order to provide a human performance perspective to Concepts of Operations, a number of other considerations must be addressed. These include the level and qualifications of staffing proposed for normal and disturbance conditions, different approaches to automation, detailed operating scenarios, expected team dynamics, and proposed interfaces that will be used.

3. Develop a model and application guidance for allocation of functions to humans and systems for aSMRs. This will use insights gained from the WDA (task 1) and human performance criteria for aSMR Concepts of Operations (task 2) to develop the technical basis for the FA model to be used for the remainder of the project. Subtopics include the following:

- Identification of the principles of dynamic allocation

- Decision criteria needed to inform system design

- The potential risk and human performance impact on non-traditional concepts of operation

- The role of FA as an iterative process in the project life cycle

- The role of FA in the NRC review process in terms of NUREG-0711 Rev3 (2012)

- Development of a foundational FA model and implementation process.

4. Analyze the regulatory aspects of non-traditional concepts of operation. This topic will address the ways that current regulation may inhibit or promote the implementation of specific design concepts and steps that designers may have to take to provide technical and safety justification and to request exemption from existing NRC requirements.

\subsection{Terminology}

Terminology is defined where relevant throughout the document, with one exception: the reader will find an apparent inconsistent use of the terms "concept of operation," "concepts of operations," "concept of operations" and "operational concept." These terms are however used consistently as follows:

- "Concepts of operations": This term is used for the generic concept that is the subject of this project and it refers to all principles and multiple concepts related to the operation of NPPs.

- "Concept of operation": This term is used only where it refers to, or forms part of the title of an existing publication, such as entry [130] and [131] in the Reference section.

- "Concept of operations": This term is used to refer to a specific deliverable, document or method applied in industry. For example, the document for a specific plant is called a "Concept of Operations."

- "Operational concept": This term is used to refer to a specific concept, such as "on-line maintenance" or "cogeneration." Such a concept could form part of a collective framework of operational concepts such as the Concept of Operation document. INCOSE also regards an "Operational concept" as a highlevel document developed very early in the project life to describe assumptions or intent regarding the operation of a new, existing or modified system (see par. 2.2.2.2).

Although the abbreviation "ConOps" is commonly used in literature for any of these terms (see 2.2.2.2 and 2.2.2.3), this often causes confusion and therefore will be avoided in this report, except where an existing document is referenced. 


\subsection{Scope}

This report summarizes progress to date on reviews of literature on FA models, methods, and issues. The review and evaluation of the FA literature was performed in the context of applicability to aSMRs, and establishes human factors engineering (HFE) design input to the design life cycle for aSMR design and deployment.

This report is not a tutorial in concepts of operations, primarily, because there is a fair amount of publicly available information on the topic. However, the report includes a clear definition of Concepts of Operations to contextualize it for aSMRs. Although Concepts of Operations is closely related to functional requirements analysis (FRA) and functional analysis, the integration of these elements is outside the scope of this report.

The September 2013 milestone will leverage the findings of the April milestone report and present the technical bases for the human factors aspects of the four key topics listed above.

\subsection{Significance}

aSMR plants are expected to introduce several innovative design concepts that have very little, if any, similarity to the past operating experience in the nuclear industry. For this reason, research and development (R\&D) opportunities and challenges for this project arise from a number of key characteristics expected for future SMRs. For example, it is expected that these plants will strive for increased utility and security to be obtained from long-lived fuels and materials for extended operation, as well as the advanced system designs required to support load-following and co-generation. Most plants will be characterized by thermalhydraulic process and systems unfamiliar to the current generation of NPP operators (e.g., metallic or gaseous primary coolant, passive heat removal, heat exchangers, and so on).

In addition, to achieve more efficient and cost-effective operations, it is very likely that advanced sensors, instrumentation and controls (I\&C) unavailable at the time that the majority of the existing NPPs were commissioned will be used to enable power and flow monitoring in integral systems, advanced prognostics and diagnostics for remote operations, and advanced control systems to manage the multiple product streams of co-generation plants.

At the front end of these new developments will be the control rooms, HSIs and operating procedures, which are likely to be significantly different from their predecessors in older-generation NPPs. All of these will have a significant influence on the role and functions of operating personnel. Human performance issues involved in aSMR designs have never been defined and evaluated in detail, and research is required to provide technical bases for designers to incorporate these principles in their designs. Non-traditional operational concepts and requirements that will arise from new technologies and new processes will include, for example, the need for fewer operators than in the past to manage multiple reactors, the ability to shut down and perform refueling while keeping adjacent reactors on line, and operating multiple plants to achieve one of the key economic requirements for SMRs: reducing the cost of O\&M.

In February 2012, the U.S. DOE issued a request for information (RFI) to inform the development of the DOE reactor technology research portfolio. Eight national and international vendors replied. In determining DOE research needs, the Technical Review Panel (TRP) review criteria, including safety security, waste generation minimization, operational capability including maintenance and inspection, concept maturity, operating experience, fuel and infrastructure and assessment of market attractiveness, and economics, were applied to various design concepts. The TRP committee reported back that a number of technical issues required resolution. Prominent among these were: implementation of defense-in-depth (DiD) different than LWRs; implementation of functional containment, licensing event selection, and passive systems behavior and reliability. Two other issues related directly to human factors in support of aSMR were identified: multi-module control and staffing of smaller units or modules. This report reviews 
a number of topics such as FA and human factors design that can provide a framework for decisions regarding the design and implementation of multi-module control and the consideration of staffing issues.

All of the above issues form part of a plant's concepts of operations, not only as a conceptual description of the plant's operational characteristics, but also as the basis of a technical document that describes and guides the development of structures, systems and components (SSC) throughout the life cycle of the new construction project.

An end goal of the research that is being performed is the development of the technical bases for nontraditional concepts of operations for aSMRs. This includes the development of FA principles as one of the primary decision criteria for staffing design and HSI design. This report describes how the aSMR concepts of operations can be used during the design, development and implementation process including meeting the FA requirements for industry submittals of new designs specified in NUREG-0711, Rev 3. Once the FA model or framework is established, it can be integrated within existing standards for human interaction design for complex digital control systems. The R\&D results from this project will therefore establish the theoretical and technical foundations for the human factors aspects of non-traditional concepts of operations for aSMRs and will therefore make an important contribution, not only to the DOE's SMR program, but also to the nuclear industry in general.

\subsection{Assumptions and Constraints}

At present there are no operating aSMRs in the U.S. to provide concrete design information or operating experience. The only predecessor plant that could provide useful information was the Experimental Breeder Reactor-II (EBR-II), shut down in 1994. It was therefore assumed that conceptual design information available in published literature would be a valid source of operational concepts. In addition, it was assumed that literature on human factors principles in nuclear power environments would provide a valid theoretical basis to derive a foundational model of FA for aSMRs.

The research to date has tested these assumptions and the findings are reported in this document. 


\section{Methodology}

\subsection{Methodology Overview}

The method followed in 2012 and first quarter of 2013 represents a series of studies whose aim has been to determine an overview of aSMR functional and operational characteristics that can support the development of a robust FA model and definition of non-traditional concepts of operation. The project team reviewed the national and international literature for evidence of a coherent, acceptable FA model. Based on this review, the project team concluded that much of the information needed regarding roles, responsibilities, and performance requirements was still evolving, and that integration was needed with emerging human factors concepts such as situation awareness, human-centered design, dynamic FA, and contextual action. Additionally, development of the next generation of HSIs for the next generation of operators working in concert with advanced automation systems is a key aspect of a the technical basis for new concepts of operation and a robust FA strategy. One of the conclusions, described in more detail later in this report, is that a final strategy for aSMR human factors is not possible without conducting a WDA, a task that will be initiated in May 2013.

The review also concluded that there is no existing plant or even a construction site to observe an aSMR in action. The project team therefore plans to visit a highly automated combined cycle plant, and possibly an advanced design fossil facility, to gather insights regarding single operator control of multiple modules, the approach to off-normal events, the design of the user interface, and operating experience with advanced I\&C.

In keeping with the current aSMR program plan, research efforts to date do not involve experimentation to determine the prescriptive elements for FA or definition of new concepts of operation. Research activities to support these elements are planned for FY14 and beyond.

\subsection{Literature Reviews Of Scientific And Technical Reports}

\subsubsection{Advanced Small Modular Reactors}

Generally, modern small reactors for power generation are designed for a high level of passive or inherent safety in the event of malfunctions. A 2010 report by a special committee convened by the American Nuclear Society (ANS) showed that many safety provisions necessary, or at least prudent, in large reactors are not necessary in the small designs forthcoming. (World Nuclear Association, 2013 Error! Reference source not found.).

The term "modular" in the context of SMRs refers to the ability to fabricate major components of the nuclear steam supply system (NSSS) in a factory environment and ship to the point of use. Even though current large NPPs incorporate factory-fabricated components (or modules) into their designs, a substantial amount of fieldwork is still required to assemble components into an operational power plant. SMRs are envisioned to require limited on-site preparation and substantially reduce the lengthy construction times that are typical of the larger units. SMRs provide simplicity of design, enhanced safety features, the economics and quality afforded by factory production, and more flexibility (financing, siting, sizing, and end-use applications) compared to larger NPPs. "Modular" also refers to the incremental or phased approach to establishing total plant electrical output. This means that additional modules can be added and commissioned incrementally as the demand for energy increases and thus allowing for an early return on investment.

The ANS committee on Small Modular Reactors (2011) compiled a list of the basic characteristics of the systems of future SMR plants. The following table has been adapted from the ANS list to highlight characteristics that are likely to have an impact on operational concepts, and therefore on human factors [5]: 
Table 1: Operational and Human Factors impact of aSMR design concepts

\begin{tabular}{|c|c|}
\hline SMR systems description & Operational and Human Factors Impact \\
\hline $\begin{array}{l}\text { No active safety injection system required. Core } \\
\text { cooling is maintained using passive systems. }\end{array}$ & $\begin{array}{l}\text { No operator intervention required for safety } \\
\text { injection. No need for manual or mental } \\
\text { calculations. Fewer emergency operating } \\
\text { procedures (EOPs) required. Ability to remove } \\
\text { core heat leads to significant safety enhancement. }\end{array}$ \\
\hline $\begin{array}{l}\text { No safety-related pumps for accident mitigation. } \\
\text { No need for sumps and protection of their suction } \\
\text { supply. }\end{array}$ & $\begin{array}{l}\text { No operator action required for coolant pump } \\
\text { failures or leaks. No need for leak calculations. }\end{array}$ \\
\hline $\begin{array}{l}\text { Passive design does not require emergency } \\
\text { alternating current (AC) power to maintain core } \\
\text { cooling. Core heat removed by heat transfer } \\
\text { through vessel. }\end{array}$ & $\begin{array}{l}\text { No operator action required for loss of AC power, } \\
\text { except to monitor condition. }\end{array}$ \\
\hline $\begin{array}{l}\text { Automatic reactor shutdown system. Reduced } \\
\text { need for manual scram. }\end{array}$ & $\begin{array}{l}\text { Even if automatic system fails, reactor will } \\
\text { automatically shut down due to negative power } \\
\text { coefficient of reactivity. }\end{array}$ \\
\hline $\begin{array}{l}\text { No active containment heat system for spray } \\
\text { systems required because of passive heat rejection } \\
\text { out of containment. }\end{array}$ & $\begin{array}{l}\text { No operator action required to activate } \\
\text { containment systems to reduce steam pressure or } \\
\text { to remove radioiodine from containment. }\end{array}$ \\
\hline $\begin{array}{l}\text { Simpler and/or passive safety systems require less } \\
\text { testing and are not as prone to inadvertent } \\
\text { initiation. }\end{array}$ & $\begin{array}{l}\text { No or very few operator actions required to } \\
\text { activate safety systems or to monitor cooling } \\
\text { systems. Simpler operation, less prone to } \\
\text { inadvertent operator actuation or other human } \\
\text { error. }\end{array}$ \\
\hline $\begin{array}{l}\text { Ability to remove core heat without an emergency } \\
\text { feedwater system. }\end{array}$ & $\begin{array}{l}\text { No operator actions related to feedwater or } \\
\text { emergency cooling water supply. Removing core } \\
\text { heat without an emergency feedwater system is a } \\
\text { significant safety enhancement and reduction of } \\
\text { operator workload. }\end{array}$ \\
\hline $\begin{array}{l}\text { Load-following entails more transitions to enable } \\
\text { the plant to increase or decrease both reactor- and } \\
\text { turbine-power in response to the external demand. } \\
\text { Also, multi-modular plants may require startup } \\
\text { and shutdown of individual modules to meet large } \\
\text { changes in load demand. }\end{array}$ & $\begin{array}{l}\text { Load-following will require more actions from } \\
\text { operators, and increased monitoring of the } \\
\text { response of the automatic systems. Hence, there is } \\
\text { more opportunity for equipment failures and } \\
\text { operator errors. This may have to be mitigated } \\
\text { through resilient designs and automation. }\end{array}$ \\
\hline Integral designs eliminate the need for seals. & $\begin{array}{l}\text { Reduced need for inspection and maintenance, } \\
\text { leading to potential reduced human resource } \\
\text { requirements. }\end{array}$ \\
\hline
\end{tabular}




\begin{tabular}{|c|c|}
\hline SMR systems description & Operational and Human Factors Impact \\
\hline $\begin{array}{l}\text { Variable modular plant configurations: } \\
\text { aSMR designs may be configured with different } \\
\text { combinations of reactors and power conversion } \\
\text { units (PCU), for example: } \\
\text { - multi-reactor, single PCU } \\
\text { - } \quad \text { single reactor, multi-PCU } \\
\text { - } \quad \text { single reactor, single PCU, etc. } \\
\text { In addition, different combinations of reactors and } \\
\text { process heat plants are possible. }\end{array}$ & $\begin{array}{l}\text { Different configurations will have different effects } \\
\text { on operations and human factors. Also, the } \\
\text { different plant modes and states for these } \\
\text { configurations will require non-traditional } \\
\text { definitions of operator and maintainer roles and } \\
\text { functions. }\end{array}$ \\
\hline $\begin{array}{l}\text { SMR designs are passive and reject heat by } \\
\text { conduction and convection. Heat rejection to an } \\
\text { external water heat sink is not required. }\end{array}$ & $\begin{array}{l}\text { Fewer operating procedures required for normal } \\
\text { operations. However, displays are required to keep } \\
\text { operator informed. }\end{array}$ \\
\hline $\begin{array}{l}\text { The plant design minimizes or eliminates the need } \\
\text { for safety-related control room cooling. Safety- } \\
\text { related control room HVAC system and associated } \\
\text { closed water cooling systems can be eliminated. }\end{array}$ & $\begin{array}{l}\text { No operator action required for emergency control } \\
\text { room ventilation. }\end{array}$ \\
\hline $\begin{array}{l}\text { Large heat capacity inherent in aSMR design. } \\
\text { Heat-up events would tend to be slow and allow } \\
\text { for time to unblock air flow pathways, associated } \\
\text { with convection cooling in liquid metal-cooled } \\
\text { Reactor (LMR) designs. }\end{array}$ & $\begin{array}{l}\text { Reduced need for operator intervention during } \\
\text { start-up. }\end{array}$ \\
\hline $\begin{array}{l}\text { Automated protection systems: } \\
\text { aSMRs are expected to employ technologies that } \\
\text { provide protection from grid disturbances through } \\
\text { automated functions like turbo-generator } \\
\text { protection, etc. }\end{array}$ & $\begin{array}{l}\text { Automated protection systems will mean } \\
\text { significantly different operating scenarios and } \\
\text { anticipated operational occurrences (AOOs) for } \\
\text { aSMRs. As with several other aSMR technology } \\
\text { innovations, this will reduce the need for operator } \\
\text { intervention and thus potentially reduced } \\
\text { procedural complexity and lower workload. }\end{array}$ \\
\hline $\begin{array}{l}\text { Coolants: } \\
\text { Coolants include molten salt, lead-bismuth, or } \\
\text { gases like helium, nitrogen or carbon dioxide. For } \\
\text { some molten salt reactor designs, the fuel is } \\
\text { dissolved in the molten fluoride salt coolant as } \\
\text { uranium tetrafluoride. }\end{array}$ & $\begin{array}{l}\text { Sodium leakage would be a concern, requiring } \\
\text { new defence-in-depth measures and new EOPs. }\end{array}$ \\
\hline $\begin{array}{l}\text { Fuel: } \\
\text { Small size ( } 50 \text { to } 150 \mathrm{MWe} \text { ) modular-type sodium- } \\
\text { cooled reactors are expected to employ uranium- } \\
\text { plutonium-minor-actinide-zirconium metal alloy } \\
\text { fuel, supported by a fuel cycle based on } \\
\text { pyrometallurgical processing in facilities }\end{array}$ & $\begin{array}{l}\text { Operators need to avoid boiling instabilities where } \\
\text { sodium boiling can occur as a result of } \\
\text { condensation and evaporation in the sodium upper } \\
\text { plenum. }\end{array}$ \\
\hline
\end{tabular}




\begin{tabular}{|c|c|}
\hline SMR systems description & Operational and Human Factors Impact \\
\hline $\begin{array}{l}\text { integrated with the reactor. Thorium based fuel } \\
\text { offers an alternative to fast sodium reactor fuel or } \\
\text { current fuel for LWRs. The thorium can act as a } \\
\text { breeder, however; it needs a moderate, not fast } \\
\text { neutron environment, so some technical } \\
\text { challenges still exist for thorium designs. }\end{array}$ & \\
\hline $\begin{array}{l}\text { Non-proliferation: } \\
\text { LMRs including sodium reactors close the fuel } \\
\text { cycle. Also, a closed fuel cycle results in less } \\
\text { radioactive waste management issues. }\end{array}$ & $\begin{array}{l}\text { Different fuel handling regimes may introduce } \\
\text { unfamiliar tasks and operating procedures. This } \\
\text { may have an impact on training and operator } \\
\text { licensing requirements. }\end{array}$ \\
\hline $\begin{array}{l}\text { Shutdown requirements: } \\
\text { Most aSMRs have a negative temperature } \\
\text { coefficient of reactivity and lower shutdown } \\
\text { margin. This helps to avoid power excursions, } \\
\text { means less need for active safety systems, and } \\
\text { enables the reactor to shut down automatically in } \\
\text { the unlikely event of a loss of coolant accident } \\
\text { (LOCA) and resulting rise in temperature. }\end{array}$ & $\begin{array}{l}\text { No safety-related operator intervention required } \\
\text { for reactivity incidents. }\end{array}$ \\
\hline $\begin{array}{l}\text { Siting: } \\
\text { SMRs can provide power for applications where } \\
\text { large plants are not needed or sites that lack the } \\
\text { infrastructure to support a large unit. This would } \\
\text { include smaller electrical markets, isolated areas, } \\
\text { smaller grids, sites with limited water and acreage, } \\
\text { or unique industrial applications. }\end{array}$ & $\begin{array}{l}\text { Operational impacts may include accessibility to } \\
\text { distributed facilities and time needed for response } \\
\text { teams. Also additional training for operators, } \\
\text { maintenance and response teams. }\end{array}$ \\
\hline $\begin{array}{l}\text { Core Design: } \\
\text { Sodium cooled reactors are highly sensitive to } \\
\text { sodium void reactivity excursions that may induce } \\
\text { positive reactivity feedback in some core zones } \\
\text { (especially in case of large cores). }\end{array}$ & $\begin{array}{l}\text { LMR aSMRs have a much smaller core cross- } \\
\text { section and the potential for sodium void and the } \\
\text { need for rapid automation or operator intervention } \\
\text { is therefore greatly reduced. Additionally, } \\
\text { increased visualization for operators regarding } \\
\text { core status will further lessen the risk associated } \\
\text { with this failure mode. }\end{array}$ \\
\hline
\end{tabular}

In addition to the system- and design related human factors implications identified above, there are also a number of human factors impacts that could be related directly to aSMR operational principles. Some of these impacts were already identified in NUREG/CR-7126 Error! Reference source not found.:

Table 2: Human Factors aspects of Concepts of Operations*

\begin{tabular}{|l|l|}
\hline Operating Context & Potential aSMR implementation \\
\hline Plant Mission & $\bullet \quad$ Electrical production and potentially process-heat \\
\hline
\end{tabular}




\begin{tabular}{|c|c|}
\hline Operating Context & Potential aSMR implementation \\
\hline & $\begin{array}{l}\text { applications would extend the traditional role of the operator. } \\
\text { This does not necessarily mean more workload, but implies a } \\
\text { broader range of responsibilities and thus more or different } \\
\text { training. } \\
\text { - Some parts of aSMR plants may employ technology with } \\
\text { minimal predecessor plant experience, especially those } \\
\text { systems and subsystems employing advanced automation } \\
\text { systems, non-traditional materials, or digital displays. }\end{array}$ \\
\hline Roles and Responsibilities & $\begin{array}{l}\text { Role and function changes are anticipated, for example } \\
\text { concurrent responsibility for multiple product streams, such } \\
\text { as electrical production, process heat and hydrogen } \\
\text { production. } \\
\text { - Single crew members may be responsible for multiple } \\
\text { modules. } \\
\text { - Extensive use of automation, sometimes complex, for } \\
\text { operations may introduce a level of complexity that will } \\
\text { require more abstract information representations in the } \\
\text { control room and more training. }\end{array}$ \\
\hline Staffing & $\begin{array}{l}\text { - Staffing levels are expected to be below requirements stated } \\
\text { in } 10 \text { CFR } 50.54(\mathrm{~m}) \text {. }\end{array}$ \\
\hline $\begin{array}{l}\text { Technology, Plant Configuration } \\
\text { and Construction }\end{array}$ & $\begin{array}{l}\text { - Modular approach to constructing plants. } \\
\text { - Some aSMR designs use shared systems; some are shared } \\
\text { across many units. } \\
\text { - Lower power levels associated with aSMRs ( }<300 \mathrm{MWe}) \text { will } \\
\text { result in lower probability for higher levels of radionuclide } \\
\text { release. } \\
\text { - Automatic turbine warm up, synchronization and integrated } \\
\text { control between the NSSS and turbine during operations. } \\
\text { Feedwater, condensate, and steam control is likely to be } \\
\text { automated. This will simplify NOPs as well as EOPs and thus } \\
\text { reduce operator workload during evolutions. } \\
\text { Expected aSMR siting is such that many systems will be } \\
\text { located underground. While this may produce improved } \\
\text { safeguards for non-proliferation purposes and provide } \\
\text { improved protection from external threats, it may make } \\
\text { access and egress problematic. } \\
\text { The siting of many aSMR systems underground leads to } \\
\text { enhanced ability to withstand seismic event. For example, the } \\
\text { spent fuel pool may be sited underground. }\end{array}$ \\
\hline $\begin{array}{l}\text { I\&C and Human-system } \\
\text { interaction }\end{array}$ & $\begin{array}{l}\text { - A high level of automation is anticipated and digital } \\
\text { (computer-based) controls and displays are used in the control }\end{array}$ \\
\hline
\end{tabular}




\begin{tabular}{|c|c|}
\hline Operating Context & Potential aSMR implementation \\
\hline & $\begin{array}{l}\text { room. Only safety-critical systems like diverse actuation } \\
\text { systems may still be hardwired. } \\
\text { Monitoring tasks will rely increasingly on trends and smarter } \\
\text { alarms, and diagnostics will provide early warning of } \\
\text { potential problems so action can be taken earlier. } \\
\text { - HSIs include large flat panel displays for group view } \\
\text { functions, as well as smaller flat panel monitors for individual } \\
\text { operator use. Operators will monitor the process using large } \\
\text { overview display panels, plus workstation displays designed } \\
\text { to provide both functional and physical views of the process } \\
\text { and systems. } \\
\text { - Indications and displays will be task-centered to support all } \\
\text { conditions, including evolutions like start-up, shutdown, and } \\
\text { system line-ups. } \\
\text { Control rooms are centralized to maximize coordination } \\
\text { between units. } \\
\text { Advanced HSI will also be used for diagnostics, maintenance, } \\
\text { communication and surveillance. } \\
\text { HSIs provided for plant evolutions of multiple units, and also } \\
\text { for monitoring and control or other missions. }\end{array}$ \\
\hline Normal Operations & $\begin{array}{l}\text { - aSMR designs use non-light-water reactor technology (for } \\
\text { example, liquid-metal-cooled or gas-cooled) that might pose } \\
\text { new operational requirements. } \\
\text { - Load following as well as base-load operations. } \\
\text { - A single crew or operator may manage multiple units and } \\
\text { additional missions from a single control room. } \\
\text { - Individual reactors may be in a variety of states (e.g., } \\
\text { shutdown, startup, or refueling, and various types of } \\
\text { maintenance and testing) and running at various power levels. } \\
\text { - Additional units can be added when needed and while other } \\
\text { - } \text { - Fewits are operating. } \\
\text { - Novel approaches to refueling, such as on-line refueling, and } \\
\text { physically relocating reactor modules to a dedicated servicing } \\
\text { area for refueling. }\end{array}$ \\
\hline Hazards & $\begin{array}{l}\text { - Operational, industrial or environmental hazards might be } \\
\text { introduced by new technology, for example, hydrogen, liquid- } \\
\text { metal (such as sodium and lead), and much higher operating } \\
\text { temperatures/pressures, and the use of high temperature gas } \\
\text { and graphite in the core. The hazards must be understood, and } \\
\text { then addressed in those safety systems that monitor and } \\
\text { mitigate the hazards, the HSIs that personnel employ to } \\
\text { monitor the plant, the procedures they use to address hazards, }\end{array}$ \\
\hline
\end{tabular}




\begin{tabular}{|c|c|}
\hline Operating Context & Potential aSMR implementation \\
\hline & $\begin{array}{l}\text { and operator training. } \\
\text { The reactor design is considered as failed safe, that is it fails } \\
\text { to a safe configuration and condition without the need for } \\
\text { operator intervention. } \\
\text { - A single unit can trip without affecting adjacent units that } \\
\text { remain at power. Operators can scram a single unit } \\
\text { individually. }\end{array}$ \\
\hline Off-normal Operations & $\begin{array}{l}\text { - New operating modes introduced by non-electrical operations } \\
\text { (e.g. process heat applications) will require new operating } \\
\text { procedures. } \\
\text { Design of the technical support center (TSC), emergency } \\
\text { operations facility (EOF) and outage control center (OCC) } \\
\text { will have to consider integration with connected non- } \\
\text { electrical operations. } \\
\text { Most safety systems are passive and require no operator } \\
\text { intervention. The emphasis in emergency operations will } \\
\text { rather shift to investment protection. }\end{array}$ \\
\hline Maintenance & $\begin{array}{l}\text { Novel approaches to maintenance, such as moving reactor } \\
\text { module to a dedicated location in the plant or to the factory } \\
\text { for servicing. } \\
\text { There are many new maintenance practices and potential } \\
\text { hazards, due to different materials, compact plant layout, } \\
\text { different product streams, advanced monitoring and } \\
\text { measurement instruments, automated diagnostics, remote } \\
\text { surveillance, and even robotic systems. } \\
\text { Advanced HSIs and special tools will be used for } \\
\text { maintenance, diagnostics and materials and fuel handling. }\end{array}$ \\
\hline Procedures & $\begin{array}{l}\text { Some level of automated procedures or procedures checking } \\
\text { system is anticipated. This will simplify operator actions and } \\
\text { potentially reduce workload during upset conditions. }\end{array}$ \\
\hline Containment & $\begin{array}{l}\text { SMR designs typically reduce the level of challenge to the } \\
\text { containment vessels and building by means of an integral primary } \\
\text { system. By integrating the reactor, steam generator and primary } \\
\text { cooling systems in the containment, catastrophic loss-of-coolant } \\
\text { accidents are eliminated. This has important implications for } \\
\text { EOPs and the range of operator actions that would normally be } \\
\text { credited in older designs. }\end{array}$ \\
\hline
\end{tabular}

* Some items adapted from NUREG/CR-7126.

\subsubsection{Concept of Operations}

A Concept of Operations (sometimes also called an Operational concept Description) describes the characteristics of a proposed system from the viewpoint of an individual who will use that system. It is 
used to communicate the quantitative and qualitative system characteristics of the plant to all stakeholders, including system owners, managers, designers, engineers, probabilistic risk analysis (PRA), HFE, utility, etc. It provides the basis for procedures (e.g. training, operating, maintenance, etc.) and serves as input to Human Factors analyses (FRA, FA, task analysis, staffing, HSI design, control room design).

Concept of Operations documents are widely used in the military, governmental services, industrial and other fields. In industrial applications such a document is typically produced as part of Systems Engineering deliverables. These organizations all agree that a Concept of Operations document is highly beneficial, not only for design or acquisition of new systems, but also for the operation of the system after implementation (Roberts and Edson, 2008).

The exact definition and application of Concept of Operations differ among various organizations, but most share a common vision, as the following descriptions will illustrate.

\subsubsection{NRC (U.S. Nuclear Regulatory Commission)}

The NRC has published several documents that mention Concept of Operations. The following are the most notable:

- NUREG-0711 - "Human Factors Engineering Program Review Model” (NRC, 2012 Error!

\section{Reference source not found.).}

NRC staff use this document as guidance to evaluate the human factors aspects of license submittals for new and modified designs. It defines Concept of Operations in terms of the goals and expectations for the new system from the perspective of users and other stakeholders and defines the high-level considerations to address as the detailed design evolves.

Revision 2 of NUREG-0711 stated the following requirements for the concept of operations:

- The primary design and operating characteristics of the plant or system and the specific staffing goals and assumptions necessary to implement the concept of operations.

- The number of personnel who will have plant monitoring and operational control responsibilities on each shift (i.e., "control personnel") and staffing levels for these personnel across shifts.

- The roles and responsibilities of each individual designated as control personnel, if that individual is responsible for control and monitoring plant or unit operations.

- The training and qualifications required for control personnel.

- The overall operating environment and primary HSIs to be used by control personnel.

- The interaction of control personnel with automated systems, including responsibilities for monitoring, operating, and overriding automated systems.

- The interaction of control personnel with automated support systems and the role of these systems in the overall management and control of the plant.

- Other mechanisms that enable or support control personnel responsibilities for monitoring, disturbance detection, situation assessment, response planning, response execution, and the management of transitions between automatic and manual control.

- The interactions of control personnel with each other and with people not directly responsible for the control and safe operation of the plant.

- Multi-unit operations.

- Operations during construction of additional units.

Revision 3 describes six dimensions of a Concept of Operations:

- Plant Goals (or Missions)

- Agents' Roles and Responsibilities

- Staffing, Qualifications, and Training

- Management of Normal Operations 
- Management of Off-normal Conditions and Emergencies

- Management of Maintenance and Modifications

These dimensions include aspects of the management of the power plant after commissioning and this is more commonly referred to as "Conduct of Operations", which differs in important respects from the technical information found in Concept of Operations documents and other sources described below. (See also the INPO description below). This is a potential source of confusion that the present report aims to clarify.

- NUREG/CR-7126: "Human-Performance Issues Related to the Design and Operation of Small Modular Reactors" [29].

The main objective of the research project described in NUREG/CR-7126 was to "delineate how the design and operations of SMRs differ from current plants and to identify potential humanperformance issues" related to these different characteristics. To achieve this goal, the same dimensions described in NUREG-0711 were used to collect information about various SMR designs.

Due to the immaturity of aSMR designs at that time, the document provides only minimal information on how the plants would be operated and what the operational challenges might be. In addition, the document included descriptions of "surrogate facilities in which operators manage multiple units in a manner similar to what we might expect from SMR operators." The systems examined were unmanned vehicles, petroleum refineries, and remote intensive-care medical centers. Based on the information obtained from these various sources, the document presented conceptual dimensions and characteristics of the various systems' design and operation, as well as generalized human performance issues. The issues focused on performance problems that potentially could arise due to the expected characteristics of the SMRs.

However, the proposed dimensions in NUREG/CR-7126 pay only minimal attention to the effect of innovative or unconventional physical plant layout, location, size, thermalhydraulic processes, product streams, etc. These effects are examined in more detail in this report.

- NUREG-1791 (Guidance for Assessing Exemption Requests from the Nuclear Power Plant Licensed Operator Staffing Requirements Specified in 10 CFR 50.54) (p. II-2-1) Error! Reference source not found..

This document uses the same the review criteria for a license applicant's Concept of Operations as in NUREG-0711.

It should be pointed out that, although the NRC sources listed above imply that the Concept of Operations should be one or more documents, none of them mentions its format or specific role as part of engineering processes.

\subsubsection{INCOSE (the International Council on Systems Engineering)}

The INCOSE Systems Engineering Handbook 3.2.2 makes a distinction between "concept of operations" and "operational concept" and points out that the two concepts are very similar, but there are important differences. The latter concept is defined as follows:

An Operational Concept is "a verbal and graphic statement of an organization's (enterprise's) assumptions or intent in regard to an operation or series of operations of a specific system or a related set of specific new, existing or modified systems. The operational concept is frequently developed as part of a system development or acquisition program. The operational concept is designed to give an overall picture of the operations using one or more specific systems, or set of related systems, in the organization's (enterprise's) operational environment from the users' and operators' perspective. It is also called the OpsCon." 
INCOSE recommends the development of an initial Operational Concept by the users and operators at the inception of the project. The customer (e.g., the Utility) could also develop it at the beginning of the concept and development phases of the project. The Operational Concept is then maintained through the production, utilization, support and retirement phases of the system life cycle jointly by the developer and the customer.

In contrast, the Concept of Operations is:

"A verbal and graphic statement, in broad outline, of an organization's (enterprise's) assumptions or intent in regard to an operation or series of operations of new, modified or existing organizational (enterprise) systems. The concept of operations frequently is embodied in long-range strategic plans and annual operational plans. In the latter case, the concept of operations in the plan covers a series of connected operations to be carried out simultaneously or in succession to achieve an organizational (enterprise) performance objective. The concept is designed to give an overall picture of the organization's (enterprise's) operations. It is also called the CONOPS and it describes the way the system works from the operator's perspective. The ConOps includes the user description and summarizes the needs, goals, and characteristics of the system's user community. This includes operation, maintenance, and support personnel."

This description implies that the Operational Concept is a very high-level document that does not contain as much detail technical content as the Concept of Operations. The latter document describes largely how the plant works and how people interact with its various systems.

INCOSE describes the purpose of the Concept of Operations document as a "story" that communicates the user's point of view on What, Who, When, Where, Why, and How a product is used throughout its life cycle:

- What - Known components, elements, and top-level capabilities that perform the necessary system functions.

- Who - The product's interaction among various human elements within a system and external interfaces.

- When - Description of activities, tasks, flows, precedence, and concurrencies (i.e. time or sequencerelated elements necessary to achieve mission objectives in various product modes and conditions).

- Where - The product's geographical and physical locations in a customer's facilities and interfacing systems.

- Why - The rationale to clarify the reader's understanding for specific events and design decisions found in operational scenarios.

- How - Expectations for the use of the product, its operation and maintenance in a given environment. (This is still conceptual and no specific system design or implementation requirements are given yet).

\subsubsection{IEEE (Institute of Electrical and Electronics Engineers)}

According to IEEE Standard 1362-1998: “IEEE Guide for Information Technology - System Definition Concept of Operations (ConOps) Document," IEEE, 1998 [17], Concept of Operations is "a user-oriented document that describes system characteristics for a proposed system from the user' viewpoint. The Concept of Operations document is used to communicate overall quantitative and qualitative system characteristics to the user, buyer, developer, and other organizational elements (for example, training, facilities, staffing, and maintenance). It is used to describe the user organization(s), mission(s), and organizational objectives from an integrated systems point of view."

Although this document is intended to be used when developing or modifying a software-intensive system, many of the principles and guidelines would also apply to aSMR plant Concept of Operations, for example: 
- High-level description of a user's operational needs - no detailed technical issues are required here.

- Description of the system's characteristics and the user's operational needs in a manner that can be verified by the user without requiring any technical knowledge beyond that required to perform normal job functions.

- A statement of desirable functions, visions, and expectations without requiring the provision of quantified, testable specifications. For example, users could express their need for a highly reliable system, and their reasons for that need, without having to produce a testable reliability requirement.

\subsubsection{INPO (Institute of Nuclear Power Operations)}

According to INPO/WANO 01-002 ("Guidelines for the Conduct of Operations at Nuclear Power Stations"), the purpose of the Conduct of Operations manual is to "assist the operations manager by providing guidelines to develop processes and behaviors that will enable the station to achieve excellence in all phases of nuclear plant operations."

The guidelines are based upon best practices in the industry and are used by all U.S. utilities to set challenging goals for the power plant and to monitor, measure, and provide positive reinforcement to improve overall performance. The guide describes the characteristics of good leadership, best practices for conducting plant operations, control room operations, operator behavior, procedure handling, maintenance and configuration control.

\subsubsection{AIAA (American Institute of Aeronautics and Astronautics)}

The American National Standards Institute (ANSI) Concept of Operations standard (ANSI/AIAA G-0431992 "Guide for the preparation of Operational Concept Documents") describes the use of an Operational Concept Document (OCD) as a complementary document to the system specification and should be prepared before the system specification. This corresponds to the INCOSE definition that regards this document as an important reference during the system requirements analysis and design phases to provide the necessary framework within which proposed system design and implementation alternatives can be evaluated. This standard also provides clear descriptions of the various stakeholders in the system engineering process and how they use the OCD.

\subsubsection{Notable aSMR Design Concepts}

\section{GE/Hitachi PRISM Design}

A number of documents related to the GE Power Reactor Inherently Safe Module (PRISM) aSMR were reviewed for aspects of safety, operational concepts, and as a means of identifying SMR contexts. With the exception of the review in Nuclear Technology presented by Triplett et al. (2012), most of the information available was generated during the 1980s and 1990s. In their earlier efforts, General Electric (GE) was assisted by the U.S. Department of Energy (DOE). One of the first of these documents was the preliminary safety information document (PSID) produced in 1993; the bulk of the material therein was generated in 1987 (GEFR-00793 December 1987). The PSID report describes the conceptual design and general plant description. During the conceptual design phase the modular plant design leveraged R\&D assistance from Oak Ridge National Laboratory (ORNL), Argonne National Laboratory (ANL), and Hanford Engineers. Modularity was offered as a means to reduce risk and cost. Because of its small size, the design allows for passive shutdown and shutdown heat removal assisted by passive safety systems. With this design, fewer safety systems are required when compared to PWRs. Like IPWR SMRs, the PRISM plant can be manufactured and assembled in a factory and is shippable by rail to various locations. PRISM designers believe that the LMR can be competitive with other generation sources while being safely operated. As with other aSMR design approaches, the modularity was proposed to allow for incremental power additions at the same site. The lifetime of the reactor is estimated to be a minimum of 60 years $($ ibid $)$. 
One of the concepts for deployment is that the reactor would be capable of being in operation within 4 years of breaking ground; this is at least competitive if not better than time estimates for current generation NPP projects. Efficiencies also come from sharing common secondary side systems. In this design, three power blocks were proposed, with each power block consisting of two or possibly three NSSSs and one common turbine generator. Each power block is designed to operate independently.

\subsubsection{Safety Concepts During Operation}

Ultimately, the safety case for SMRs will dominate all other considerations. There are a number of ways in which passive safety systems in SMRs and aSMRs may reduce the safety burden associated with O\&M activities. These are summarized in Table 3.

Table 3: Comparison of current-generation plant safety systems with potential SMR design*

\begin{tabular}{|c|c|}
\hline Current-generation safety-related systems & SMR safety systems \\
\hline $\begin{array}{l}\text { High-pressure injection system. } \\
\text { Low-pressure injection system. }\end{array}$ & $\begin{array}{l}\text { No active safety injection system required. Core } \\
\text { cooling is maintained using passive systems. } \\
\text { A number of aSMR designs are high temperature } \\
\text { low pressure. }\end{array}$ \\
\hline $\begin{array}{l}\text { Emergency sump and associated net positive suction } \\
\text { head (NPSH) requirements for safety-related pumps. }\end{array}$ & $\begin{array}{l}\text { No safety-related pumps for accident mitigation; } \\
\text { therefore, no need for sumps and protection of their } \\
\text { suction supply. }\end{array}$ \\
\hline Emergency diesel generators. & $\begin{array}{l}\text { Passive design does not require emergency } \\
\text { alternating current }(\mathrm{ac}) \text { power to maintain core } \\
\text { cooling. Core heat removed by heat transfer through } \\
\text { vessel. }\end{array}$ \\
\hline Active containment heat systems. & $\begin{array}{l}\text { None required because of passive heat rejection out } \\
\text { of containment. }\end{array}$ \\
\hline Containment spray system. & $\begin{array}{l}\text { Spray systems are not required to reduce steam } \\
\text { pressure or to remove radioiodine from containment. }\end{array}$ \\
\hline $\begin{array}{l}\text { Emergency core cooling system (ECCS) initiation, } \\
\text { I\&C systems. Complex systems require significant } \\
\text { amount of online testing that contributes to plant } \\
\text { unreliability and challenges of safety systems with } \\
\text { inadvertent initiations. }\end{array}$ & $\begin{array}{l}\text { Simpler and/or passive safety systems require less } \\
\text { testing and are not as prone to inadvertent initiation. } \\
\text { For example, some designs do not require an ECCS. } \\
\text { Others will employ the use of natural convection as } \\
\text { a cooling source. Electromagnetic pumps are } \\
\text { another aspect of design. }\end{array}$ \\
\hline $\begin{array}{l}\text { Emergency feedwater system, condensate storage } \\
\text { tanks, and associated emergency cooling water } \\
\text { supplies. }\end{array}$ & $\begin{array}{l}\text { Ability to remove core heat without an emergency } \\
\text { feedwater system is a significant safety } \\
\text { enhancement. }\end{array}$ \\
\hline
\end{tabular}

*Adapted from "Small Nuclear Power Reactors," World Nuclear Association

aSMR designs have a number of approaches and criteria that contribute to the concept of operations. One of the prime assumptions of most new designs is that the reactor can always be put into a safe state, including situations involving loss of offsite power. Another assumption is that the reactor can always be operated within fuel design limits.

A number of the more important PRISM safety and operations design concepts may be applicable also to other liquid metal-cooled reactor designs: 
- Protection against natural phenomena such as fire, earthquake, flood, tornadoes, which is achieved by siting of the individual reactor module within its own silo.

- Protection from unintended sodium reaction(s) through structure location, fire control systems implementation, and leak detection.

- Single boundary failure of a passive system will not allow the primary coolant $(\mathrm{Na})$ to come in contact with water or steam.

- Shared structures for efficiency and economics, reviewed to determining that sharing will not impact accident response.

- Suppressed power oscillations.

- Improved containment design.

- Separation of protection and control systems.

- Protection from reactivity control malfunctions (achieved through redundancy, capability factors) and ability to automatically initiate operation of systems including the reactivity control system

- Improved shutdown heat removal.

- Prevention and mitigation strategy for core faults.

- The design of containment is leak-tight and serves as a barrier against uncontrolled release to the environment.

- All protection systems are designed to fail-safe.

- Fuel storage will employ criticality safe geometry to prevent inadvertent criticality

Note that the original 1980s PRISM design considered a 3-power-block of nine standard reactor module design with a combined rating of $3825 \mathrm{MW}$ thermal. Reactor buildings are separate from steam generator buildings and are connected by piping that runs below grade. A single sodium purification vault services every three reactors. The plant can be brought online with a minimum configuration of 3 reactors and a single turbine generator. Spent fuel is processed separately on-site. During shutdown for refueling, the reactor is brought down from full power to hot standby via condenser cooling. Sodium flow can be maintained by natural circulation even with the electromagnetic pumps turned off. Heat is also removed from the steam generator via natural air flow over the outer shell of the steam generator.

NUREG-1368 (1994) summarizes the Preapplication Safety Evaluation Report (PSER) for PRISM including major systems and subsystem configurations and functions. Sections of the report focus more heavily on conduct of operations as opposed to concept of operations. Not surprisingly, there is considerably more emphasis on the number of reactor modules per power block (3) and it is stated that a single operator may be all that is needed to staff the power block. There is a general lack of information on how the crew is to respond to transient conditions, and key parameter information available to the crew during accident scenario progression. The concepts presented in NUREG-1368 suggest that all reactors on site will be controlled from a single control room, that there will be a common maintenance facility, and that each power block is to share a single sodium service vault. Because of features of the design, all design basis transients are expected to be associated with a negative reactivity coefficient, limiting the potential for radionuclide release.

Four electromagnetic pumps powered from AC distribution supplied from offsite sources force coolant flow; a secondary source also exists. If all power is lost from AC sources, then coastdown is provided by 4 turbogenerator (TG) sets. Control is supplied via a hierarchical distributed digital control system.

Concept of operations related to enhanced safety. In the event of accidents, operators will have more time to respond due to the PRISM passive design that results in heat up times longer than what is the case with commercially available reactors. No ECCS is required (see Table 2 above), as a result there is no concern for inadvertent ECCS actuation, and additionally operator actions can be made through the residual heat removal system thus simplifying the required response. Overall, the PRISM design and other sodium designs, reduce the probability associated with severe accident occurrence. This reduction in severe accidents is associated with low power, primary reactor coolant pressures than atmospheric, a smaller 
core profile, seismic isolation features of the design, and prompt reactivity shutdown and passive heat removal systems.

Automation. One of the concepts for limiting operator burden is that startup operations can be streamlined by having the operators approve a series of hold points for an otherwise automated started up. Once $25 \%$ power is reached through the hold point approval process, the plant will automatically implement power escalation from $25 \%$ to $100 \%$ power. This will allow the operator to have oversight, but additionally the operator will have more time to be able to attend to other tasks. Other examples of digital control include computer control of the reactor protection system (RPS). The digitally controlled RPS is quad redundant and fully independent from the process control system (PCS).

Important in our analysis of aSMR Concepts of Operations is identifying the extent of automation present in the design. In addition to the global level of automation introduced in support of power escalation as discussed above, the following 5 examples of automation in NUREG-1368 are expected to reduce operator burden and increase system efficiency:

1. Automatic coordination of power block operations

2. Automatic apportionment of the load to the turbine generator sets (coordination of the NSSS and balance of plant (BOP)

3. Automatic operation of power train systems (25-100\% including rod profile adjustments)

4. Automatic turbine generator warm up, roll and synchronization

5. Automatic startup of the power conversion part of the plant (feed, condensate, turbine control, venting and draining of main steam and extraction).

Three operating modes are considered: normal startup, load follow, and shutdown. The normal startup mode within a power block is expected to distribute load among the modules equally. Another feature of the design is that sodium flow rates can be maintained at a constant flow rate. Load following is expected to be accurate within $1 \%$ power gain or loss per minute. Shutdown is expected to have fewer operator holdpoints than is typically the case, freeing up the operator to attend to other duties. There are also a number of features associated with reactor scram. These include scramming a single reactor module without inadvertently scramming other modules within the same or adjacent power block. The current design concept ensures that the manual scram capability is present in the control room as well as in the remote shutdown facility.

Bounding events. Also within the design and safety analysis approach is the identification of a series of transients or bounding events to which the design may be subject. For this analysis, GE performed an inhouse PRA and used those results to guide in event determination. They acknowledge the lack of a final design, and challenges in terms of the availability of reliability data for digital systems, use of atmospheric systems in support of decay heat removal, less operating experience than with LWRs and incomplete analytic tools (multi-physics codes applicable to aSMRs). Nonetheless, the determination and identification of bounding events goes toward FA, the role of the operator and the general nature of concept of operations. The following are the bounding events identified in NUREG-1368 as applicable to the PRISM design: transient overpower, station blackout, loss of heat sink from full power, unscrammed loss of flow events, steam generator tube rupture and failure to isolate, large sodium leak followed by fire, flow blockage to or from fuel assembly, and external events (those associated with external events for traditional LWRs - tornadoes, fire, flood, seismic, tsunami).

\subsubsection{Operational Issues with Sodium Cooled Reactors}

Sodium reactors have efficient heat transfer and operate at low atmospheric pressure and the operating characteristics of these reactors are well understood. As stated by the International Atomic Energy Agency (IAEA) (2007) "Among the fast reactor systems, the sodium-cooled reactor has the most 
comprehensive technological basis as result of the experience gained from worldwide operation of several experimental, prototype and commercial size reactors."

In terms of issues related to sodium-cooled aSMRs at least two challenges are worth noting. The first is blockages that prevent the introduction of sodium coolant with an end result of high temperature, which, in turn, leads to overheating and fuel damage. The second is the potential hazard associated with sodium leakage. There are three instances of these conditions leading to cancellation of LMR projects.

Fermi 1, located in Monroe County Michigan, was operational from 1957 through 1972. It was closed down after blockage to spigots introducing sodium cooling caused a temperature excursion resulting in partial melting of the fuel assembly. The second instance of a canceled sodium reactor design was caused by a series of leaks associated with the sodium cooled USS Seawolf commissioned in 1957. After a number of such leaks, the project was abandoned and the submarine was converted to a pressurized water reactor (PWR) type SMR. All subsequent U.S. submarine designs have been of the PWR type. The third operational challenge for sodium reactors was with the Japanese Monju plant. Monju was a sodium cooled mox (metal oxide) fueled plant that began construction in 1986, went on line in 1994 and was shut down in 1995 due to sodium leaks in the secondary cooling side leading to fire and explosion. The unit once again went online in 2010; however, sufficient funds were not available to take the reactor to a $40 \%$ power test necessary prior to taking the unit online and providing power to the grid in 2012 . Uncertainty regarding nuclear power post-Fukushima has made a restart of the Monju sodium reactor unlikely.

Inspection and Maintenance. The characteristics of sodium also make the in-service inspection and repair (ISI\&R) more difficult. (IAEA 2007).

Idaho Operating Experience. The Idaho National Laboratory (INL) was responsible for operation of the EBR-II sodium reactor facility.

Another operational need for sodium reactors in general is to keep an inert gas blanket over the sodium. This is essential in a pool-type reactor such as the EBR-II design at the INL, where argon gas was chosen for this system because of its wide availability, relatively low price, and its superiority for pumping, heat transfer, and sealing. To maintain a low level of atmosphere contamination, a gas cleanup system was provided through which the argon could be re-circulated and purified. This system maintained a static argon gas blanket over the primary sodium. The argon system is valuable not only for the above reasons, but it is a covered gas monitoring system that allows for early detection of fuel failure. The argon system picks up the release and runs it through a gamma monitoring system. The constant covered gas monitoring system was alarmed in the control room, and trend information was presented to the operators. Unlike many of the issues found in the above designs, with a pooled design sodium leaks in the primary system were not of concern. Within the heat exchanger a tube leak is picked up by a detection system, and it will be contained with tubes.

The secondary side in the EBR-II was the non-radioactive sodium heat transfer loop between the radioactive primary system and the steam system. The principal function of this system was to transfer heat from the primary sodium system to the steam system in an efficient manner. The flow rate was $2.5 \mathrm{x}$ $10^{6}$ pounds per hour (approximately 6,000 gallons per minute). The heat exchanger inlet temperature was $588^{\circ} \mathrm{F}$ and the outlet temperature was $866^{\circ} \mathrm{F}$. The principal components of the secondary system, in flow sequence, were the sodium circulating pump, the heat exchanger, the steam superheater and the steam evaporator. One of the aspects of the EBR-II that could have benefited by enhanced visualization or automation was the control rod maneuvering that could be automated. This was a mentally intensive activity where it fell upon the operator to continually monitor reactivity during rod control. A reactor operator and secondary coolant operator were required to jointly perform this task. Other operators included an electrical plant operator and steam plant operator, often the same person who formed part of the team. However, EBR-II was operating at a time when most controls were analog and the digital control systems readily available today were not options in terms of harnessing their capability to help run the plant. 
Perhaps the longest running LMR is the Joyo Reactor in Japan. Joyo went critical in 1977 and is still in operation as an experimental test reactor. Its primary use has been to support development of the Monju reactor whose future is now in doubt. This reactor has gone through a number of power upgrades, the last having been in 2003 where output has been raised to 140MWt. Its latest use during the time that Monju has been unavailable has been on fuel irradiation studies. (As reported in Nuclear Engineering International). Further detail regarding the Joyo fuel irradiation experiments can be found in Yokoyama and Shono (2011 [175]).

\section{Operating Scenarios}

The determination of operating scenarios is an important aspect of Concept of Operations that will be supported by research efforts planned for FY14 after identification of a candidate baseline aSMR has been achieved through discussions with DOE.

Design Concepts. In 2007, The Nuclear Energy Agency (NEA) Committee on the Safety of Nuclear Installations (CSNI) and Committee on Nuclear Regulatory Activities (CNRA) Task Group on Advanced Reactor Experimental Facilities (TAREF) was initiated based on discussions held by the NEA in regards to fast test reactors. In their survey among nations and experts, they succinctly summarize aspects of safety and Concept of Operations in a number of areas [78]:

"Innovative design features have been incorporated into the SMFR design including a metallic fuelled core with high internal conversion ratio, inherent passive safety characteristics, simplified reactor configuration for modular construction and transportability, and supercritical $\mathrm{CO}_{2}$ Brayton cycle power conversion system. The primary and intermediate systems are embedded below the ground level for physical protection. The primary system is configured as a typical pool arrangement with the core, pumps, intermediate heat exchangers, and auxiliary cooling decay heat exchangers all contained within the reactor vessel. The intermediate sodium exits the vessel and flows to the sodium-to- $\mathrm{CO}_{2}$ heat exchangers. Note that this is for a general pooled design fast breeder reactor (FBR) and may not apply to all sodium designs."

Long life reactor core (>30 years) placse more stress on equipment due to the long intervals between maintenance opportunities. There is also a greater accumulated backlog of maintenance activities required during each outage. Such conditions are expected to drive the need for advanced diagnostics, prognostics, and health monitoring to support condition-based maintenance and to ensure better-informed investment protection. Maintenance actions needed to ensure reduction of stress of vulnerable components and safety actions to reduce personnel exposure must be factored into concepts of operations.

Additional safety concerns for concept of operations. Sodium temperatures in the upper part of the core are quite high, and it is possible that there will be thermal gradients and turbulence that can result in the mixing of temperatures. The resulting oscillations may stress structures and induce thermal fatigue on components. Thus, although sodium itself is not considered corrosive on stainless components, potential temperature fluctuations may weaken these very same components. One of the concepts of operations must therefore be that temperature oscillations will not occur to the extent that they pose a significant problem for operations and safety. From the operations perspective, operators need to be given precise temperature readouts and trending information that can be used to monitor the range and spatial location for temperature gradients. This will call for advanced sensor information and visualization capabilities.

\subsubsection{Multi-modular Control Rooms}

One of the more obvious aspects of aSMRs that may lead to different human performance challenges is the plan for some designs to have multiple reactor modules. For some of the designs examined, a single crew will simultaneously monitor and control multiple units (or modules) from one control room. In some cases, multiple operators may be managing multiple modules from the same control room. To support this mode of operations, the modern control room of a single reactor and its secondary systems would 
typically have a large overview display, several operator workstations, a supervisor's workstation, and supplemental workstations for engineering and maintenance work.

Regarding control of modular units, Wood et al. (2003) noted:

"The challenge is to address operability issues of the shared and common systems when the first module is declared operational and the follow-on modules are still under construction. Because of the advances in $1 \& \mathrm{C}$ technology, common data networks that transmit and utilize large amounts of information will serve as integrated data links rather than the traditional direct point-to-point wiring. Thus, the control and monitoring operations of these modules must be fully operational and not susceptible to interference from construction and testing activities in the non-operational modules. Research is needed to address basic guidelines that may include modifications to the data highway and control room design to optimize the construction sequencing. This may result in a control room that is less optimal for human factors at all levels than would otherwise be possible if all the modules simultaneously completed construction. In addition to licensed operation, an option to consider is the use of a dedicated commissioning room in which a module would be commissioned and then 'transferred' to the shared control room." (Error! Reference source not found., p. 59)

Maintaining sufficient awareness of the status of multiple modules may tax crews and individual operators. For example, when operators in current plants are focused on a particular problem, other operators would take over their tasks. Such cooperation may be problematic when each operator is responsible for multiple units. A key requirement therefore would be for designers to demonstrate that operators can effectively and reliably accomplish this task with good teamwork, good situation awareness and minimal workload.

A related aspect is that multiple modules will add variability and complexity to crew and operator tasks and this requires the following to be considered in the operational design:

- Different modules in a multi-modular plant can be at different power levels or different states, such as shutdown, startup, transients, accidents, refueling and various types of maintenance and testing.

- Since different modules might be added at different times during the construction period, design and configuration differences may arise.

- Control systems may be able to manage multiple units in an integrated fashion. This could include systems that the units share in common, such as for circulating water or the ultimate heat sink for removing decay heat, and also systems for instrument air, service-water cooling and AC and direct current (DC) electric power. It may also include common control of systems that are similar but not shared between units, such as balance-of-plant systems. The integrated control of multiple modules and their shared systems would thus be not only an automation challenge, but also an operational challenge. The demand placed on operators to maintain situation awareness, not only of the plant overall, but of individual units and shared systems, may impose a severe cognitive workload. In fact, without evidence to the contrary, this may challenge current assumptions that workload in aSMR control rooms will be lower, thus allowing operators to handle more than one module at a time. It can thus be concluded that automation system design has to be informed by results from a comprehensive HFE process, in particular, FRA, FA analysis, and task analysis.

- The detailed design of HSIs (alarms, displays, and controls) to enable a single operator to effectively manage one or more SMRs will be an additional challenge. HSIs must enable monitoring the overall status of multi-units, as well as easy retrieval of detailed information on an individual unit.

Another factor that will have a significant effect on future plant operations and thus on the role and function of the operating staff, is the design of the automation system and procedures to handle the range of new missions and tasks that might be required by the SMR designs. While the primary mission of the plants would still be to safely generate electrical power, some aSMRs may be designed to accomplish 
additional missions, such as producing high-temperature steam for hydrogen generation and other hightemperature industrial applications.

These missions would give rise to new operating modes, such as unplanned shutdowns, degraded conditions in one module that may affect other modules, or off-normal conditions at more than one unit, will require new tasks such as load following operations, managing non-LWR processes and reactivity, and novel refueling methods. New plant modes and tasks will inevitably create complexities and require innovative treatments in the design and use of appropriate HSIs. Ultimately, all of these conditions will require development of a new family of Normal Operating Procedures (NOPs) as well as EOPs for multiunit disturbances.

It is a well-known fact that new I\&C technologies make it possible to automate systems in ways not possible with the analog systems of older nuclear plants. One of the longer-term objectives of this project is to sensitize designers to the importance of keeping operators aware of the state of the automation system at all times. To ensure this, new automation philosophies must be informed by the tasks that operators are required to perform, and their abilities and limitations in performing those tasks under various operational conditions. Making design decisions must be based not only on an understanding of the criteria for allocating functions to humans or to systems, but on the synergistic collaboration between them during the different plant states. Current FA methods are outdated because they do not offer specific analytic tools for deciding when and how to apply new types of automation. This report will address that shortcoming and present new findings that could lead to the development of more appropriate techniques to design for a dynamic collaboration between operators and plant systems.

\subsubsection{New Maintenance Concepts For Asmrs}

The implementation of aSMR design for maintenance will take advantage of digital systems capability in a number of ways. Digital systems are expected to use sensor technologies that can identify when equipment is malfunctioning and when preventive or corrective maintenance is required. Smart systems will be able to diagnose equipment conditions such as malfunctions in level controllers or sensors and determine the associated maintenance activities, including equipment replacement. Failed sensors will mostly be alarmed and logged to support maintenance activities. Digital systems may also be able to confirm that equipment is in a safe state to be worked upon, with corresponding indications in the control room, thus reducing the potential for maintainer injury, such as exposure to electrical or radiological hazard. After tasking is completed, digital systems could be used to verify both the proper functioning of equipment as well as the configuration needed for startup. Truly advanced systems will be able to selfconfigure the equipment after maintenance. As part of the overall safety concept, distributed control system may be able to ensure that systems with the potential for injury are not energized once personnel have begun to work on them.

In terms of staffing, a number of approaches have been proposed including an in-house maintenance crew that performs routine activities for the multiple, similar modules that will be in different states of operation such as refueling, or outage work. In comparison to the large number of subcontractors present at LWR sites during outage work that may number in excess of 1000 workers, the outage crew required for a smaller, 50MW plant should be much smaller. It is likely that if a site has a mixture of older LWRs and newer aSMRs that the maintenance crews will not be the same. Thus, the modularity is expected to decrease the number of personnel required while providing more experience and similarity for the crews performing those activities.

A number of additional assumptions included in the concept for maintenance for aSMRs are that advanced digital systems, including online prognostics, can reduce, if not preclude, the potential for anticipated transient without scram (ATWS), and that out-of-service status can be automatically detected. It may also be the case that digital systems can detect maintenance errors in real time and alert maintenance personnel in order to preclude damage to equipment. The aSMR is also likely to maintain a large set of databases that can be data mined for trends to a greater extent than is now possible with the 
current LWR fleet. For example, there will be a database to support equipment tagging during outage control, a situation that is mostly handled in today's LWRs by paper and pencil. Main control room (MCR) operators are likely to be updated on ongoing maintenance activities through a combination of video feed, electronic statusing of equipment condition, and location of personnel and by voice communication, which is now the predominant mode of informing the control room. Maintenance procedures and work orders for work to be performed outside of the control room are likely to be available on handheld mobile devices and verification may include video streaming of equipment status back to control room operators.

As a final consideration, aspects of maintenance for aSMRs are expected to differ from those for IPWR SMRs. For some IPWRs the steam generators are to be integral with the module and its containment, not allowing easy access to the steam generators. NUREG/CR-7126 notes that for Toshiba's 4S ("super, small, safe and simple") and GE's PRISM designs (both sodium-cooled), maintenance on the two external steam generators is hazardous and may entail specific training because operators must wear specialized personal protective equipment (PPE) and work in an inert gas atmosphere Error! Reference source not found.

\subsubsection{Concept of Operations: Advanced Diagnosis and Prognosis.}

Masys et al. (2013 [68]) present a number of problems in diagnosis and prognosis shared by the medical and nuclear industries, which may be even more pronounced for operators monitoring and control of multiple reactor modules and common systems. These problems can be summarized as:

1. Information overload and need to perform real time data reduction for emergent problems.

2. Problem diagnosis under conditions of sparse or conflicting data.

3. Optimal presentation of relevant data.

4. Understanding mechanisms of degradation (fuel, cladding, structures).

5. Effects of false positives on diagnosis.

6. Near real time requirements for diagnosis and prognosis of emergent problems.

7. Cognitive limitations for multi-tasking.

Items 1 and 2 are opposite sides of the same coin, in the first instance, we have the capability to produce large numbers of measures of plant performance and equally large numbers of displays, and this has to be balanced or refined to support what is really crucial to supporting operations and the operator's role in plant management. In a highly digital world, the issue of conflicting data or sparse data is reason for concern. For example, when multiple units are being surveyed if there are conflicting data it is likely to tax the crews' information processing capability and situation awareness. Similarly, if only partial data are available for one unit and complete data are available for another, this may call into question the selection of the correct mitigative measures. Advanced prognostics and diagnostics can help to reduce uncertainty and aid in operator response.

By placing data presentation within the context of prognostics and diagnostics, the challenge of optimal data presentation (3) can be achieved. This assumes that diagnostics and prognostics can be context sensitive in terms of such factors as such operating mode, current conditions, and operating limits. One of the problems facing operators of LMRs is to understand the mechanisms of degradation and diagnostics keyed to temperature swings and partial sodium voiding. (4) Advances in multiple robust sensors combined with prognostics and diagnostics may greatly enhance the operator's understanding of plant degradation.

The presence of false positives (5) can produce confusion and thus, greatly impair crew response. By running system models and performing automatic cross checking of data conditions, diagnostic and prognostic support systems will result in more accurate interpretation of actual plant and system conditions. Also, assisting crew identification of false positives will reduce cognitive workload. Emergent problems (6) are associated with complex emergency conditions and are often observed during 
the conduct of long-term outage work. SMR concepts of operations regarding simplification of the sheer number of systems to which the crew must attend and maintain may simplify outage work, but the complexity presented by the number of reactor modules simultaneously in service will produce relatively high levels of workload that can be reduced by real-time aiding and diagnostic evaluation of emerging conditions. Once an appropriate diagnosis has been performed, the automation can suggest or call up the appropriate procedures for response. Cognitive limitations for multi tasking (7) particularly during busy times are a real phenomenon and advanced diagnosis and prognosis that support a collaboration among the crew or between the crew and smart systems can be used to lessen the effects of multi-tasking.

\subsubsection{Beyond Design Basis Accidents for non-LWRs}

Severe accident management guidelines (SAMGs) were developed post-Chernobyl and embraced by the U.S. NRC and industry. Severe accidents involve fuel damage and/or damage to the reactor core, leading to radiological release to the reactor vessel, containment or the environment. One of the conditions leading to such an accident for LWR designs is uncovering the top of the fuel. When the fuel cladding in a traditional LWR reactor interacts with steam, the temperature can exceed $1200^{\circ} \mathrm{F}$ and hydrogen and zirconium oxide are released. Outside of the core, there is the potential to uncover fuel residing in the spent fuel pool. In 2006, the NEI and owners groups issued guidance on the use of makeup systems to keep spent fuel covered.

As was evidenced in Fukushima, there are a number of actions that operators may consider in order to try and protect the core and spent fuel pool including the use of portable generators and pumps, and alignment of various injection sources not typically part of control room or field evolutions. Research determining crew performance requirements at aSMRs for severe accidents is warranted.

Although there are a number of safety features inherent in aSMR designs, there still exists the potential for beyond design basis events. As of 1997, three such beyond design basis generic events were evaluated for the PRISM reactor: loss of primary flow, reactivity insertion through unprotected control rod withdrawal and extended loss of heat sink. Maximum transient effects occur at full power and calculations determined in the design take this into account. After running simulation software, the designers concluded that the PRISM core would be intact by the following: lack of boiling in the peak fuel assembly, temperatures within the cladding midwall limit of $1450 \mathrm{~F}$, temperatures not exceeding the reactor structures limit of $1300^{\circ} \mathrm{F}$, no fuel melt at $2000^{\circ} \mathrm{F}$, and lack of issues with the fuel cladding interface below eutectic formation.

The Brookhaven National Laboratory (BNL) report (NUREG/CR-7126 Error! Reference source not found.) suggests that $\mathrm{I} \& \mathrm{C}$ will play a key role in protecting the plant from leaks within the reactor vessel. The existing design allows for sodium leak detection leading to automatic shutdown based upon the presence of detectors in the reactor vessel and in containment.

As a key concept, the vessel structure and properties is to be kept to less than $1300^{\circ} \mathrm{F}$. Fuel melt is at $2000^{\circ} \mathrm{F}$ and boiling of the sodium coolant can occur at $1800^{\circ} \mathrm{F}$. On a high level, for all three events, the crew-system performance goal is to maintain cladding integrity and prevent radioactive release through control of the temperature, including both the surface temperature of the fuel and cladding temperature. Combined direct or indirect operator feedback on cladding temperature and coolant levels may be the sort of information needed in the control room and at the TSC during events.

In review of the available literature, it appears that most of the analysis was performed in terms of the physics and structures and not on the basis of human performance requirements and ability of the crew to complete various SAMG procedures. If this design, or other aSMRs for that matter, were to be certified, the recent U.S. NRC Near Term Task Force Findings for Fukushima (2012) would have to be addressed, with particular reference to emergency power supplies at the site and loss of ultimate heat sink. Addressing these challenges for aSMRs may require training, new procedures for severe accidents, identification of portable equipment (pumps, generators), installation of new filtration to reduce release of 
radionuclides, and extending simulation capability to extend to the severe accident realm. aSMR design requirements may include the configuration of modules such that a severe accident would not be capable of spreading to adjacent modules and overwhelming common systems key to system safety.

Additional design information including response to transients mentioned in research above is available in Slovik et al. (1990 [119], 1991 [120] and 1992 [121]).

The Japanese 4S design was also reviewed and determined to have much in common with the PRISM design. For example, intermediate heat exchangers and electromagnetic pumps are prominent features in both designs. However, the $4 \mathrm{~S}$ design produces close to 1/10th of the power output of the PRISM, 30MWe versus $311 \mathrm{MWe}$. This design concentrates on some ATWS conditions, but maintain that passive reactivity feedback mechanisms and passive heat removal will protect fuel integrity. The safety analysis report states that radiological release is limited due to the low power associated with a reactor module, retention of fission products within the core and sodium, and design margin for cladding failure in design basis and beyond design basis events. As in the GE design, one innovative system for residual heat removal is the auxiliary cooling system that uses natural convection of air outside the reactor vessel.

As in the case of the GE PRISM, the Toshiba 4S design does not list any safety critical operator actions, or information regarding information requirements and criteria for human-system interaction. Not surprisingly, no consideration in either design is given to the human as initiator of these beyond design basis events or to the FA strategy for O\&M.

\subsubsection{The Relationship between Systems Engineering, Human Factors Engineering, and Concept of Operations}

The following diagram describes the relationships and dependencies between the licensing process (NUREG-0800, etc.), systems engineering (INCOSE [56], IEEE 1220) and HFE (NUREG-0711, etc.): 


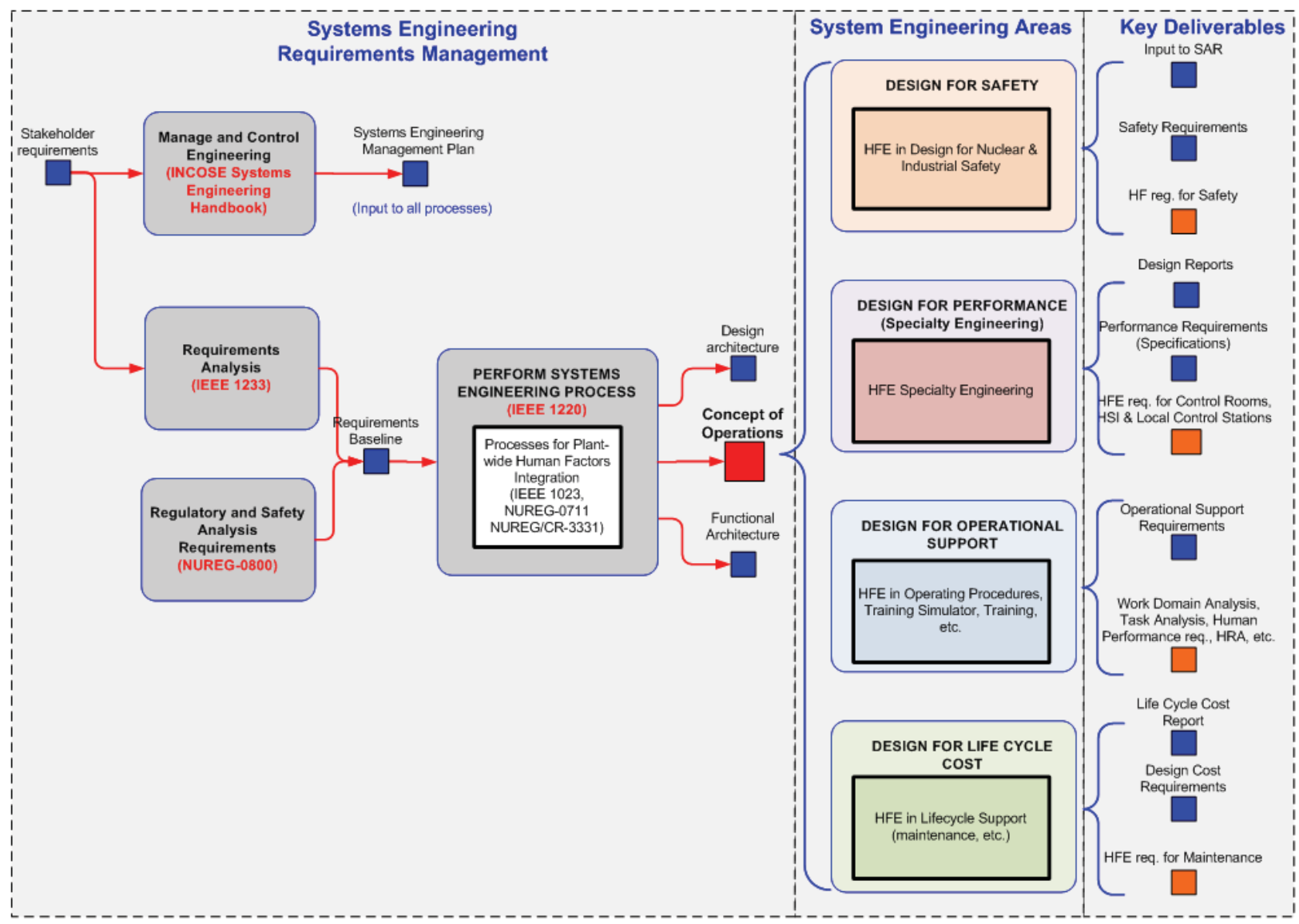

Figure 1: Integration of HFE with Systems Engineering and Licensing Processes

The diagram illustrates that the Concept of Operations document is developed very early in the project life cycle as part of requirements engineering. It is also shown Human Factors requirements are developed as part of the Systems Engineering Process (SEP) and this is guided by integration requirements derived from IEEE 1023, NUREG-0711, NUREG/CR-3331 and other guidance, such as EPRI 1010042). The Concept of Operations document, together with high-level system and functional architectures serve as critical input to the four main dimensions of the SEP in the development of a nuclear plant. The integrated dimensions are performed concurrently during the plant design, and each one has specific SEP as well as HFE functions and deliverables. To achieve this, HFE interfaces with all engineering groups to ensure integration of human factors requirements during the entire plant life cycle, as shown in Table 4.

Table 4: Life cycle dimensions of the integrated HFE process

\begin{tabular}{|l|l|l|}
\hline SEP Dimension & $\begin{array}{l}\text { Systems Engineering } \\
\text { Functions }\end{array}$ & $\begin{array}{l}\text { Human Factors Engineering } \\
\text { Products }\end{array}$ \\
\hline Design for Safety & $\begin{array}{l}\text { Development of the Safety } \\
\text { Analysis Report, as prescribed } \\
\text { by NUREG-0800, as well as } \\
\text { DiD measures, probabilistic } \\
\text { safety analysis (PSA) and } \\
\text { ALARA. }\end{array}$ & $\begin{array}{l}\text { Human factors requirements for } \\
\text { safety, including habitability, } \\
\text { accessibility, egress, and } \\
\text { industrial safety. }\end{array}$ \\
\hline
\end{tabular}




\begin{tabular}{|l|l|l|}
\hline Design for Performance & $\begin{array}{l}\text { Detail functional and technical } \\
\text { requirements of plant SSC } \\
\text { needed to achieve plant mission } \\
\text { goals. }\end{array}$ & $\begin{array}{l}\text { Human performance criteria for } \\
\text { systems, including specifications } \\
\text { for control rooms, local control } \\
\text { stations, HSIs and work } \\
\text { environments. }\end{array}$ \\
\hline Design for Operational Support & $\begin{array}{l}\text { Analysis and development of } \\
\text { policies, procedures and } \\
\text { measures to ensure system } \\
\text { resilience, reliability and } \\
\text { efficiency during operations. }\end{array}$ & $\begin{array}{l}\text { Human factors requirements for } \\
\text { different operational conditions, } \\
\text { task analyses, staffing, and } \\
\text { human reliability analysis } \\
\text { (HRA). }\end{array}$ \\
\hline Design for Life-cycle Cost & $\begin{array}{l}\text { Also important contributions to } \\
\text { operating procedures and } \\
\text { training simulator development. }\end{array}$ \\
$\begin{array}{l}\text { Development of the processes } \\
\text { toeded for systems to satisfy } \\
\text { including production, test, } \\
\text { distribution, logistic support, } \\
\text { training, decommissioning and } \\
\text { disposal. }\end{array}$ & $\begin{array}{l}\text { Human factors requirements for } \\
\text { integrated system validation, } \\
\text { maintenance, and human } \\
\text { performance monitoring } \\
\text { requirements. }\end{array}$ \\
\hline
\end{tabular}

The following concept map describes in more detail how the different engineering activities and products are related and how the key topic of this project, concept of operations, relates to specific human factors methods and products, in particular the way that FA, HSI design, and automation are dependent on, and influenced by, the results from a WDA. 
The Concept of Operations Document and its relationship to other engineering processes

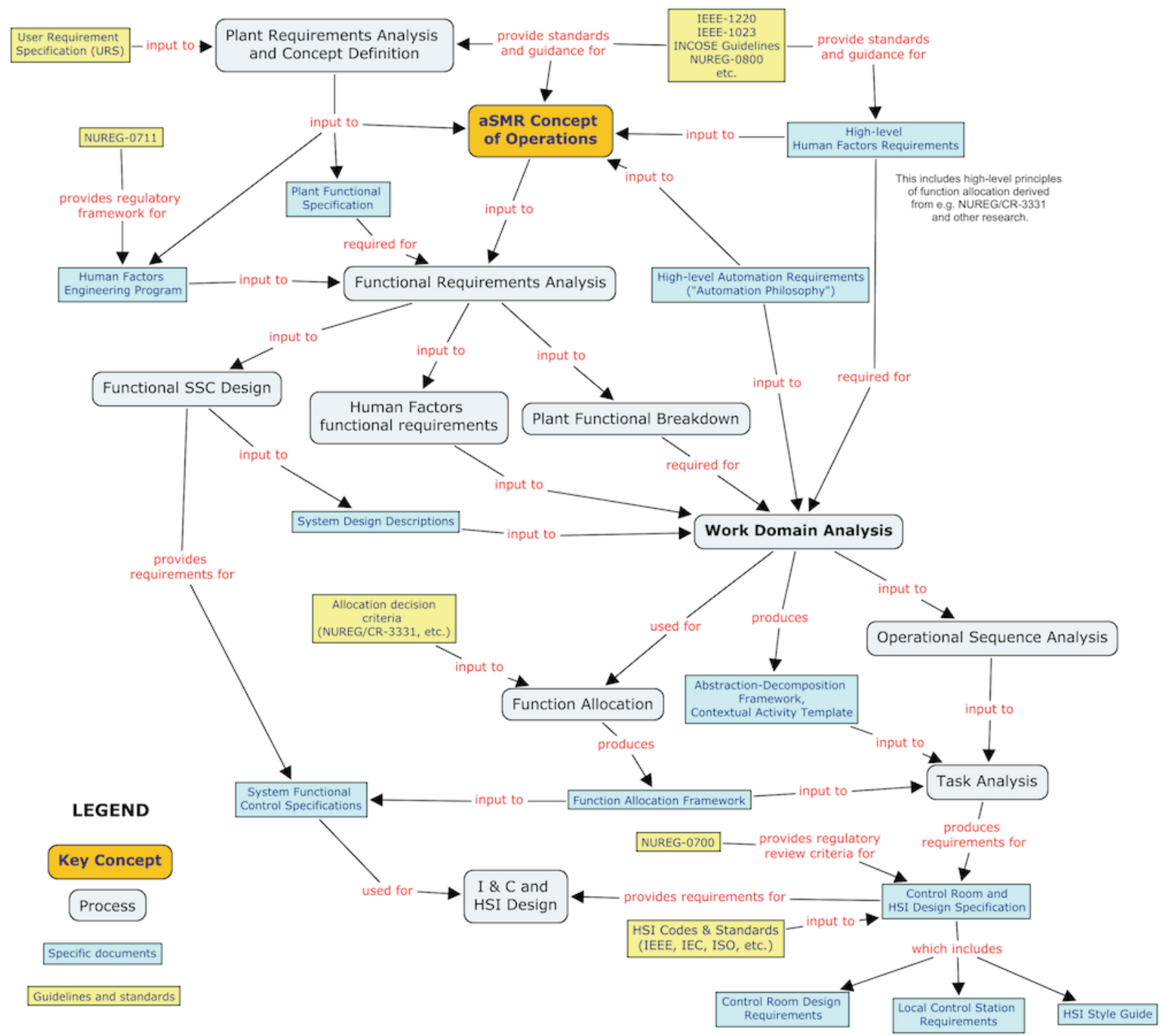

Figure 2: The Concept of Operations Document and its relationship to other engineering processes

As indicated in the concept map, there are multiple inputs to the definition of a plant's concept of operations. These inputs come from several engineering disciplines, with special emphasis on high-level, predetermined plant and system functions, high-level human factors requirements, regulatory requirements, automation philosophy, and standards and guidelines. As described previously, the Concept of Operations document guides a lot of downstream design and development. In particular, it provides essential information for FRA and the subsequent functional design of SSC and automation system design. It also helps to define the scope of the WDA, which in turn is the essential input to FA, operational sequence analysis, task analysis, and HSI design.

\subsubsection{Development of Concept of Operations documents in the Nuclear Industry}

From the descriptions above, we can now summarize the difference between the three key concepts as follows: 
1. Conduct of Operations: This describes how a plant is managed and how its daily operations are to be conducted to conform to industry best practice. This document therefore comes into force after the plant has been commissioned and will remain in force for the life of the plant.

2. Operational concept: This is a high-level document developed very early in the project life cycle and it documents the enterprise's assumptions or intent regarding the operation of a new, existing or modified system.

3. Concept of Operations: This is a technical document that describes the characteristics of a proposed system from the viewpoint of an individual who will use that system. It describes the structural and functional architecture of the planned system, how its components interface and how specific users will interact with it during various phases and conditions of plant operation.

The third definition is taken as the one that governs the scope and intent of this project. However, it is clear that the three definitions overlap to some extent and implications of this for aSMR designers will be considered during the next phase of the project.

The definitions of Concepts of Operations from the various sources listed above also demonstrate that Concept of Operations documents are developed in different ways in different industries, but they generally share the same properties. For a nuclear plant, the implementation of the "What, Who, When, Where, Why, and How" described by INCOSE will produce a Concept of Operations document that is a collection of procedural and high-level technical information that would include the following:

- An overview of the plant and its main systems.

- A description of the plant's subsystems, their purpose and functions.

- A description of the plant safety functions.

- High-level descriptions of the main and subsystems.

- A description of the operational modes and states of the plant, including normal transitions, AOOs and transients.

- General description of the operational design of the MCR.

- A description of the basic role of operators and other operational personnel.

- The basis for the allocation of control functions to MCR, to the remote shutdown facility, or to local control stations.

- The coordination of team members' activities, such as the interaction between different types of operators, and the coordination between maintenance and operations personnel.

- Operating requirements for facilities such as the control rooms, HSIs and operator workstations, local control stations, communication equipment, procedure systems, etc.

- High-level description of operator interaction with HSIs and the basis for FA.

- High-level descriptions of the staffing strategies for the plant and the high-level roles that are to be assigned to operational and maintenance personnel.

- High-level principles for operator display assignment, including annunciators and safety-related displays.

- An overview of operational procedures, including automatic and manual operations, outage management, normal and abnormal operating procedures (AOPs), alarm handling, etc.

- Guidance to enable designers to do initial assignment of automatic versus manual controls (i.e. level of automation).

- High-level descriptions of the I\&C architectures;

- Guidance to enable designers to develop initial HSI recommendations, including but not limited to assigning criteria for alarm priority categorization.

- Guidance on operating and maintenance procedures.

- Principles of operating with degraded I\&C 
- Description of the requirements for monitoring, interacting, and overriding automatic systems, and the interaction with computerized operator support systems (COSSs).

- Basic principles of commissioning, maintenance, test and surveillance concepts.

In addition to the items above, the Concept of Operations document should also provide an overall methodology to realize the goals and objectives for the system.

The Concept of Operations is not a standalone document but is typically linked with a Systems Engineering Management Plan (SEMP) and plans that are more detailed for all specialty-engineering disciplines. One of the latter is the Human Factors Engineering Program Plan that describes how human factors activities are synchronized with other engineering activities and what products are developed during each phase. For HFE in particular, the Concept of Operations is a vital source of information on system functions and the intended roles of operators. This provides the starting point of all HFE activities for a new plant, as outlined in NUREG-0711: FRA, FA, task analysis, HSI design, and more. 


\section{Development of a Function Allocation Model for aSMR Concepts of Operations}

\subsection{Overview}

One goal for this Concepts of Operations project is to develop a FA method for aSMRs. Specifically, the goal is to develop a preliminary method for allocating plant functions that aSMR designers can use to determine how functions could be allocated to agents within their specific aSMR design. Because current FA methods still have some technical gaps, in order to develop this FA method properly, some additional FA research will need to be performed, particularly in order for this FA method is to work effectively in an aSMR context. As explained later in this report, the remaining research will be informed partly by the WDA to be conducted during the next phase of the project.

Developing this FA method is an important contribution to the R\&D activities under the DOE ICHMI pathway for a number of reasons, including the fact that an FRA and FA are elements of the Human Factors Engineering Program Review Model that the NRC uses as part of its license application review (NUREG-0711, Rev. 3). As such, this FA methodology can be a resource to aSMR designers as they prepare their designs for license review.

The goal of this section is to provide a review of FA methods and models, to describe their applicability to the Concepts of Operations project, and to describe the principles and requirements for the development of a new foundational model.

\subsection{Definition of Function Allocation}

FA is an HFE decision-making process and method that is used during the design life cycle of complex systems to distribute individual work functions among all agents in a team, human and automated machine. The function can be assigned to a human or automation agent, or to a multi-agent team (for example, comprised of automation and human(s), a team of human agents, or a team of automation agents).

FA is complex because of the many interdependent factors that must be considered. Unlike conventional NPP designs that can rely on a significant body of operating experience and well-defined system functions for making allocation decisions, many design decisions for SMRs have very limited technical bases for human factors issues. Current methods for FA in particular are often subjective and prone to error. Where higher levels of automation are envisaged, the definition of system functions and operator roles and tasks must be based on a first principles analysis of all the factors that may influence the behavior and performance of each. Due to the fact that no new reactors have been built in the United States in the past 30 years, there is very limited experience with applying HFE for new designs. This makes R\&D for the development of state-of-the-art human factors techniques for aSMRs of vital importance.

According to NUREG-0711, Rev $3^{2}$, FA is the assignment of functions identified from the plant's functional requirements to personnel (e.g., manual control, automatic systems, and combinations of both). aSMR license applicants' submittals will be assessed in terms of the extent to which the design exploits "...the strengths of personnel and system elements enhances the plant's safety and reliability, including improvements achievable through assigning control to these elements with overlapping and redundant responsibilities. Function allocations s should be founded on functional requirements and HFE principles in a structured, well-documented methodology that produce clear roles and responsibilities for personnel." (page $\mathrm{x}$ ). In particular, the early human factors analyses performed in preparation for developing the plant's Concept of Operations must identify the functions that must be performed to satisfy the plant's safety objectives, that is, to prevent or mitigate the consequences of postulated accidents that could cause

2 Note that, unless stated otherwise, all further references to NUREG-0711 will be to Rev 3. 
undue risk to the health and safety of the public. This analysis determines the objectives, performance requirements, and constraints of the design, and sets a framework for understanding the role of controllers (whether personnel or system) in regulating plant processes. New and different functions associated with SMR designs (such as passive features, design simplicity, increase in required response time, monitoring and control of multiple modules) need to be evaluated thoroughly. (NEI Position Paper on Control Room Staffing for Small Reactors Error! Reference source not found.).

\subsection{Summary of Existing Function Allocation Methods}

Within the field of HFE, FA has a long and checkered history. The earliest research in this field began in the 1950's with the advent of what is now commonly referred to as Fitts' List. In 1951, Paul Fitts published his "HABA/MABA" list, by which different functions are categorized based on what "Humans are Better At" versus what "Machines Are Better At" (Fitts, 1951 [26]). The list has been used (many human factors experts would argue incorrectly) as a simple decision aid to assign the functions to human operators or automation, depending on what agent the designers believed would be better able to perform the function. Using Fitts' List as a starting point, other researchers, including Nof, Knight, and Salvendy (1980 [76]) developed revised lists as a means to improve the outcome quality of the decision-making process, but also as a way to customize the list to the capabilities of the automation being used in that specific context.

A number of conventional or simplified methods have been applied over the years and as described in the discussion that follows, most of them applied a version of the list presented in Table 5, based on various interpretations of Fitts' List.

Table 5: Basic Criteria for Allocation (Example)

\begin{tabular}{|l|l|l|}
\cline { 2 - 3 } \multicolumn{1}{l|}{} & \multicolumn{2}{c|}{ Typical Assignment } \\
Characteristics & Human & System \\
\hline Load & Moderate & High or very low \\
\hline Time margins & Large & Small or very large \\
\hline Rate & Moderate & High or very low \\
\hline $\begin{array}{l}\text { Complexity of action } \\
\text { logic }\end{array}$ & Simple & Complex \\
\hline $\begin{array}{l}\text { Types and complexity } \\
\text { of decision-making }\end{array}$ & Ill-structured & Well-structured \\
\hline
\end{tabular}

More recently, numerous researchers, including Sharit (1997 [114]), Chapanis (1996 [18]), Clegg, Ravden, Corbett, \& Johnson (1989 [20]), Sheridan (2002 [117]), and Pulliam, Price, Bongarra, Sawyer, and Kisner, 1983 Error! Reference source not found.), Price (1985 [101]), and Price and Pulliam (1988 [103]), have tried to improve the technical basis for FA methods. While many of these researchers have proposed their own FA methods, in the process of doing this, they have addressed a number of global issues with FA by filling in knowledge gaps present in the earlier FA approaches.

For example, Sharit (1997) pointed out that a necessary preparatory step to conducting a FA analysis is to deconstruct the system into its functions, which is not a specific step that a designer would use if they used Fitts' List as a simple decision aid. He proposed three approaches, which are flow analysis methods (e.g., modeling the progression of events in the system), time line analysis (e.g., assessing whether the progression of events is on, ahead of, or behind the predetermined schedule), and network analysis (e.g., examining the relationship among events, agents, and functions). Other researchers have had similar 
thoughts, and have suggested that the rest of FA processes also be performed in a series of steps. For example, Chapanis (1996) recommended the following steps (as documented in Nemeth, 2004 [75]):

1. Identify all functions that require mandatory allocation to either personnel or equipment and remove them from consideration.

2. List the remaining functions.

3. Prepare descriptions of the alternate ways the functions could be accomplished.

4. Establish weighting criteria.

5. Compare alternatives against criteria.

6. Select the alternative with the best performance and cost-effectiveness. (p. 183)

Note that Chapanis' steps assume a static allocation of functions. That is, once the allocation decision is made, it does not change as a function of changing operational conditions. Clegg et al. (1989 [20]), on the other hand, proposed a dynamic allocation, which is depicted in Figure 4.

Sheridan (2002 [117]) also filled in a gap in FA methods by pointing out that human cognition and level of automation interact to produce different outcomes depending on the nature of their interaction. From the perspective of cognitive psychology's concept of information processing, humans (in this context, aSMR operators) progress through different stages of cognitive processing as they execute their tasks in the control room. Sheridan called these cognitive processing stages: acquire information, analyze and display, decide action, and implement action. He also recognized that the amount of automation used in a given situation could vary from fully manual to fully automatic, with intermediate levels in between. He was then able to demonstrate that across different systems (e.g., air traffic control versus automated manufacturing), in order to allocate functions effectively between operator and automation, thereby optimizing overall system performance, the designers needed to know the operator's cognitive processing stage in order to determine level of automation would be most appropriate to execute a given function.

\subsubsection{Review of notable methods and models}

As indicated before, FA provides the basis for subsequent efforts relating to crew or operator task analysis and description, operator performance analysis, display and control selection or design and HSI design, development and evaluation. FA decisions greatly affect operator workload, staffing, selection and training requirements (Hugo and Engela, 2005 [43]). The present research aims to identify and evaluate relevant and applicable FA methods. This section provides a review of recent literature on FA methods and models.

\section{Measuring Human-Automation Function Allocation. Kim, Feigh, Pritchett (2012).}

Kim, Feigh and Pritchett's research [61] is based on a computational framework for modeling FA with support for both static analysis and dynamic computational simulations. Specifically, this paper demonstrates how certain FA metrics can be assessed from computational simulations of an air transport flight deck in the approach and arrival phases of flight. These metrics include: workload, stability of work environment, mismatches between responsibility and authority, incoherency in FA, interruptive automation, automation's boundary conditions, allocations limiting human adaptation to context, and mission performance. A full range of FAs, explicitly or implicitly, is examined in any design. The researchers proposed four critical factors to be considered in the establishment of a FA model including:

1. Collective "task work of a team" spanning the functions required to achieve work goals.

2. Allocation of task work functions to create a need for additional teamwork functions. This leads to coordination between "agents".

3. Ability to predict the dynamic aspects of tightly coupled agent interactions that arise when the allocated functions are interdependent or interleaved.

4. Support of FA evaluation within engineering design. 
Researchers created scenarios selected to establish off-nominal conditions predicted to stress the FA. Modes were designated as opportunistic, tactical and strategic. Tradeoffs between eight metrics were evaluated to identify potential trade-offs and conflicts existing between them.

The researchers offered criticism of other current FA methods, dismissing these as too abstract or conceptual to serve as guiding standards. Earlier work by Parasuraman, Sheridan and Wickens (2000 [99]) is critiqued for its broad generalizations based on general heuristics for criteria evaluation and failure to deliver detailed analysis. Our research team asserts that quantitative analysis is critical for future research in order to recognize the tradeoffs that can occur between measures of good FA. Further, it is noted that while automating as many functions as possible may reduce the workload of human agents, this results in significant increases or imbalances elsewhere - in the degree of monitoring work allocated to the human operator in a supervisory role, in the unpredictability of the human work environment, and ultimately in the confusion as to which 'left-over' work is then assigned to the human.

\section{Formal Function Allocation Method for First-of-a-kind Designs - Hugo and Engela (2005)}

This method (Hugo, 2005 [40], 2006 [41], 2009[42]; Hugo and Engela, 2005 [43]) describes a formal, systematic FA method for use as an analytical tool to distribute defined control functions to humans (i.e. manual control), system elements (automation control and passive, self-controlling phenomena) and combinations of humans and system elements (shared control systems and systems with manual backup). This method, based primarily on NUREG/CR-3331 principles, is broken into three sections as follows:

Primary factors that determine or influence allocation of functions:

- Comparison of performance requirements between humans, hardware and software, specifically the functional control requirements and comparison of these requirements with the capabilities (mainly performance and feasibility) of the human and the machine.

- Cost and economics tradeoffs.

- The availability of task support for the operators (cognitive and procedural support).

- Information and decisions required to initiate, sustain, and otherwise support the functions.

- Relative performance of humans, hardware, and software for specific functions.

For further determination, five fundamental questions were posed, in accordance with NUREG/CR-3331 principles:

- Is automation essential or mandatory?

- Is automation predetermined by constraints established during the requirements analysis phase?

- Is automation predetermined by constraints established during the requirements analysis phase?

- Is human interaction essential or mandatory?

- Is it technically feasible to automate the function?

- Is it feasible for the human to perform the function?

Employing this method places focus on functions and decisions allocated as determined by system requirements, environmental conditions, organization policies, and operator role mandated by policy, regulation or system physics. When determination of unambiguous allocation to human or automation proves difficult, tasks may be allocated as a shared function. These shared functions may be carried out in one of three scenarios. First, the function may be performed by both automation and human given certain conditions. Another scenario would have the human operator performing certain portions of the function with additional steps allocated to the automation. A third scenario would include an automated function with manual functions allocated to the human as a backup measure for abnormal or emergency operations.

The researchers present a practical approach, adapted from NUREG/CR-3331, to remedy the difficult FA decisions engineers face in a variety of industrial and commercial settings along with a variety of 
additional task environments. Emphasis is placed on the inclusion of at least a primary FA early in the design life cycle, as shown in Figure 3:

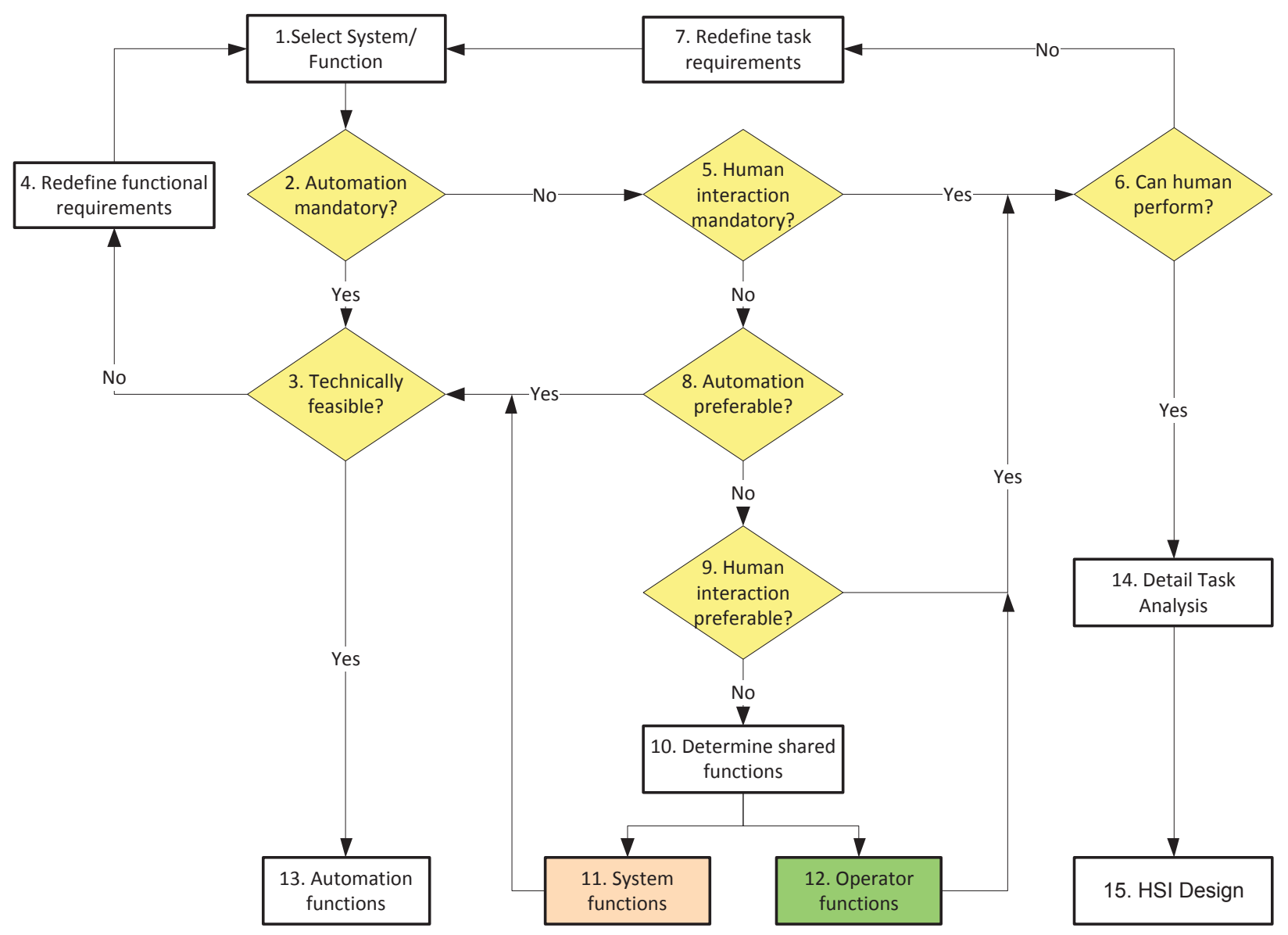

Figure 3: Process Flow Diagram

(Hugo, 2009, adapted from NUREG/CR-3331)

\section{Method for allocating function in advanced manufacturing systems - Clegg, Ravden, Corbett, and Johnson (1989)}

From an analysis of FA in dynamic systems, a number of similar methods were found, for example the Clegg, Ravden, Corbett and Johnson model (1989 [20]) and the Nemeth model (2004 [75]). It was found that the model generated from the Nemeth method is quite simplistic in design. The allocation method contains 7 phases as shown in Figure 4. 


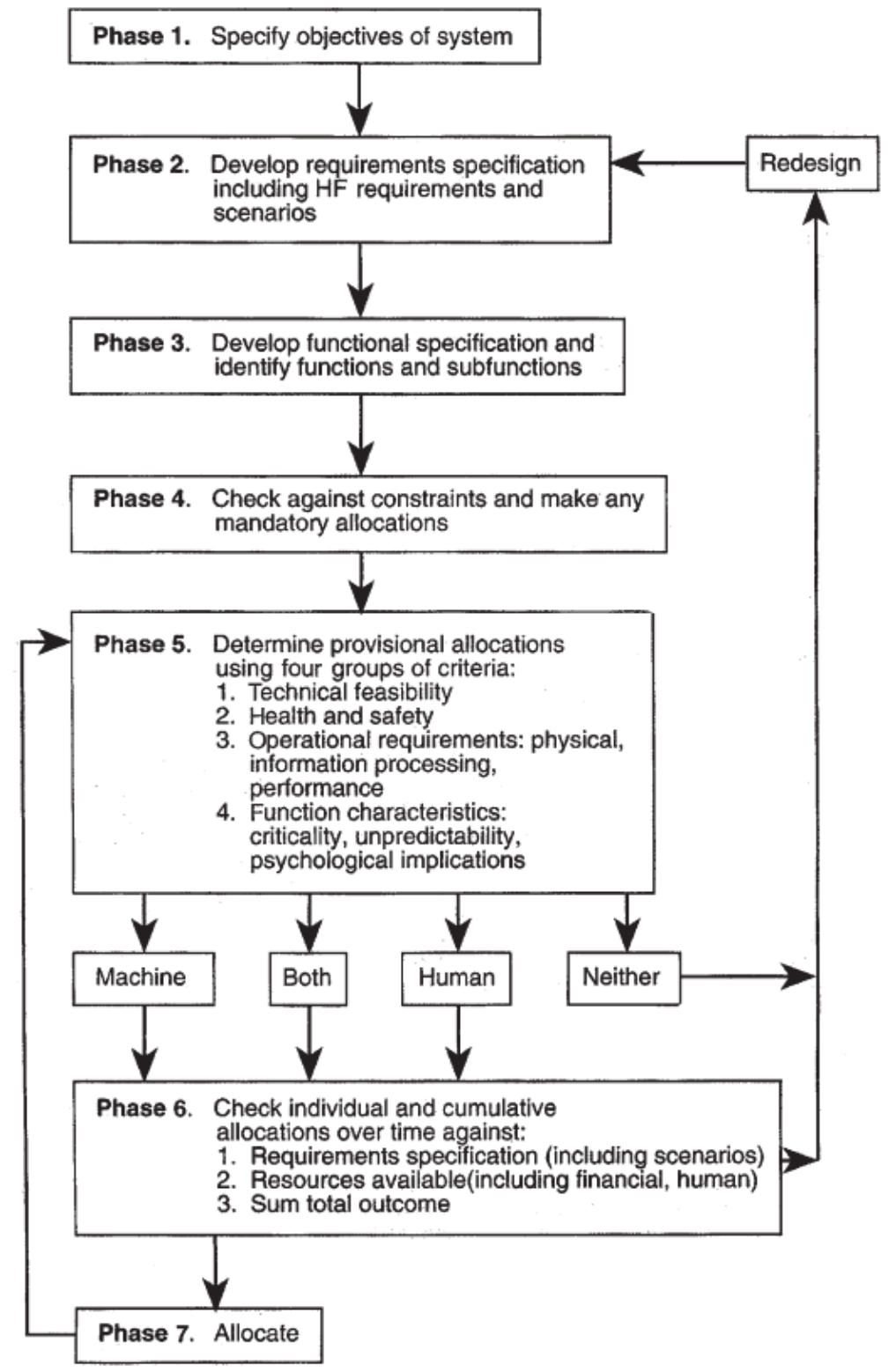

Figure 4: Broad-based methodology for allocation of functions (Nemeth, 2004)

The majority of the allocation is centered between phases 4 and 7 as outlined in Steps 1-5 (Nemeth, 2004):

- Step 1: Check against constraints and make any mandatory allocation.

- Step 2: Determine provisional allocations using four groups of criteria:

- Technical feasibility

- Health and safety

- Operational requirements: physical, information processing, performance

- Functional characteristics: criticality, unpredictability, psychological implications.

- Step 3: Based on information in Step 2, allocated to Human, Machine or Both.

- If neither human or machine are appropriate, reassess the intended "human machine' product. 
- Step 4: Check individual and cumulative allocations over time against:

- Requirements specifications (including scenarios)

- Resources available (financial, human)

- Sum total outcome.

- Step 5: Allocate functions.

Implementing Adaptive Function Allocation - Scallen and Hancock, 2001.

Scallen and Hancock (2001 [111]) proposed a method of adaptive FA designed to determine the efficacy of adaptive allocations via multi-task aviation simulation. The researchers evaluated pilot performance to determine the costs and benefits associated with the adaptive allocation of tasks, including tracking, system monitoring and target identification tasks. Findings of the research indicated that adaptive allocation was an effective countermeasure to predictable decreases in tracking performance associated with the initial presentation of a surface target. The research also indicated that the design was beneficial for monitoring task performance and improving accuracy of time estimates. Finally, the research demonstrated benefits for part-task conditions for the tracking, monitoring, targeting and time estimation. On a negative note, the implementation of adaptive automation may not necessarily provide a simple solution to the problems created with pilots operating in out-of-the-loop situations. The researchers stressed that current flight crews are generally trained to make full use of automation, but not trained to make partial use or revert to manual modes when they feel they must. Potential costs were identified in the form of performance variability in tracking when task partitioning was the adaptive strategy.

\section{A pragmatic approach to function allocation for new and modified systems - Mersiol, 2001}

Another approach was proposed by Mersiol (2001 [72]) as a practical methodology for the re-allocation of functions for modernization of existing designs. This methodology is very similar to the Hugo and Engela (2005) method and is also based roughly on the principles described in NUREG/CR-3331, and addresses a number of the standard criticisms of FA through the following eight steps:

- Step 1: Analysis of the operational requirements of the plant. This is dependent on the existence of design information like a Concept of Operations and FRA.

- Step 2: Analysis of functions, as derived from the operational requirements. This also relies on a welldocumented functional breakdown.

- Step 3: Identifying mandatory allocations: these would include functions that can be performed only by machines or only by humans, due to predetermined cost, regulatory, policy, physical or other technical constraints.

- Step 4: Definition of the human roles in the plant. This again would have been described as high-level expectations in the Concept of Operations.

- Step 5: Developing operating scenarios. This is where the Mersiol methodology differs significantly from the more classical approach - by selecting specific operating conditions, it is possible to identify contextual activities for human and automation agents. This approach makes it easier to identify opportunities for shared or dynamic FAs later in the process.

- Step 6: Applying the identified roles and scenarios to identified functions. This step is achieved in three stages: allocating functions between humans and systems, determining functions that must be fully automated, and determining functions that would be partially automated. Mersiol describes several criteria for these decisions, including consideration of how roles might be affected, acceptability in relation to the relative capacities, etc.).

- Step 7: Identifying candidate functions for dynamic or shared allocation. This step identifies the functions for which scenario analysis did not unambiguously identify a single agent that will be assigned to the function. Therefore, depending on the context as identified in Step 5, the allocations may be shared between systems and humans and part of this step is to resolve conflicting choices and 
to define the conditions for dynamic allocations. Mersiol states clearly that dynamic allocations are ideal, but very difficult to implement.

- Step 8: Evaluating the allocations. This step aims to synthesize the allocation decisions of the functions performed. It requires all allocations to be re-evaluated and balanced, according to a number of trade-off criteria, determined in Step 3.

\subsubsection{Strengths And Weaknesses Associated With Current Function Allocation Models:}

While it is difficult to determine which FA model is most applicable for current allocation needs, it is easy to find a wealth of criticism for what is lacking in present models. Indeed, there is a great deal of information offered as suggestions for the ideal model. Weaknesses associated with current FA models are detailed as follows:

- Too conceptual.

- Too abstract.

- Allocation of functions occurs in isolation without taking into account the "future working context."

- Failure to take into account data coming from the operational context.

- Inability to guide designers according to design specification that will become constraints for humans, limiting their behaviors.

- Inaccurate scope and use of FA.

- Establishment of a proper FA method is difficult because the problem is not appropriately posed.

- No one perfect FA method will ever be established, therefore, it is best to accept that the methods designed can merely "help and guide them as a heuristic."

- Excessive use of "Leftover allocation" (a term coined by Bailey [1982 [7]] that refers to the process of automating as many functions as the technology allows and assign remaining functions to human operators).

- Leftover allocation can result in a condition called "brittle" automation (Woods and Hollnagel, 2006 [174]), which is associated with increased unexpected automation failure or lack of support in offnominal conditions when support to human is most critical.

- The process of FA itself has been deemed by some researchers as a failure in that it is a "static and dichotomous listing of capabilities insensitive to the influence of environmental variables. These do not take into account the environmental context and constraints (Scallen and Hancock, 2001).

- Traditional FA does not address emotional and affective requirements; for example, recognizing the operator for the valuable work carried out along with the human's need to feel valuable, secure and in control.

By far the most detailed guidance and approach to FA is NUREG/CR-3331 (Pulliam et al., 1983 Error!

Reference source not found.). Updates to this method can also be found in Price (1985 [101]), and Price and Pulliam (1988 [103]). It takes a systems approach (i.e., a structured, top down approach) to design and is based on what they called the hypothetical-deductive model, which explicates in a more succinct step-wise manner how FA should proceed, and includes specific test and evaluation criteria to judge the appropriateness of the allocation decisions. The steps are:

1. Prepare for design, which consists of three preliminary activities:

a. Organize the design team(s) - assemble a multi-disciplinary team (e.g., design engineers and human factors engineers), and establish the rules of engagement (e.g., role and responsibilities, defining decision making and adjudication processes)

b. Identify and clarify requirements and system constraints - including defining the mission statement clearly. Price and Pulliam (1988) also write, "Clearly state the intended role of man, including level of intended technology, acceptable human life-cycle costs, responsibility for policy and operational decisions, responsibility for failure, and acceptable level of risk." (p. 645).

c. Create a robust and easily accessible database - to serve as a repository for important design documentation and a record of design and allocation decisions. 
2. Preliminarily identify and define functions in terms of its inputs, outputs, and related/dependent functions. In addition,

a. Define functions as either necessary (i.e., required) or accessory (i.e., functions that are not required but their inclusion enhances system performance relative to the cost of their inclusion).

b. Identify required and accessory display and control functions, and characterize them in terms of how well they provide cognitive support to the operator. This is an iterative step and designers need to revisit this step as a result of the "discovery" process that occurs in the next step. Tasks include updating the preliminary identifications and definitions of functions, and partitioning the functions into sub-functions.

3. Hypothesize design solutions as an interdisciplinary design team by:

a. Proposing an engineering hypothesis (i.e., an assertion about how a function can be executed by hardware and software). That is, hypothesize an engineering solution to verify that machines or automation can perform the function, as defined in the previous step.

b. Make an allocation hypothesis, which defines how functions and sub-functions will be allocated to agents. That is, based on the engineering hypothesis, determine how to allocate functional responsibilities to humans and automation/machines, paying particular attention to control functions.

c. Hypothesize a human factors solution, which defines the requirements for the human and what resources must be available to support the operator. That is, evaluate the proposed allocation produced in the previous step against various human factors criteria, such as whether the human is capable of performing the tasks required to execute the function, and whether the tasks are designed to take advantage of human cognitive strengths.

4. Test and then evaluate the preliminary allocation solution. For the first part of this step (i.e., Test), Price and Pulliam (1988) suggest using analytical and empirical tests (depending on whether the system is built or not) to check for the following issues:

a. Internal consistency of the engineering, allocation, and human factors solutions for each function.

b. Function-to-function consistency of engineering, allocation, and human factors designs throughout the whole system.

For the second part of this step (i.e., Evaluate), they suggest using the following evaluation criteria, which are hierarchical in nature:

a. Mandatory allocation: Functions that must be allocated to automation or humans because of regulatory requirements, system constraints, and/or human limits are, in fact, allocated correctly.

b. Balance-of-value allocation of functions: In the absence of a mandatory requirement, the allocation of functions should be evaluated based on the relative strengths and weaknesses of humans and automation. The following decision matrix was developed by Pulliam et al. (1983 Error! Reference source not found.) as a tool to help facilitate the FA decision-making process (see Figure 5). 


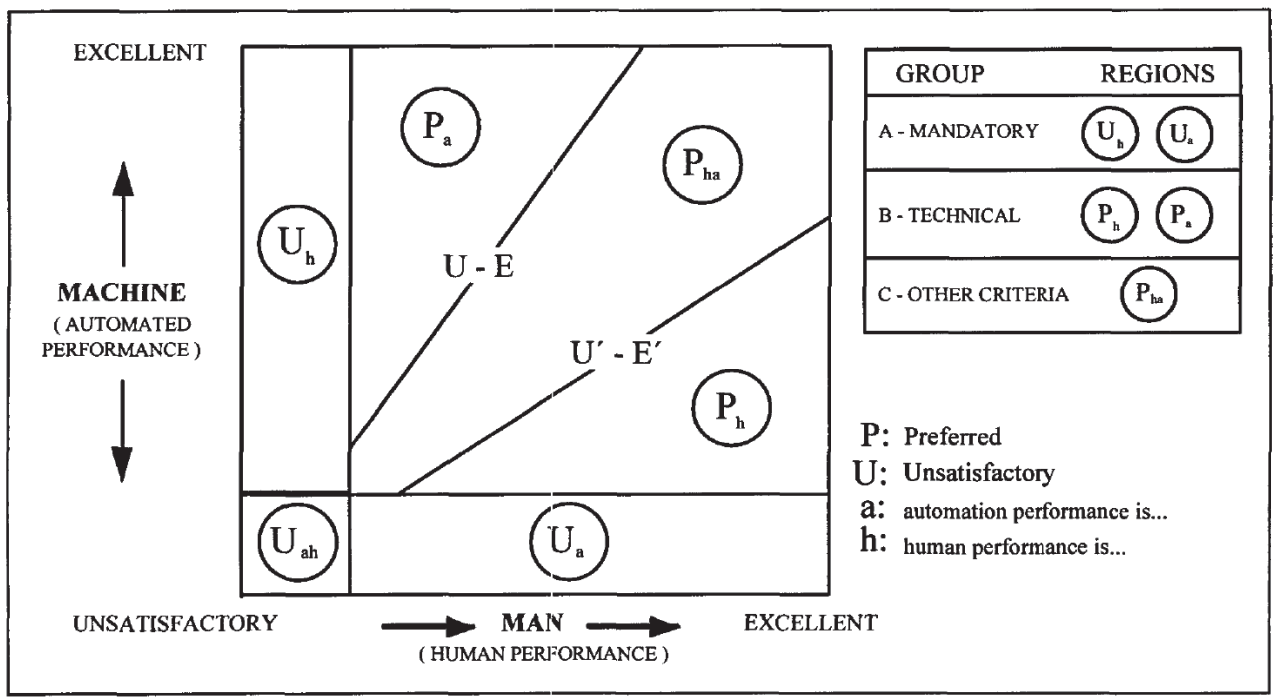

Figure 5: Allocation Decision Matrix (Pulliam, 1983)

As stated in NUREG/CR-3331, the matrix includes two regions shown as shaded, $\left(\mathrm{U}_{\mathrm{a}}\right)$ (unacceptable: automation), and $\left(\mathrm{U}_{\mathrm{h}}\right)$ (unacceptable: human). Functions falling in region $\left(\mathrm{U}_{\mathrm{a}}\right)$ are too low on the "machine performance" scale to be considered for automation; they can presumably be allocated to human by default. Conversely, in region $\left(\mathrm{U}_{\mathrm{h}}\right)$, any allocation will presumably be to machine. However, at the intersection of $\left(U_{a}\right)$ and $\left(U_{h}\right)$ is the region $\left(U_{a h}\right)$, where both humans and machines perform unacceptably. Any function that falls in this region should be considered for redesign or included in a system only as a final resort.

The regions not shaded in the matrix represent functions that might be acceptably performed by either human or machine, with varying degrees of advantage. In the region $\left(\mathrm{P}_{\mathrm{h}}\right)$ (preferred: human), the human is expected to be substantially superior as a control component. Functions in this region will be allocated to humans in the absence of other overriding considerations. Conversely, in the region $\left(\mathrm{P}_{\mathrm{a}}\right)$ (preferred: automation), allocation will ordinarily be to machine.

Finally, there is the region $\left(\mathrm{P}_{\mathrm{ha}}\right)$, bounded by regions $\left(\mathrm{P}_{\mathrm{a}}\right),\left(\mathrm{P}_{\mathrm{h}}\right),\left(\mathrm{U}_{\mathrm{a}}\right)$, and $\left(\mathrm{U}_{\mathrm{h}}\right)$, and by the lines of constant proportional difference U-E and U'-E'. At all points in this region the difference between the expected performance of human and machine is not great. This is a region of less certain choice so far as the relative control performance of human and machine is concerned. In this region the allocation decision can be based on considerations other than the engineering performance of human and machine as control components. The considerations include costs, worker preferences, and the availability of proven design experience.

c. Utilitarian and cost-based allocation. These criteria can be used when the mandatory and balanceof-value allocations do not clearly dictate a decision on how to allocate a function. Price and Pulliam (1988) defined Utilitarian as cases where "a function may be allocated to humans simply because they are present, and there is no compelling reason why they should not perform the work." (p. 648). The cost-based criterion simply dictates to allocate the function to whichever agent can execute it in the most cost-efficient manner.

d. Allocation of functions for affective or cognitive support. This criterion are related to human factors considerations, and dictate that if the allocation of functions (1) does not support human needs (e.g., Maslow, 1943 [68]) within the context of the workplace, or (2) is not designed with 
key "human-centered" design principles that facilitate human cognition and performance, then the design of function should be reevaluated.

5. Iterate the design cycle to correct errors, optimize the design, and complete the design to an acceptable level of detail.

\subsubsection{Criticisms of Function Allocation Methods}

Despite the generation of new FA methods (described above, but for an additional review, see Sharit, 1997 [114]), and other general improvements to the FA process, the usefulness and value of FA has been criticized. Criticisms include specific methodological issues with using Fitts' List, general criticisms of FA as a method (Sheridan, 2002 [117]; Fallon, 2006 [25]), and philosophical issues of FA as a practice (Fuld, 1993 [29] and 2000 [30]). Both Sheridan (2002) and Fallon (2006) have argued that FA has not been useful to the design process by pointing out issues such as:

1. There is little consensus on how to define the term "function" in a manner that differentiates it from task.

2. Some allocation methods are static and do not take into account of the changing nature of operating scenarios or conditions (e.g., increases in human workload during unexpected conditions).

3. The emphasis in some allocation methods has tended to be on single operator-machine systems, or groups of operators and machines treated as several single operator-machine systems.

4. Some early allocation methods did not explicitly address a number of important criteria (e.g., cost, reliability, job design, and organizational considerations).

5. Even when methods address or provide evaluation criteria, the criteria are often difficult to quantify without some implicit or subjective bias.

6. Many methods assume functions are independent when there are, in fact, subtle dependencies between them, which can lead to discrepancies between how the FA method models the system and how the system actually works.

7. Once an allocation method is published, it is difficult for it to adjust its method and criteria to accommodate the evolving capabilities of machines (e.g., improved pattern recognition and advances in artificial intelligence) and humans.

8. The guidance many newer FA methods provides is often at too high a level to be useful in addressing more nuanced and complex FA decisions.

9. Experience with addressing the FA issue in practice reveals that at the very least, allocation of functions is an iterative process. Some people now believe that the nature of work to be carried out in human-automation systems can only be determined through actual operation.

10. The requirement for a formalized proscriptive approach to allocation of functions has not, generally speaking, been justified by the results of the allocation process.

Other researchers, in particular Fuld $(1993,2000)$ have echoed these sentiments. For example, with respect to many existing FA methods, Fuld (1993) argues that, "Although allocation can serve as a useful descriptive framework for some problems, its systematic application to design has far greater cost than practical benefit" (p. 22), which is similar to item 10 on the list above, but he went on further to suggest that FA has merely become the means by which human factors engineers get their 'foot in the door' to participate as early as possible in the design cycle process.

Hancock and Scallen (1996 [33]) acknowledge and agreed with many of Fuld's (1993) criticisms. Their assessment was that, "The fundamental problem is time. At all points in the design process, the allocation problem is chronically under-specified. That is, there is never sufficient knowledge of the situation so that all tasks can be described in Fitts-like terms and apportioned respectively. It is thus the indeterminacy of the real world that defeats the determinacy intrinsic to the static allocation strategy." (p. 27). However, instead of suggesting that FA be abandoned, they propose a dynamic allocation approach to address the issue of under-specification. This proposal is discussed later in more detail in Section 3.5. 
Similarly, Sheridan $(2000,2002)$ has taken a more nuanced position on FA. As a human factors engineer, Sheridan has been a proponent of FA (as evidenced by his work to improve FA by showing how human cognition and level of automation interact). But he has also been a critic in that he has recognized that FA is still, "Essentially an artful design synthesis with a modicum of science." (p. 215). However, de Winter and Dodou (2011 [22]) counter Sheridan's point that FA only has a modicum of science by showing how Fitts' List meets the definition of scientific theory in the sense that the assumptions in the Fitts' List model are plausible, the model itself is interpretable, and that the theoretical explanations it asserts are reasonable, descriptive, straightforward, and generalizable.

Jordan (1963 [58]) also somewhat obliquely countered the critics of FA by arguing that the fundamental issue is the different ways the problem is being framed. That is, it is the initial assumptions the critics are making about the FA process that are leading them to draw the critical conclusions that they have, but he argues that if they framed the FA problem differently, they would draw different conclusions. Both Jordan (1963), as well as de Winter and Dodou (2001), Reason (1987 [107]), and Fitts (1962 [28]), assert the key assumption differentiating critics from proponents of FA is whether humans are described in mechanical terms or not. Jordan stated, "Anytime we can reduce a human function to a mathematical formula we can generally build a machine that can do it more efficiently than a man. In other words, to the extent that the human becomes comparable to a machine we do not really need him any more since he can be replaced by a machine." (p. 162). Instead, Jordan asserted that if the FA process is to take maximum advantage of the capabilities humans have to offer, then it needs to view humans in a more humanistic (as opposed to mechanistic) manner. As a corollary to this recommendation, he also suggested that the FA process should be viewed a complimentary process, whereby the strengths that both humans and automation have are identified and combined to produce emergent capabilities, rather than a comparative process, which tends to produce "either/or" thinking.

It is worth noting that others, namely Kim (2011 [60]), have expanded upon Jordan's thinking, and in many respects is addressing many of the criticisms of FA. Kim (2011) described four perspectives that characterize FA research in fields such as engineering, human factors, and cognitive systems engineering, and that these different perspectives lead to different issues with FA. These perspectives are technologycentered, human-centered, team-oriented, and work-oriented. According to Kim, each of these perspectives focuses on different aspects of FA, for example, the capabilities and characteristics of human and automation agents, team structures and processes, work structure, and the work environment.

Kim (2011) highlights the differences between the four perspectives as follows:

Technology-centered perspective: this approach allocates functions based upon the capabilities of the automation system, which relies to a great extent on an interpretation of Fitts' List. This approach assumes that humans are unreliable and inefficient and that automation can take over human functions without sacrificing system performance. However, as pointed out by Wickens (2010 [170]) and Haight (2011 [31]), there are very clear indications that high levels of automation can improve overall system performance and reduce human workload for routine operations, but that system failure under high levels of automation has significant impacts on overall system performance, due to the potential loss of situation awareness.

The human-centered perspective requires that the automation system be designed as a tool for the operator and should therefore support human abilities and limitations for a given task. Research has shown that automation works well in routine operations where operator workload is well regulated (Billings, 1997, Parasuraman and Riley, 1997, Wiener and Curry, 1980). However, in off-nominal conditions, which typically increase human workload, automation tends to add operator tasks, which increases workload. Environmental conditions can also push the automation out of its boundary conditions, thus requiring the operator to take over functions and further increasing workload. This means that allocating functions to humans on the assumption that they will perform well because the system has 
been designed "to fit human needs" is no guarantee that workload will be reduced under all conditions and therefore that overall system performance will be optimized.

The team-oriented perspective considers the automation system as a member of the operating crew and thus views interaction between humans and automation as similar to interaction among operators in the crew. Some researchers use this approach to describe the integrated human-system team as a "joint cognitive system" (Woods and Hollnagel, 2006 [174]) where humans and automation work together cooperatively, with each agent contributing its unique strengths within the specific task context. However, the teamwork metaphor is only appropriate in conditions where there is a clear distinction between accountability and responsibility for humans and automation. The automation system obviously cannot be expected to have "teamwork skills" like humans. It does not have a "sense of responsibility", it does not have a sense of consequences like humans, and it does not adapt to unpredictable outcomes as well as humans. This means that the automation system cannot function well outside its boundary conditions as well as a human team member who is likely to attempt effective mitigating actions in unfamiliar conditions. Another factor that makes this perspective difficult to realize with the current state of technology is the assumption that humans and automation can share responsibility for functions. The underlying premise is that the system should be aware of what human team members are doing, and conversely, that the system should provide information to let the humans know what it is doing. In the human crew the exchange of information is easy and natural and facilitates decision-making under any operating condition. Interruptions between crew members are often seen as part of the normal three-way communication process in the control room. As Kim (2011) points out, "a good team member knows when interruption is warranted, versus when it will be detrimental. Unfortunately, too often automation unduly interrupts other human team members." Although the automation system can act on its own under conditions that allow autonomous operation, it typically "provides poor feedback and interrupts team members without consideration of context or the status of the humans" (Sarter and Woods, 1995 [110], cited in Kim, 2011 [60]). The automation system requires displays and interfaces to facilitate interaction with team members and this can create significant additional workload for the operator.

The work-oriented perspective focuses on the functions, as purposeful activities, that need to be performed to accomplish the plant mission. To accomplish mission goals, the whole sociotechnical system and associated human/automation behavior must support the inherent dynamics of the work. Since this perspective deals with the sociotechnical system in all its facets (human, organization, environment, physical artifacts, procedures, and so on), the Cognitive Work Analysis (CWA) methodology (Rasmussen, Pejtersen, and Goodstein, 1994 [105]) is fundamental to an understanding of work and the entities needed to support it. Within the CWA methodology, five consecutive phases are used to model, analyze and define the work domain and its architectures, the tasks, work execution strategies, social organization and staffing, and worker competencies. Of these five phases, WDA is particularly useful in analyzing the structure of new and unfamiliar work domains. This phase typically identifies the information and functions required to achieve work and represents it in a multi-level means-ends representation of the work environment, called an abstraction-decomposition framework. Kim (2011) concludes that the work-oriented perspective is the most comprehensive and rational approach to identify hidden, complex relationships between goals, functions, information required, work environment, and agents. In particular, the CWA phases of analyses provide useful tools to model human-automation FA and the abstraction-decomposition framework can be used to identify and model what functions are needed in a work domain.

In spite of the key differences described above, all four perspectives agree on a number of problems with traditional FA practices (ibid.):

- Changes in the nature of workload, workload spikes, concurrent tasks, or channel saturation, can result from additional tasks induced by FA choices.

- Inconsistent and incoherent FAs due to poorly defined roles and work practices for team members could lead to conflicting activities between agents. 
- Mismatches between assignment of responsibility and authority make operators responsible for the outcome of automation functions and thus require monitoring functions to supervise functions that had been delegated.

- Automation functions may unnecessarily interrupt humans or procedures that are in progress.

- FAs can be contextually inappropriate where they force the automation system outside the boundary conditions within which it can effectively and reliably operate.

- FAs could prevent the human from adapting to changing contexts because of implicit assumptions about human behavior as a fixed pattern. Such assumptions may be invalid, because human team members adapt to context by selecting strategies or as part of cognitive control.

- FAs can destabilize the humans' work environment: predictability in the work environment allows humans to anticipate upcoming tasks, but automation can add unpredicted behaviors to the work environment.

- Ultimately, as emphasized in the description of the work-oriented perspective, FAs should support mission performance.

Based on the eight issues described above, Kim has established eight types of metrics to assess the extent to which each issue exists with a given FA. The metrics would be used to assess workload, coherency of a FA, mismatches between responsibility and authority, interruptive automation, automation boundary conditions, human adaptation to context, stability of the human's work environment, and mission performance (ibid.).

Implementation of the proposed metrics would require a framework such as provided by CWA. This would allow analysts and designers to examine and define all aspects of FA, as well as many aspects of the broader sociotechnical system, for example, the work environment, the dynamics inherent to the work, agents, and relationships among them. Further, such a framework would also enable static modeling as well as dynamic simulation of temporal elements of work, such as operator response times and alternative strategies during upset conditions.

\subsection{General Principles For The Development Of A Dynamic Function Allocation Model}

\subsubsection{Function Allocation Issues With Digital Control Systems}

The design of new control rooms and the conversion from analog automation technology to digital systems pose significant challenges to the operator workload and design of HSI. Reduction of both physical controls and analog instrumentation and emergence of digital displays greatly changes the visual landscape and the manner by which work is carried out. Rather than a large amount of information displayed around the MCR, information is provided to the operator via a small number of computer screens with abstract process mapping rather than spatial mapping to the physical plant. Increasing capabilities afforded by automation comes at the price of an increase of complexity (Sheridan, 2000 [116]). There are a number of issues identified as a result of this degree of complexity including the Keyhole Effect, Misplaced Salience, Complexity Creep, and the Information Gap.

The "Keyhole Effect" refers to the increased complexity of navigation within the HSI, which occurs as the hierarchical information space is mapped onto a limited display space. The number of physical controls including switches and knobs has been greatly reduced, a number of them have been converted to digital displays, and this amount of display space is minimal. Operators are thus tasked with the challenge of scanning hundreds of different displays on a mere few screens (Hugo and Engela, 2009 [43]). As Endsley, Bolte, and Jones (2003 [24]) assert, "The capacity of technology in many systems to present data far surpasses the ability of the human to process it." The great number of computer windows and screens of information accessed through menus or buttons can contribute to problems with feedback, with the operator missing key information on a window obscured by another in use. "The problem with the current systems is not a lack of information, but rather the ability to find what is needed when it is needed 
(Endsley, 2000)." Increased display complexity and computerized display format contributes to issues with salience or prominence of key information, reducing the perceptual salience of information even if it is available (Endsley, Bolte, and Jones, 2003). The Keyhole Effect has also been shown to break down traditional three-way communication and shared workspace. Great effort must be made to ensure the digital replacement systems afford opportunity for both individual and collaborative work (Boring and Agarwal, 2012 [13]).

Salience is a perceptual attribute of display design used to highlight critical information. With proper use and carefully placed cues, salience can alert the operator and increase the degree of focus (Bolstad, Costello, and Endsley, 2006). As display complexity increases and computerized display formats change, it creates issues with salience or prominence of key information, reducing the perceptual salience of information even if it is available (Endsley, Bolte, and Jones, 2003). Designers must use salience "appropriately and sparingly" (Bolstad, Costello, and Endsley, 2006 [11]). This could be translated to mean, "if everything is important, then nothing is important."

Complexity creep refers to the condition by which system users are affected by new system designs, which ultimately prevent them from forming adequate internal representations of how systems function. These inadequate and inaccurate mental models lead to misinterpretation of information and interference with task completion (Bolstad, Costello, and Endsley, 2006). It is critical that designers work to reduce complexity creep.

The enhancement of operator situation awareness is a challenge for designers of operator interfaces, automation concepts and training programs. Endsley (2003) coined the term Information Gap to describe the challenges faced by users of the increased complexity associated with the information age. More data does not mean more information, as Endsley illustrates in Figure 6:

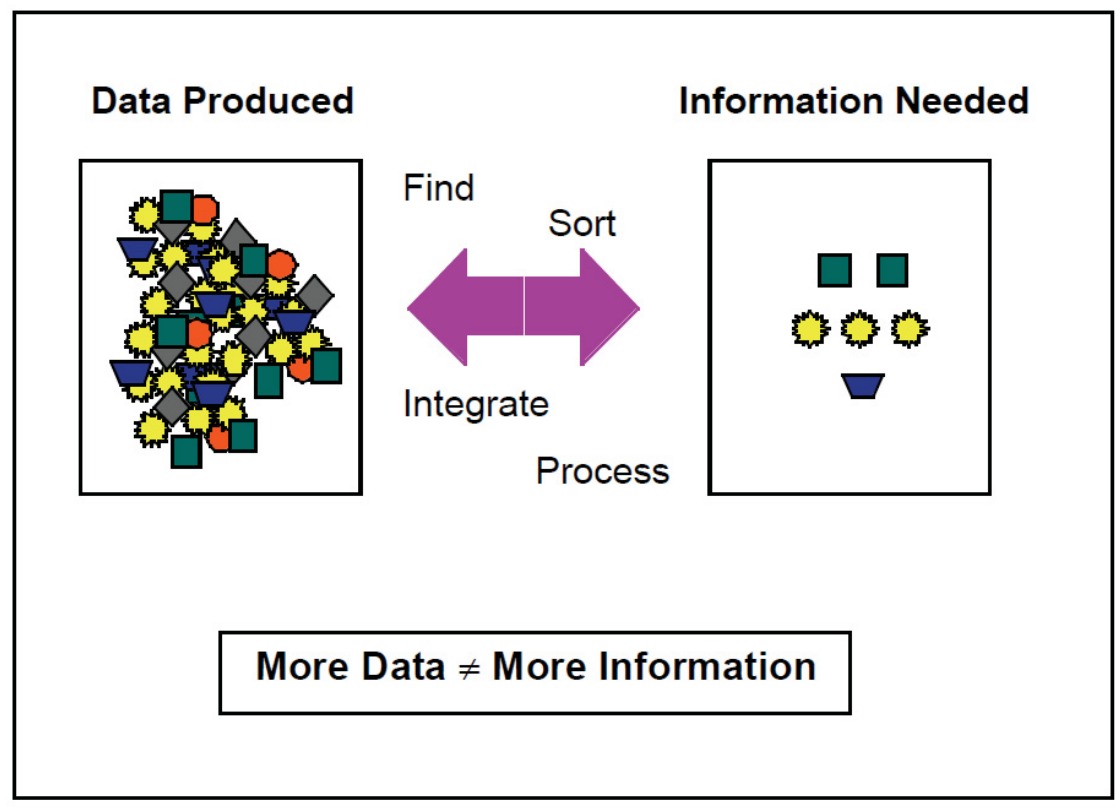

Figure 6: The Information Gap

(Endsley, 2003)

To address the struggle with integration of new technology into the existing technology in the modernization of the MCR, designers must create new solutions. As there is no set method for how to achieve this, designers must carefully navigate between management of the analog and digital systems with a focus on operator and system performance. Boring and Agarwal (2012) proposed ten principles for 
achieving a resilient control room. Among the strategies proposed were those geared at indicators in the MCR that reveal current operations or trend past operations. One of the principles of situation awareness (SA) is the ability to plan or anticipate. To increase operator SA, HSIs must be designed to direct operators to what has occurred as well as predict future operations

Additionally, Endsley proposes that one way of designing products capable of addressing effective and efficient interaction is to focus the design process around maintaining and improving the end users' situation awareness, or an SA-Oriented Design approach. Fifty design principles are grouped into 6 main categories, including:

- General

- Confidence and Uncertainty

- Dealing with Complexity

- Alarms, Diagnosis and SA

- Automation and SA

- Supporting SA in Multi-Person Operation.

\subsubsection{Role of Function Allocation in the NRC review process}

As part of the license review process by the NRC, an HFE plan in accordance with NUREG-0711 must be submitted. Overall, the intent of the plan is to ensure that HFE is implemented in the design, development and evaluation of the plant. In executing -0711, the licensee must address the requirements from Chapter 4, "Functional requirements analysis and function allocation." The goal of the FRA is to identify functions that are needed to satisfy public safety goals, prevent accidents to workers or the public, and to generate power. In the case of aSMRs, the goal of generating power may be enlarged to include delivering process heat. Plant goals are supported by high-level functions that are defined in terms of parameters and linked to structures, systems, subsystems, and components down to the plant configurations responsible for sustaining functions and operability during normal, abnormal, or emergency conditions. From the breakdown into high-level functions, the designer is able to specify actions and assign them to either personnel or automation. As part of this process, the designer must take into consideration capabilities, strengths, and limitations of both the automation and personnel. As NUREG-0711 states, "during the FA process the aggregate of all human actions (and the project team would add "decisions") is defined. In their review, the NRC staff is to verify that the design, including operations, "takes advantage of human strengths and avoids human limitations." This is meant to cover cognitive as well as physical limitations. The physical limitations for vision and audition and ergonomics including taking simple actions are well understood. The cognitive limitations of working memory and impacts of complexity, information requirements, coordination among team members, and mental workload on response time and accuracy for crews under dynamic conditions are less easily calculated and hence the ability of personnel to carry out their tasking may have to be validated in the simulator.

Since aSMRs are planned to have relatively high levels of automation described in the submittal to NRC, licensees or prospective licensees are required to indicate whether a function is to be one of the following:

- Under manual control,

- Shared operation,

- Operation by consent,

- Operation by exception, or

- Fully automatic.

\subsubsection{Dynamic Allocation Principles}

Dynamic FA refers to the variable distribution of functions in real time between the system and one or more operators to achieve optimal system performance. "Unlike traditional approaches to FA where the goal is to identify those tasks best performed by the operator or the machine, the objective under the 
dynamic approach is to identify those tasks that can best be performed by either the operator or the system and allocate them according to a triggering strategy. This form of system operation is qualitatively different from others in which the user is responsible for enabling or disabling system functions. Thus, the ultimate authority over the human-system operation is shared. Further, the overall quality of performance is determined by the actions of both the operator and the system." (Scerbo, 2006 [112]).

As pointed out by Mersiol (2001, p.87 [72]) and Scerbo (2006), dynamic FA principles are theoretically sound, but difficult to implement and validate, due to the added complexities this capability brings to the FA decision making process. To date there have been many theories and recommendations, as described in this report, but very few practical implementations. This makes dynamic FA a tantalizing topic for research for aSMR concepts of operation.

\subsection{Proposed New Foundational Function Allocation Model And Process To Support The Design And Licensing Of aSMRs}

As stated in Section 3.1, the research team is developing a preliminary model and process for allocating plant functions that aSMR designers can use to determine how functions could be allocated to agents within their specific aSMR design. This is because current FA methods still have some technical gaps, particularly with respect to FA working effectively in an aSMR context. To this end, this research is proposing a new foundational FA model and process to support the design and licensing of aSMRs. This report documents the preliminary steps the research team and performed to date to develop this model.

The following statements summarize the current state-of-practice for FA methods:

1. FA should not be viewed as an "either/or" proposition. In order to capitalize on the strengths that both humans and automation can offer in executing a function, the FA process needs to view how their strengths can be combined to produce emergent capabilities (Jordan, 1963).

2. FA is an iterative process that starts in the design phase of aSMRs and is re-examined and validated in later phases (e.g., start-up). It cannot be performed only once during the design phase and then never validated in later phases, nor can designers wait until start-up to consider how functions should be allocated.

3. It is relatively easy to identify what functions cannot be done by humans and therefore need to be automated, and vice versa.

4. It is relatively difficult to determine how to allocate functions when both humans and automation are capable of performing the function well.

5. It is challenging for a FA decision to address dynamic changes in the system that affect the ability of agents to execute their assigned functions.

Given this assessment, the obvious opportunities to improve current FA models and processes are (1) to bolster the technical basis for determining how to allocate functions when both humans and automation are capable of performing the function well and (2) to improve FA's ability to address dynamic changes in the system that affect the ability of agents to execute their assigned functions. Both of these research opportunities are discussed in detail below.

\section{Opportunity 1: Bolster the technical basis for determining how to allocate functions when both humans and automation are capable of performing the function well.}

Cases where both humans and automation are capable of performing the function well correspond to the situation that NUREG/CR-3331 describes as instances where the difference between the expected performance of human and automation is negligible. The ways in which the technical basis for these kinds of FA decisions could be improved includes:

- Improving the technical basis of the evaluation criteria by adapting quantitative methods to the evaluation process and criteria. Two promising approaches are the modification of Papantonopolous and Salvendy's (2008 [98]) cognitive task allocation decision model for cognitive task allocation, and 
the use of Pareto Frontier Charts (Sheridan, 2005 [115]). These approaches will be studied more closely and evaluated for the feasibility and practicality as this project continues.

- Improving the technical basis of the evaluation criteria by clarifying how to properly use the primary metric for deciding how to allocate functions. Best practices from design and human factors engineers who have used existing methods, such as NUREG/CR-3331, should be captured and applied. One effort in particular by GE to obtain NRC approval of the Economic Simplified Boiling Water Reactor (ESBWR) design provides numerous valuable insights (NEDO-33220, Rev. 0, and Rev. 4 Error!

Reference source not found.). Other efforts by human factors engineers in support of a first-of-akind reactor design to use existing FA methods will also provide numerous important insights (Hugo, 2006).

- Improving the technical basis of the evaluation criteria by making the primary metric for deciding how to allocate functions multi-dimensional. The work by Kim (2011) to identify 8 metrics to evaluate FA decisions needs to be evaluated and research on whether and how these can be included into the new foundational FA need to be performed. Similarly, work by Woods and Hollnagel (2006) on joint cognitive systems needs to be evaluated for applicability such that best practices from that work can be applied.

- Improving the technical basis of the evaluation criteria by enhancing the meaning of the primary metric for deciding how to allocate functions. Current methods still fundamentally assess which agent or agents should perform the function based on who is better at executing it. This key evaluation metric needs to change, and go beyond identifying what agent is better suited to execute a given function, and identify the relative roles of the agents. Research performed by Hugo (2005, 2006, 2009) on Task Support Systems can provide, albeit indirectly, some important insights into how this could be done.

\section{Opportunity 2: Improve function allocation's ability to address dynamic changes in the system that} affect the ability of agents to execute their assigned functions.

The allocation between the human and the automation will never be ideal, given dynamic changes in the system that affect the ability of agents to execute their assigned functions. Therefore, the operator must be afforded the tools to handle all possible system conditions including indeterminate states such as valves stuck between open and closed. Until the HSI is designed from a task-centric point of view, the level of complexity in the MCR will be a significant obstacle (Hugo, 2009).

A new approach to HSI design is critical to address the increased complexity of new designs. It is the HSI designer's role to design while avoiding complexity, reducing the amount of information the operator needs to access at any time, while at the same time ensuring accurate assessment of current plant status and rapid access to detail information. Designs with these necessary features will satisfy the key objective of advanced control room HSI design to support the operator's primary task of monitoring and controlling the plant, without imposing an excessive workload association with using the HSI (O'Hara et al., 2004, p.A-1 Error! Reference source not found.). This approach will also provide clear traceability from the FA for the design decisions.

Little research has been devoted to advanced operator support systems, and in the nuclear power field, this is especially lacking. Formal guidance for NPP HSIs is limited to information in Appendix A of NUREG-0700 Rev.1 and Section 9 of Rev. 2. Previous developments heralded as "computerized operator support systems" have been identified rather as primarily computer-based procedure (CBP) systems. One such system concept that takes this concept further is the Task Support System (TSS).

The TSS is a state-of-the-art system that provides an interactive, dynamic, adaptable environment aimed at improving human performance and reliability.

The TSS will be a vital addition to advanced HSIs in that it addresses the high level of abstract system processes as well as the complexity and volume of information characterizing the manner way in which the operational control system is presented to the operator. The components and core functionality of 
TSSs ensure peak operator performance, safety, as well as optimal system effectiveness in increasingly complex process control environments (Hugo, 2009).

The main objective of integrating the TSS into the HSI is to address many critical MCR performance problems with the five following features:

- Aims to improve operator performance and reliability, actively engaging operators in finding and selecting solutions to operational requirements and enabling them to meet normal and abnormal needs safely, reliably, promptly and efficiently.

- Effective at addressing non-routine tasks, particularly those anticipated in Beyond Design Basis Events, a designation during which the operator faces a high degree of pressure to make rapid, accurate decisions in order to ensure equipment protection as well as human and environmental safety.

- Supports collection, synthesis, and creation of task-oriented information.

- Enables operators to accomplish a greater amount of work with greater accuracy.

- Optimizes the functionality of the automated system with increased rational allocation of tasks.

The main function of the TSS is to achieve the objectives detailed above. It is imperative that the TSS provide as many functions from the list below as follows:

- Ensure that the operator is in command, even during automated functions.

- Ensure that the operator maintains optimum situation awareness and is fully informed of plant state and trends at all times, including the state of automated processes.

- Enable the operator to monitor processes at various levels of detail.

- Assist the operator in executing procedures for effective process control.

- Assist the operator in diagnosing faults and other occurrences.

- Assist the operator in performing preventive and corrective maintenance tasks.

- Assist the operator in recovering from both planned and unplanned events.

- Provide facilities to monitor the operator - the operator and the automation system should have knowledge of each other's intentions.

- Ensure that information presented is always provided in a situational context.

Related to TSS are three studies. Vicente et al. (1996 [169]) found that operators at an existing LWR NPP performed better using a new display that was designed using TSS principles. They performed better on their detection and diagnosis tasks than when they used their traditional displays based on the singlesensor-single-indicator design philosophy. Lin, Yang, Lenn, and Cheng (2009 [65]) investigated how to allocate HSI functions with respect to levels of automation and developed TSS-like guidance based on their investigation that other human factors engineers can use to improve the operational performance of their MCR designs. Mumaw, Roth, Vicente, and Burns (2000 [74]) performed a number of field study observations of NPP control room operators with the purpose of analyzing how they monitor the plant's state during normal operations. They found that "Monitoring during normal operations was a complex, cognitively demanding task that was better characterized as active problem solving than as passive vigilance." While these studies were conducted at an existing LWR NPP, the conditions for aSMR operators will probably be similar, and even exacerbated by the increased use of automation and the "keyhole effect" of digital systems and their HSIs. As such, it is very critical that the HSIs for the advanced digital I\&C that will be used in aSMRs are designed with TSS principles in mind. 


\section{Regulatory Aspects of aSMR Concept of Operations \\ 4.1 Purpose}

Current NRC regulations were developed based on traditional large NPP LWR designs. However, aSMR designs differ substantially from traditional designs in a number of aspects, including size and number of reactors, inherent passive safety systems, fuel type, and coolant type, among others. These differences present unique issues in terms of licensing and regulation.

This section will overview the aSMR regulatory issues related to Human Factors, discuss the current licensing process and current regulatory guidance, identify the gaps between current regulations and what is needed for aSMR designs, and present guidance for working within the current regulatory framework.

\subsection{Overview of Concept of Operations-Related Issues}

\subsubsection{Staffing}

The U.S. NRC staff has been engaging in public pre-application activities with the U.S. DOE and with individual SMR designers to discuss potential policy, licensing, and key technical issues for SMR designs. In SECY-10-0034, "Potential Policy, Licensing, and Key Technical Issues for Small Modular Nuclear Reactor Designs," dated March 28, 2010, one of the key issues identified is the application of current on-site operator staffing requirements to small or multi-module facilities. Staffing is one of the most important parameters that play a role in developing a concept of operations.

In response to SECY-10-0034 and its associated staff requirements memorandum, the NRC staff established an issue identification and ranking program (IIRP) in January 2011. The IIRP was tasked with looking further into SMR design characteristics and modes of operation to identify potential control room staffing issues that may not have been recognized previously. The IIRP compiled its results and recommendations in a report titled, "Control Room Staffing Final Report," issued in May 2011 (Smith, 2011). In addition to identifying specific technical issues, a primary concern identified by the IIRP is how the NRC will address SMR operator staffing reviews in the future without making every SMR a special case. In place of forecasting all possible SMR designs that the agency might receive for review, the IIRP recommended that the staff enhance its guidance for staffing and revise 10 CFR 50.54(m). Unfortunately, characterizing staffing as a single issue related to numbers of individuals in the control room ignores the complexities of HFE. It is not just the numbers of individuals but also their qualifications (training, education, experience, and certifications). The HSI, level of automation, control room layout, procedure format, and number of units controlled all interact with the numbers of staff and have to be considered.

From an industry perspective, the ANS released a report, "Interim Report of the American Nuclear Society President's Special Committee on Small and Medium Sized Reactor (SMR) Generic Licensing Issues," in July 2010, to promote discussion on multiple licensing issues for SMR designs, including control room staffing issues. The ANS report discusses the potential for SMR designs to call for a much smaller number of staff per reactor than existing large reactors because the operation of an SMR is simpler, relying on more passive reactivity control, heat removal, and automated control systems. The ANS report concludes with a recommendation that the NRC update its regulatory guidance to better accommodate the changes to staffing requirements that may be appropriate for SMRs, and that current guidance and requirements are adequate to address the submittal of staffing exemptions by early applicants and their review by the NRC. Early resolution of this issue, or identification of a clear path to resolution, is essential, both so that designers can incorporate appropriate changes during the development of their concepts of operation, designs, task analyses, and staffing plans before submitting a design review or license application, and to support the staff's review of the design and license applications.

\subsubsection{Multi-Unit Operations}

The primary issue that is expected to influence HFE aspects for aSMRs is the effect of multi-module operations on human performance. This is compounded with the issue of staffing discussed above since 
the current staffing regulation would not accommodate multi-unit operations. O'Hara, Higgins, and D'Agostino (2012), reported on a study they performed for the NRC in which lessons learned from three different non-nuclear systems were reviewed. These three systems are: unmanned aircraft systems (UAS), oil refineries, and tele-intensive care units (tele-ICUs). A summary of their findings that are particularly applicable follows.

1. Monitoring and controlling multiple units can be accomplished by a single operator or crew in a single control room.

2. Enabling technologies that support operators to monitor multiple units include:

- Automation

- Advanced designs of HSIs and alarm systems

- Control rooms that foster teamwork and communication

- Procedures and HSIs that support the transition from normal to off-normal operations and to emergency management

- Information technology support for troubleshooting

3. The effect of unit differences on performance is unresolved. At the refinery, such differences were helpful in monitoring and distinguishing between units; while for tele-ICUs and UAS operators, differences complicated operations.

4. Automation is a key enabling technology but it should be interactive and flexible. Training may improve operators' understanding and use of automation.

5. Clear responsibilities need to be defined for staff. Allocating tasks to crew members is vital in terms of the performance of the overall team and integrated system.

6. Managing off-normal situations requires crew flexibility. Significant organizational changes may need to be made to manage these situations. Additional staff may be needed for the off-normal unit and for some transitions, such as unit start-up or shutdown. Having a way to transfer responsibilities for reactors in off-normal states to a person or team specialized in dealing with them may be beneficial to SMR operations. Communication between personnel is crucial for maintaining SA during off-normal situations.

7. Designing the control room and HSI for multi-unit monitoring and control is challenging. HSIs must enable monitoring of the overall status of multiple units and the easy retrieval of detailed information on an individual unit. The design of alarms particularly must ensure operators are aware of important disturbances, thus minimizing the effects of change blindness and neglect. The organization of information is another critical HSI consideration, e.g., deciding on what information crew members need to access, both individually and as a crew, to support teamwork.

8. The design for multi-unit management can be aided by detailed HFE analyses of staffing and operator tasks, via task analysis, human-performance modeling, and operator-in-the-loop simulations.

Thus monitoring and control of multi-unit facilities by a single operator or crew in a single control room is possible. However, the successful accomplishment by a single crew of multi-unit operations in the commercial nuclear industry is yet to be demonstrated. The unique operational demands of different systems need to be addressed before conclusions about multi-unit NPP operations can be developed. The special demands of one industrial application may limit making generalizations to another. For example, while multi-unit operations may be routine in the petrochemical industry, it is proving a difficult challenge for unmanned vehicle operations, which, according to O'Hara (2012) is an appropriate analogy for an aSMR multimodule control room. The authors therefore recommend conducting more research on surrogate systems to answer questions, such as the impact of unit differences on monitoring.

The information obtained from these non-nuclear systems will help the understanding of the issues and human performance challenges associated with multi-unit operations and provide a technical basis to develop guidance for the design and safety review of the HFE aspects of SMRs. 


\subsection{Current Regulatory Basis and Guidance for SMR Designs}

\subsubsection{Current Regulatory Basis}

The most direct regulatory basis for HFE for aSMRs can be found in 10CFRPart 52, Licenses, Certifications, and Approvals for Nuclear Power Plants. This part governs the issuance of early site permits, standard design certifications, combined licenses, standard design approvals, and manufacturing licenses for nuclear power facilities. Each Subpart includes some reference to the requirements in 10CFR Part 50, which addresses various aspects of HFE depending on the certification, license, or approval desired. For instance, all of the relevant Subparts reference 10CFR50.34 (f), Additional Three Mile Island (TMI) Related Requirements. These requirements include HSI, procedures, training, staffing, and the Safety Parameter Display System (SPDS). For instance, 10CFR50.34(f)(2) includes the following paragraphs:

(ii) Establish a program, to begin during construction and follow into operation, for integrating and expanding current efforts to improve plant procedures. The scope of the program shall include emergency procedures, reliability analyses, HFE, crisis management, operator training, and coordination with INPO and other industry efforts. (Applicable to construction permit applicants only) (I.C.9)

(iii) Provide, for Commission review, a control room design that reflects state-of-the-art human factor principles prior to committing to fabrication or revision of fabricated control room panels and layouts. (I.D.1)

(iv) Provide a plant safety parameter display (SPDS) console that will display to operators a minimum set of parameters defining the safety status of the plant, capable of displaying a full range of important plant parameters and data trends on demand, and capable of indicating when process limits are being approached or exceeded. (I.D.2)

(v) Provide for automatic indication of the bypassed and operable status of safety systems. (I.D.3)

The parenthetical references, I.C.9, I.D.1, I.D.2, and I.D.3. are the relevant section numbers from a series of documents conveying TMI requirements - NUREG-0660, NUREG-0737, and NUREG-0737, Supplement 1.

Some other Subparts of 10CFR Part 52 also refer to other aspects of HFE depending on stage or type of license, for instance Subpart C - Combined Licenses, includes references to training and use of operating experience:

$\S 52.78$ Contents of applications; training and qualification of nuclear power plant personnel.

(a) Applicability. The requirements of this section apply only to the personnel associated with the operating phase of the combined licenses.

(b) The application must demonstrate compliance with the requirements for training programs established in $\S 50.120$ of this chapter.

$\S 52.79$ Contents of applications; technical information in final safety analysis report. ...

(14) A description of the operator training program, and its implementation, necessary to meet the requirements of 10 CFR part 55;

(17) The information with respect to compliance with technically relevant positions of the Three Mile Island requirements in $\S 50.34(\mathrm{f})$ of this chapter, with the exception of $\S$ $50.34(f)(1)(x i i),(f)(2)(\mathrm{ix}),(\mathrm{f})(2)(\mathrm{xxv})$, and (f)(3)(v); ...

(29)(i) Plans for conduct of normal operations, including maintenance, surveillance, and periodic testing of structures, systems, and components; 
(ii) Plans for coping with emergencies, other than the plans required by $\S 52.79(\mathrm{a})(21) ; \ldots$

(33) A description of the training program required by $\S 50.120$ of this chapter and its implementation; ...

(34) A description and plans for implementation of an operator requalification program. The operator requalification program must as a minimum, meet the requirements for those programs contained in $\S 55.59$ of this chapter; ...

(37) The information necessary to demonstrate how operating experience insights has been incorporated into the plant design;

10CFR Part 52 also states in the Subpart on Standard Design Approval that:

Applications filed under this subpart will be reviewed for compliance with the standards set out in 10 CFR parts 20,50 and its appendices, and 10 CFR parts 73 and 100.

This Subpart thus incorporates other requirements such as that for staffing that is in 10CFR50.54(m). As stated in the issues section above, staffing is an important consideration for aSMRs. The focus has been mostly on the number of staff, but there are other requirements that are important here such as:

(k) An operator or senior operator licensed pursuant to part 55 of this chapter shall be present at the controls at all times during the operation of the facility.

(1) The licensee shall designate individuals to be responsible for directing the licensed activities of licensed operators. These individuals shall be licensed as senior operators pursuant to part 55 of this chapter.

(m)(2)(ii) Each licensee shall have at its site a person holding a senior operator license for all fueled units at the site who is assigned responsibility for overall plant operation at all times there is fuel in any unit. If a single senior operator does not hold a senior operator license on all fueled units at the site, then the licensee must have at the site two or more senior operators, who in combination are licensed as senior operators on all fueled units.

(iii) When a nuclear power unit is in an operational mode other than cold shutdown or refueling, as defined by the unit's technical specifications, each licensee shall have a person holding a senior operator license for the nuclear power unit in the control room at all times. In addition to this senior operator, for each fueled nuclear power unit, a licensed operator or senior operator shall be present at the controls at all times.

(iv) Each licensee shall have present, during alteration of the core of a nuclear power unit (including fuel loading or transfer), a person holding a senior operator license or a senior operator license limited to fuel handling to directly supervise the activity and, during this time, the licensee shall not assign other duties to this person.

Other regulations important to HSI include 10CFR50.120 - Training and qualification of nuclear power plant personnel and 10CFR Part 55 - Operators' Licenses.

10CFR50.34 imposes its requirements in 10CFR Part 52 by stating in paragraph (f) that:

... In addition, each applicant for a design certification, design approval, combined license, or manufacturing license under part 52 of this chapter shall demonstrate compliance with the technically relevant portions of the requirements in paragraphs (f)(1) through (3) of this section, except for paragraphs (f)(1)(xii), (f)(2)(ix), and (f)(3)(v).

All of these requirements, if applied to aSMRs, can have very different impacts then when applied to large LWRs and must be considered in evaluating the concept of operations. 


\subsubsection{Current Guidance for SMR Designs}

In evaluating the issues related to aSMR licensing identified by SECY-10-0034, including "issues related to licensing of prototype reactors, operation programs for small or multimodule facilities, installation of reactor modules during operation for multi-module facilities, industrial facilities using nuclear-generated process heat, and aircraft impact assessments for small modular reactors," the NRC concluded in SECY11-0012 that the NRC staff expects to be able to address these issues within the existing regulatory policy and framework for the foreseeable future. At present, the NRC staff does not expect to require rulemaking or changes to existing NRC policies for SMRs planned for near-term deployment.

Consequently, existing regulatory guidance for traditional LWR reactors also applies to new aSMR designs. This section will provide a high-level overview of the current regulatory guidance that relates to aSMR Concepts of Operations. The Standard Review Plan (NUREG-0800) documents the areas of the license application, design, and operations that the NRC reviews. The chapters of NUREG-0800 that are most relevant to concepts of operations are Chapter 13 and Chapter 18, which detail the HFE requirements. Other regulatory guidance related to concepts of operations can be found in several documents, including NUREG-0700, NUREG-0711, and NUREG-1791.

NUREG-0800 details the acceptance criteria for the areas the NRC reviews in Licensee submittals. Chapters 13, Conduct of Operations, has several sections that are relevant to aSMR Concepts of Operations: 13.1.2-13.1.3 (Operating Organization), 13.2.1, (Reactor Operator Requalification Program; Reactor Operator Training), and 13.5.2.1 (Operating and EOPs). Chapter 18 details the HFE acceptance criteria. Additional guidance on the HFE program is provided in the Human Factors Engineering Program Review Model (NUREG-0711).

NUREG-0711 provides guidance on twelve sections:

- HFE Program Management

- Operating Experience Review

- FRA and FA

- Task Analysis

- $\quad$ Staffing and Qualifications

- Treatment of Important Human Actions

- HSI Design

- Procedure Development

- Training Program Development

- Human Factors Verification and Validation

- Design Implementation

- Human Performance Monitoring

Many of these areas are relevant to aSMR Concepts of Operations. NUREG-0711 provides the overall guidance and references additional sources of guidance and information for each respective area. Each of these areas is summarized at a high level below, with additional information from other guidance sources included when available.

\section{HFE Program Management}

According to NUREG-0711, the licensee applicant should have an HFE program implemented by a qualified HFE design team. The NRC uses the review criteria described in Chapter 2 to verify that:

- The applicant has an HFE design team with the responsibility, authority, placement within the organization, and qualifications to verify that the plant design commitment to HFE is met.

- The applicant has an HFE program plan that reasonably assures that the HFE is properly developed, executed, overseen, and documented. 
- The HFE program plan describes the HFE elements to ensure that HFE principles are applied to the development, design, and evaluation of HSIs, procedures, and training.

- The HFE program plan appropriately considers and addresses the deterministic aspects of design, discussed in Regulatory Guide (RG) 1.174.

- The HFE program provides assurance that modifications to the plant do not compromise good human factors design.

The HFE review covers the MCR, remote and technical centers, emergency operations facilities, the design of HSIs, procedures, and training, and personnel and operator staffing and qualifications (O'Hara et al., 2012). Additional guidance for the HFE process is available in IEEE Standard 1023-2004.

\section{Operating Experience Review}

NUREG-0711 states that license applications include an operating experience review to ensure that the applicant has reviewed previous designs that are similar to the design included in the application, and has "identified, analyzed, and addressed HFE-related problems to ensure that any negative features in the predecessor designs are avoided in the current design" (p. 18). This review should include human factors issues in predecessor plants or highly similar plants, systems, and HSIs, and it should also address HFE issues that generally affect the industry, as identified in NUREG/CR-6400.

Currently, there is no operating experience base for aSMRs, so to satisfy this element of NUREG-0711 it will be necessary to gather information from the operation of similar facilities. As noted above O'Hara et al (2012) studied UAS, oil refineries, and tele-ICUs to identify potential issues for SMRs. In the future, more advanced NPP control rooms may provide relevant operating experience. An applicant would need to provide a justification as to why an analogous operational situation would be relevant to their design.

\section{Functional Requirements Analysis and Function Allocation}

According to NUREG-0711, license applicants should conduct an FRA using a structured, documented methodology that reflects HFE principles to define the high-level functions that must be accomplished to meet the plant's goals, delineate the relationships between high-level functions and plant systems responsible for performing the functions, and provide a framework for determining the roles and responsibilities of personnel and automation (O'Hara et al., 2012). The NRC uses the review criteria in NUREG-0711 to ensure that the applicant has defined the functions that must be carried out to ensure the plant's safety and power production goals, and allocated those functions to personnel and automation in a manner that takes advantage of human strengths and minimizes human limitations. Guidance on conducting an FRA is available in IEC 61839, and NRC guidance on FA can be found in NUREG/CR2623 and NUREG/CR-3331.

See Section 3 of this report for a review of the FA literature and its applicability to the aSMR context.

\section{Task Analysis}

NUREG-0711 contains criteria that applicants can use to conduct a task analysis on those functions that have been allocated to the human operators to examine the tasks that humans must perform to accomplish them. Task analysis forms the basis for evaluating staffing and personnel qualifications, HSIs, procedures, and the design of the training program, and task support verification (O'Hara et al, 2012). The NRC uses the criteria in NUREG-0711 to ensure that the applicant has properly analyzed and identified the specific tasks that personnel must accomplish to perform their functions and the alarms, relevant information, controls, and task support necessary to perform their tasks (O’Hara et al., 2012).

Additional guidance on conducting task analyses may be found in a number of sources, including Kirwan and Ainsworth (1992), Shraagen, Chipman, and Shalin (2000), Vicente (1999), and NUREG/CR-3371.

\section{Staffing and Qualifications}


NUREG-0711 states that applicants should conduct and submit as part of their applications a systematic analysis of the required number and necessary qualifications of personnel as determined necessary by task and regulatory requirements. Additionally, this staffing analysis must be risk-informed. NUREG-0800, Section 13.1 also speaks to staffing and qualifications, and there are a number of other NRC documents related to staffing, including Smith's (2011) report from the Office of New Reactors titled "Control Room Staffing" for the Small Modular Reactor Issue Identification and Ranking Program, NUREG-1791, and Regulatory Guide 1.114 .

Regulatory Guide 1.114 expands on the requirements of 10CFR50.54 (1) and (m)(2)(ii), which state that "an operator or senior operator who is licensed pursuant to 10 CFR Part 55, 'Operators' Licenses,' must be present at the controls at all times during the operation of a facility" (p. 1). The term "controls," when applied to nuclear reactors, means "apparatus and mechanisms, the manipulation of which directly affects the reactivity or power level of the reactor" (p. 1). Furthermore, (m)(2)(ii), "each licensee must have a person possessing an active senior operator license for the nuclear power unit present in the control room at all times" (p. 1).

Until such time as the NRC publishes new rules related to the specific issues of SMR reactors, licensees can use the exemption process to request exemptions from requirements that do not apply well to SMR designs and operation. NUREG-1791 (Persensky, Szabo, Plott, Engh, and Barnes, 2005) provides detailed guidance on how licensees can use the exemption process to obtain an exemption related to staffing, and NUREG/CR-6368 provides the NRC's methods, criteria, measures, and reasoning for reviewing the exemption requests. Specifically, the NRC reviews the exemption request, determines the scope of the exemption(s), and identifies any new or modified concepts introduced by the application (Persensky et al., 2005). The NRC then reviews the Concept of Operations to understand the role of plant personnel in overall plant operations and the operational conditions that the licensee considers to justify the exemption(s). The NRC also reviews all the data and analysis that the licensees submit to provide technical support for the exemption request (Persensky et al, 2005).

The Nuclear Energy Institute, an industry organization, summarizes the regulatory issues related to staffing from an industry perspective on staffing needs for SMR plants in a position paper titled "Control Room Staffing for Small Reactors" (Nuclear Energy Institute, 2011). The NEI recognizes the need for a task analysis and a strong HFE review for each SMR design to identify and support the appropriate staffing level for plant safety.

Other sources of guidance related to staffing include ANSI/ANS 3.1, NRC Information Notice 95-48, NUREG/CR-6753, and Regulatory Guide 1.8, Rev 3.

\section{Treatment of Important Human Actions}

SECY-11-0024 (Borchardt, 2011) documents the NRC's commitment to using a risk-informed framework for evaluating SMR and aSMR designs. The NRC uses risk analyses to prioritize activities and ensure that regulators and applicants focus their efforts and resources on activities that best assure the health and safety of the public (O'Hara et al., 2012). Chapter 19 of the final safety analysis report (FSAR), the design control documents (DCD), NUREG-0800, and NUREG-0711 provide guidance to license applicants to identify the human actions that are most safety significant via a combination of probabilistic and deterministic analyses, the former of which is typically conducted via a PRA, which includes an HRA. The deterministic engineering analyses are typically completed in the FSAR/DCD analyses conducted for NUREG-0800 Chapters 7 and 15. Consequently, the NRC uses Section 7 of NUREG-0711 and NUREG-0800, Chapters 7, 15, and 19 to review the complete set of risk-assessed human actions and ensure that the applicant has properly identified and analyzed the important human actions (O’Hara et al., 2012).

An HRA evaluates the potential for and mechanisms that may lead to human error that might affect plant safety. It is therefore an essential part of the HFE program and assists in assuring that the design 
minimizes personnel errors, supports error detection, and ensures recovery capability. The HRA supports both HFE design and PRA activities, and provides valuable insights into the characteristics needed of the HSI design (O'Hara et al., 2012). The HFE design must pay special attention to the plant scenarios, riskimportant human actions, and HSI issues that the PRA or HRA highlights as vital to plant safety and reliability (O’Hara et al., 2012).

There is extensive regulatory guidance available on conducting PRA and HRA, including IEEE Standard 1082-1997, NUREG-1792, NUREG-1624, Rev. 1, NUREG-1764, Rev. 1, NRC Information Notice 9778, Regulatory Guide 1.174, Rev. 2, and Regulatory Guide 1.177, Rev. 1.

\section{HSI Design}

NUREG-0711 provides guidance for the review of license applications on the systematic evaluation of the design of the plant HSI. The HSI design process is where the function and task requirements are translated into specific design requirements, and thusly to the detailed design of all of the aspects of the HSI with which the human operators interact, including the alarms, displays, and controls (O'Hara et al., 2012). The NRC uses Chapters 7, 18, and Section 14.3.9 of NUREG-0800 in evaluating the application's HSI design to verify that the applicant has used a structured HFE methodology to design, test, and evaluate the HSI design (O'Hara et al., 2012). The HSI design encompasses the design of the computer systems, the displays, the controls, the workstations, the alarms and annunciators, the automation interface, the CBPs (if any are utilized), in not only the control room but also the TSC, operations support center, and any other remote control or shutdown facility. Due to the critical importance of the HSI to the operators and to the safety and productivity of the plant, the NRC provides detailed and specific regulatory guidance for design of the HSI in NUREG-0700 (O'Hara et al., 2002).

Additional guidance for HSI design can be found in ANSI/HFES 100-2007, ANSI/HFES 200, BNL TR E2090-T4-1-9/96 (Stubler and O'Hara, 1996), BNL TR E2090-T4-4-12/94 (Stubler and O'Hara, 1996), BNL TR 91017-2010 (O’Hara and Higgins, 2010), DI\&C-ISG-05, Rev. 1 (U.S. NRC, 2009), IEC 60964, IEEE Standard 1023-2004, NUREG-0835, NUREG/CR-6633, NUREG/CR-6634, NUREG/CR-6635, NUREG/CR-6636, NUREG/CR-6637, and NUREG/CR-6684.

\section{Procedure Development}

Procedures are critical to plant safety because they guide and support personnel interaction with plant systems and response to plant events (O'Hara et al., 2012). Individual utilities are responsible for the development of procedures for their respective plants, and NUREG-0711 provides guidance on how license applicants should develop their procedures according to accepted HFE principles (O'Hara et al., 2012). The NRC uses NUREG-0800 Chapter 13.5 to review applicant procedures, and NUREG-0711 to ensure that the applicant's program for developing procedures adheres to HFE principles, criteria, and other design requirements to develop procedures that are accurate, comprehensive, specific, easily utilized, validated, and conform to 10 CFR 50.34(f)(2)(ii) (O’Hara et al., 2012).

Additional regulatory guidance on procedure development can be found in DI\&C-ISG-05, Rev. 1, IP 42001, NUREG/CR-6634, NUREG/CR-5228, NUREG-0899, and NUREG-1358.

The current NPP fleet uses paper-based procedures, and the NRC regulatory guidance reflects this fact. However, aSMRs, which rely on technology and HSIs that are more advanced than the current fleet, are likely to develop computerized procedure systems. The NRC has not yet endorsed any particular guidance on computerized procedures; however, NRC staff is evaluating the recent IEEE Standard 1786-2011 for endorsement related to CBPs (Personal communication with NRC staff, 2013).

\section{Training Program Development}

Operator qualifications and training are governed by 10 CFR 50.120 and 10 CFR Part 55. NUREG-0711 provides guidance on how license applicants should demonstrate that their training program is developed and implemented based on accepted HFE principles. Training programs are essential to safe, reliable 
operation of the plant, and as such, a quality, thorough training program aids in assuring that personnel have the knowledge, skills, and abilities to perform their responsibilities (O'Hara et al., 2012). The NRC uses NUREG-0800 Chapter 13 when reviewing an applicant's training program, and recommends that the training program be designed and coordinated with the other aspects of the HFE design process.

Specific regulatory guidance on training program development can be found in ANSI/ANS 3.1-1993, ANSI/ANS 3.5-2009, IP 415000, NUREG-1021, NUREG-1220, Regulatory Guide 1.149, and Regulatory Guide 1.8 .

\section{Human Factors Verification and Validation}

Verification and validation $(\mathrm{V} \& \mathrm{~V})$ evaluations are the process used to comprehensively determine that the human factors design conforms to HFE principles, and that it enables plant personnel to successfully perform their responsibilities and assure plant safety and operational goals (O'Hara et al., 2012). The $\mathrm{V} \& \mathrm{~V}$ consists of sampling of operational conditions, design verification, integrated system validation, and resolution of any identified human engineering discrepancies (O'Hara et al., 2012). NUREG-0711 details the criteria that the NRC staff uses to verify that the applicant has sampled an adequately broad range of conditions that could be encountered during operation, reflects characteristics that can contribute to variability in system performance, and considers the safety significance of the HSIs. The NRC staff also use NUREG-0711 to verify that the HSI inventory and characterization are accurate, that the HSI provides needed alarms, information, controls, and task support, that the HSI conforms to HFE guidelines, that the applicant has validated that the integrated system design supports safe operation of the plant, and that any human engineering discrepancies have been identified, evaluated, developed solutions, and verified implementation of solutions (O'Hara et al., 2012).

Additional regulatory guidance on V\&V may be found in ANSI/AIAA G035A-200, ANSI/ANS 3.52009, IEC 1771, IEC 60964, IEEE Standard 845-1999, ISO 11064-7, and NUREG/CR-6393.

\section{Design Implementation}

This section of NUREG-0711 provides guidance on the implementation, installation, and testing of the HFE aspects of the plant's design for both new plants and plant modifications. For aSMR designs, the relevant guidance is that for new plants, which is carefully monitored by start-up procedures and testing (O'Hara et al., 2012). The purpose of this guidance is to allow the NRC staff to verify that the applicant's as-built design conforms to the verified and validated design produced by the HFE design process, and that the implementation of plant changes considers the effect on personnel performance and provides the necessary support to assure safe operations (O'Hara et al., 2012). Specific review criteria for new plants are listed in 12.4.1 of NUREG-0711.

Additional regulatory guidance is primarily focused on the modification of existing control room systems. However, some of the guidance found in these documents may still apply to new systems, including IEC 62096, NEI 96-01, Rev. 1, and Regulatory Guide 10174, Rev. 2.

\section{Human Performance Monitoring}

The final section covered by NUREG-0711 related to the HFE process is Section 13, "Human Performance Monitoring." A human performance-monitoring program serves to provide assurance that the $\mathrm{V} \& \mathrm{~V}$ of the HFE program, control room, and integrated systems design is maintained over time. Review criteria provided in this section serve to aid NRC staff in reviewing license applications and verify that the applicant has prepared a human performance monitoring program that adequately assures that the conclusions of the integrated system validation remain valid over time, and that the program ensures that no significant degradation of safety occurs due to any changes made in the plant (O'Hara et al., 2012).

Additional regulatory guidance specific to human performance monitoring may be found in CN Number 02-001, CN Number 01-015, IP 71715, and NUREG-1649. 


\subsection{Overview of Current Licensing Process}

The NRC states in its 2012 report to Congress that:

"Ensuring readiness to carry out its responsibilities relating to reactor licensing applications that may be submitted in the future presents a challenge that the NRC has ably addressed in anticipation of applications for diverse reactor designs and technologies in the past. The NRC's current licensing requirements and processes set forth in 10 CFR Part 50 and 10 CFR Part 52 can be used for licensing future reactor designs and technologies. However, enhancements to the regulatory framework to address potential policy, licensing, and technical issues presented by advanced reactor designs could contribute to improvements in the effectiveness and efficiency of future licensing."

The ANS in its 2010 report provided support to the NRC position by stating that: "Light water reactor requirements provide assurance of safety system quality, capability, reliability, and redundancy commensurate with the safety characteristics of current designs." However, they qualify their position by indicating that SMR designs which incorporate passive safety features, enhanced safety margins, slower accident response, and improved severe accident performance, provide opportunities to simplify and streamline the regulatory process.

They go on to specify that there is a preference is to rely on licensing advanced reactors under current regulations, where the experience base is robust and the review process is proven. Projects that rely on regulatory certainty prior to significant investment may prefer to use the 10 CFR 52 one-step process. A more research-oriented project may prefer use of the 10 CFR 50 (Ref. 2) two-step process for first-of-akind SMRs to advance construction of the first unit prior to completing design, while using 10 CFR 52 to license follow-on units that can incorporate design finalization work and operating experience from the first (or prototype) unit.

NEI in a 2010 position paper also supports the notion that the existing license structure for SMRs is recommended to be similar to that used for the larger LWRs. Specifically, for planned multi-module plants, this would be a combined license (COL) application with a single NRC review and COL hearing, resulting in a single NRC SER. The COL application would request a separate license per reactor module for the multi-module facility.

However, the NRC does allow licensees to seek exemptions from regulatory requirements when warranted. See 10 CFR 50.12. For instance, applicants or licensees may request exemptions from the staffing regulations in 10 CFR 50.54(m) and NRC guidance. NRC guidance document NUREG-1791 offers the staff guidance on exemption requests from power plant licensed operator (LO) staffing requirements.

Beyond the regulations, NRC regulatory guidance and technical requirements also apply to SMRs. All SMR designs deviate to a greater or lesser extent from the standard LWR design that is the focus of the current regulatory framework. Many of the differences relate simply to the small scale of these designs. Others relate to differences in the configuration of systems, structures, and components that are important to safety. Any changes to the guidance or technical requirements must provide reasonable assurance of adequate protection of the public health and safety. Realistically, consistent with NRC policy, it will also have to be shown that the level of protection provided by an SMR is at least equivalent to, or better than, what is provided by current designs.

Where aSMR design characteristics deviate from regulatory guidance but do not violate a binding requirement, approval for the deviation can be obtained by making an acceptable technical argument. The technical challenge may be significant in some instances, but the approval process is straightforward.

Although there appears to be general agreement that there is no need to change the current regulations, the NRC published SECY-04-0157, which outlined the staff's proposed regulatory structure for new plant 
licensing and potentially new policy issues. The objective of the regulatory structure for new plant licensing is to provide a technology-neutral approach to enhance the effectiveness and efficiency of new plant licensing in the longer term (beyond the advanced designs currently in the pre-application stage). The staff 's proposed regulatory structure consisted of four major parts:

1. A technology-neutral, risk-informed framework that will provide guidance and criteria to the staff for the development of technology-neutral requirements.

2. The content for a set of technology-neutral, risk-informed requirements that will be based on the guidance and criteria established in the technology-neutral framework NUREG.

3. A technology-specific framework that will provide guidance and criteria for the staff on how to apply the technology-neutral framework and requirements on a technology-specific basis.

4. Technology-specific RGs that will be derived from the implementation of the technology-specific framework and will provide guidance to licensees on how to apply the technology-neutral regulations on a technology-specific basis.

The ANS 2010 report agrees that for non-LWR designs, a technology-neutral framework is needed. Two options for a technology-neutral framework are presented in their paper: the general-safety-standards option and the parity option. It may be impractical and expensive to pursue rulemaking to accommodate each of the areas in which SMRs differ from LWR designs. It may also be impractical to contemplate the issuance of numerous exemptions to approve the ways in which SMRs do not conform to current requirements. ANS agrees that it would be more efficient to pursue rulemaking to implement a technology-neutral framework based on the parity change process, where the advantages of SMRs can be compared on an equal footing to those of current designs. In this way, decisions about compliance of SMRs with the regulations can be made in a balanced manner. This process would allow an innovative design to be approved by demonstrating "parity" with current plants, that is, protection equivalent to or greater than that provided by compliance with the current regulations. The change process proposed allows for the provision of a coherent safety case, i.e., a convincing demonstration that the design is safe enough.

The ANS SMR Special Committee recommends that the SMR community plan for the use of current regulations to license SMRs for near-term deployment, with licensing review basis documents negotiated to provide a framework for approval that will satisfy the regulator where current guidance may not apply. In order to compensate for the current absence of SMR-specific licensing criteria, the SMR Special Committee proposes (1) the incorporation of licensing review basis documents within the existing regulatory process, and (2) the recommendation of new licensing criteria for advanced technology such as SMRs, to be implemented in the long term.

More emphasis on risk-informed and performance-based licensing for SMRs will bridge the gap between current, LWR-focused regulations and new review criteria specific to more advanced, smaller reactors. By focusing review and deterministic analysis on those aspects of SMR design that are most critical to safety, risk-informed methods will facilitate the use of much of today's regulatory framework for near term construction and operation of SMRs

The NRC's 2012 report to Congress indicates that the NRC is integrating the use of risk insights more fully into pre-application activities and the review of applications, focusing on iPWR designs in the near term. The agency's objective is to focus the review and staff resources on risk-significant SSCs and other aspects of the design that contribute the most to safety. The approach includes: (1) use a more riskinformed and integrated review framework for staff pre-application and application review activities pertaining to iPWR design applications; and, (2) develop, over the longer term, a new risk-informed, performance-based regulatory structure for licensing non-LWR advanced reactor designs (e.g., hightemperature gas-cooled reactors (HTGRs) and LMRs).

SECY11-0156 states that the staff plans to continue its efforts to risk-inform SMR reviews. These efforts include the activities discussed in SECY-11-0024, which consist of the preparation and application of 
Design-Specific Review Plans (DSRPs) in the review of SMR design applications. In addition, the staff is prepared to review any application referencing existing regulations, such as 10 CFR 50.69, to apply risk insights and 10 CFR 50.12, "Specific Exemptions" to request exemptions as stated above. The staff believes that the current provisions of 10 CFR 50.12 would permit the Commission to approve regulatory exemptions that allow for implementation of risk-informed changes to operational and qualification requirements.

In the longer term, the staff has devised an approach as described in SECY-11-0024 for the development of a new risk-informed and performance-based regulatory structure. This would involve development of a risk-informed framework for both LWRs and non-LWRs and would not be limited to SMRs. The staff's approach is a multistep process that will extend over several years and is expected to include several pilot studies that consider the principles of a technology-neutral regulatory framework. The first step in the staff's longer-term approach would include a pilot study in which the principles of a technology-neutral regulatory framework are considered for an iPWR design application.

\subsection{Regulatory Guidance Needed for SMRs}

Although current NRC guidance provides a general framework for conducting design specific reviews, the NRC staff expects the reviews of staffing plans and potential exemption requests to be challenging for SMR designs because of the differences between the SMR designs and previously licensed reactor designs and a lack of research and data to provide an adequate technical basis for decisions. The NRC's initial evaluation has identified the following differences between the SMR design and operating philosophy and the reactor designs currently licensed or being evaluated for licensing:

- SMRs may require different operator tasks. The task requirements will include operating multiple units in different modes of operation. A major challenge will be to identify tasks that may be omitted and those that could substantially affect operator workload.

- Very limited operational experience will be available to use as a resource, as these designs are first of a kind. The use and observation of simulator activities will be important to the verification of the task analyses and staffing plans. Parallels in other industries may be useful, if they exist.

- Integration challenges exist in defining not only tasks required for operating the unit but also for interacting with other on-site maintenance and support organizations for multiple units.

- The skill set for control room operators may require a different distribution of qualifications (e.g., more senior reactor operators, fewer reactor operators, or even a new class of personnel).

- For some SMR designs, operators will face the challenge of managing the operation of additional units as they are placed on line. As the number of modules increases, the demands on the operators will change, and potentially the number of operators required for safe operation (i.e., multiple staffing plans may be needed to address the addition of more units during the construction period or subsequent operating periods).

When one considers these issues and the current guidance available in NUREG-0800 and NUREG-0711, there are certain gaps that exist that may be subject to new or modified guidance. NUREG-0711, NUREG-0700, and NUREG-0800 have undergone updates over the last several years to better recognize the use of digital control rooms and update procedures and I\&C systems. NRC staff intends to keep up with new technologies, processes, and research and to modify these documents as appropriate. The NRC does need to maintain an awareness of such changes in the nuclear arena to have the information need to make the modifications to guidance in a timely fashion. Feedback from the industry and research domain is crucial to this activity. Because of the speed of technological change in the devise industry, the DOE and its contractors may be in a better position to maintain awareness and stay ahead of changes, perform research, and work with the technology and nuclear industries. 


\subsection{Guidance for Working Within Current Regulatory Framework}

Given the limited change currently expected for the regulatory and licensing framework, applicants need to adjust their approach to applications to be somewhat more flexible. As stated in the NRC's 2012 report to Congress:

It is important to recognize that the "robustness" (i.e., overall quality, completeness, and level of detail) of a licensing application directly impacts the work needed to support the licensing review and, correspondingly, the resources required to conduct the review. In compliance with current NRC regulations, applicants have the primary responsibility to demonstrate the "safety case," which is further described below, for their applications. The NRC expects that license applications will be complete, high-quality submittals supported by sufficient R\&D (where necessary), and any follow-up submittals will provide timely and sufficient information to address the staff's questions and concerns. The NRC expects that required testing and code development will be completed to support the application and that preapplication reviews will have been successfully completed with no remaining open policy or technical issues or only a limited number with a clear path to resolution identified.

The applicant's demonstration of the "safety case" supporting its application requires comprehensive documentation of the research conducted, testing accomplished, and analyses performed necessary to support both the design and the technical basis for the safety analysis. For example, applicants are responsible for conducting R\&D to (1) demonstrate safe performance of the proposed design and applied technology, (2) provide the technical basis for the application, (3) demonstrate sufficient margins to safety-significant SSC design and safety limits, (4) search for and identify, as well as assess and resolve, safety issues involving large uncertainties, (5) develop, verify, and validate the proposed safety analysis evaluation methods, (6) provide the technical basis for requirements, criteria, codes, or standards that are proposed for the licensing design basis, (7) quantify the failure thresholds for safety-significant SSCs, and (8) support NRC regulatory and licensing decisions.

Therefore, it is important that the applicants develop a strong technical basis for their design and their concept of operations. The guidance in NUREG-0711 and 0800 for HFE aspects of the design and concept of operations will be used by the staff in their reviews of applications, so applicants should adhere to the guidance or be prepared with a sufficient technical basis to deviate from that guidance. A good example as to how to approach such an effort is described in NUREG-1791 on seeking an exemption from the staffing rule. 


\section{Discussion and Conclusion}

\subsection{Concepts of Operations}

One of the aspects of Concepts of Operations not well documented in the literature was the organizational impact associated with implementing SMRs, specifically the expected impacts on engineering, operations, I\&C, and maintenance functions for multimodular sites. The same is true for multiple-purpose hybrid energy centers where the boundaries between processes may interact and personnel may have dual roles. Further, the project team could find nothing written on the type of safety critical operational scenarios that might include aSMR interaction with other processes. Currently, the effects of tsunami would be examined in terms of each process individually, and would not focus on the areas where interdependent processes would have a common intersection and vulnerability. A less safety-significant issue but perhaps important from a workflow and economic perspective would be the approach to a clear process for monitoring and resolving conflicts among the interconnected processes. As part of this effort's continued review in FY14, the project team expects to be able to determine a number of these potential operating scenarios.

Another area in need of further refinement is the identification and definition of failure modes for passive systems. For example, debris in tanks and pools can lead to passive systems failure. Closed vent doors or obstructions may drastically reduce the efficacy of natural convection. Implications of such failures will be considered as more information becomes available.

\subsection{Work Domain Analysis}

The September 2012 milestone report [39] explained that WDA has never been applied in the development or analysis of concepts of operation in the nuclear industry. Previous efforts in various industries to standardize the format and the process of developing concept of operations documents have also not paid much attention to human factors issues. Nevertheless, examples in the literature (Roth, Patterson and Mumaw, 2012 [109]; Bisantz and Vicente, 1994 [10] and Kim 2011 [60]) suggest that WDA is the most systematic and structured method for this purpose.

In an effort to better define this gap, an exploratory WDA exercise was conducted in FY12. The results from this exercise, which was based on the EBR-II sodium-cooled reactor, indicated that WDA would be a powerful method to structure a large part of the research planned for the next phase of the project. The primary focus for the remainder of FY13 would thus be on the development of a WDA to the extent allowed by technical information available from vendors, appropriate predecessor plants, and general SMR design concepts. The resulting WDA will help to define the scope of the main topic for the FY14 research: determining unique aSMR operational scenarios for at least one candidate design. The results from the FY13 reports (for example, the Contextual Activity Analysis part of the WDA, combined with human performance criteria) would also be used to assess the crew performance aspects associated with the identified operational concepts.

\subsection{Human Performance Perspective}

The human performance perspective in the FY12 Milestone report focused on risk-informing the development of concepts of operation and the identification of human performance requirements for aSMR designs. However, due to the unavailability of PRA models to support a literal risk-informed approach, along with the level of effort associated with using PRA models in this way, the intent is to "risk-inform" the approach in a different sense than might have been understood from that report. In general, the human performance approach that will be taken for aSMR Concept of Operations will have the goal of limiting the conditions for human errors or human failures. Thus, as described in Chapter 5, Task 2, of the milestone report (the Path Forward), the goal will still be to establish how human factors and human performance can be used to risk inform Concepts of Operations, but in the sense that a process 
will be developed to identify the human performance requirements and conditions that could contribute to the likelihood of human failure to achieve a needed response.

As before, a crucial part of the effort will be to determine the means by which to identify human decisions, actions, and interfaces, along with personnel-related aspects, that could impact the success of achieving system critical functions. This information will be determined largely through the WDA performed as part of this project. Part of this process will identify how a system is to be used, where it is located, how it fits in operational sequences, and operator performance requirements in conjunction with that system. Then the impact of the operator not meeting performance requirements will be determined. The procedure developed by the INL team will specify how human performance information can be used to inform or supplement the process for addressing allocation of function issues for Concepts of Operations. In other words, the goals are consistent with those in last year's milestone report, but the sense in which the approach will be risk-informed has been better specified. 


\section{Path Forward}

The project plan for FY13 outlined in the previous milestone report described ambitious goals that relied largely on the availability of design-specific information from at least one aSMR. This expectation was proven too optimistic for this phase, and this resulted in the need for some adjustment in the project goals.

\section{Task 1: Work Domain Analysis}

As explained in a previous section, the exploratory WDA in FY12 and research during the past phase provided a much clearer direction for the remainder of the project. In fact, all literature reviewed indicated that the WDA provides information and context in a way not available from any other method. For this reason, a significant portion of the remainder of this project will rely on the results from the WDA exercise that will be conducted in preparation for the next milestone report in September 2013.

Task 2: Develop definitions and criteria for human performance for aSMRs and their contribution to the development of Concepts of Operations.

In order to provide a human performance perspective to Concepts of Operations, a number of other considerations must be addressed. These include the level and qualifications of staffing proposed for normal and disturbance conditions, different approaches to automation, detailed operating scenarios, expected team dynamics, and proposed interfaces that will be used. A crucial part of this analysis will be to determine the means by which to identify all human personnel, decisions, actions, and interfaces with others. This information is determined largely through the WDA performed under Task 1. Part of this process will identify how a system is to be used, where it is located, how it fits in operational sequences, and operator performance requirements in conjunction with that system. Then the impact of the operator not meeting performance requirements will be determined. The procedure developed by the INL team will specify how human performance information can be used to inform or supplement various types of risk analyses related to Concepts of Operations. This will be performed for design, the regulatory process and plant operations. Results from Task 2 will be summarized in a Draft Final report due September 30, 2013.

\section{Task 3: Refine and finalize the Function Allocation Model for aSMR Concepts of Operations}

Using insights gained from the WDA (Task 1) and the human performance criteria for aSMR Concepts of Operations (Task 2), develop the technical basis for the FA model to be used for the remainder of the project. This may involve a synthesis of the work done for this current report and defining a model to support evaluation of FA strategies for the development of aSMR Concept of Operations documents by designers. As part of this task, operational scenarios identified from the WDA will be selected for detailed analysis in a tabletop exercise to refine the model and ensure that the model meets the needs of aSMR designs and has an adequate technical basis to support regulatory review. 


\section{References}

[1] American Institute of Aeronautics and Astronautics (1992). Guide to the Preparation of Operational Concept Documents (ANSI/AIAA G-0943-1992). Washington DC: American National Standards Institute.

[2] American Institute of Aeronautics and Astronautics (2001). Guide to Human Performance Measurements (ANSI/AIAA G-035A-2000). Washington DC: American National Standards Institute.

[3] American Nuclear Society (2009). Nuclear Power Plant Simulators for Use in Operator Training (ANSI/ANS 3.5-2009). Washington DC: American National Standards Institute.

[4] American Nuclear Society (2010). Interim Report of the American Nuclear Society President's Special Committee on Small and Medium Sized Reactor (SMR) Generic Licensing Issues. Washington DC.

[5] American Nuclear Society (2011). Small Modular Reactors Position Statement, ANS Committee report, Position Statement 25. Washington DC: American Nuclear Society. http://www.new.ans.org/pi/ps/docs/ps25.pdf.

[6] Antkowiak, M., Ruth, M., Boardman, R., Sitton, S., Cherry, R., and Shunn, L. (2012). Summary Report of the INL-JISEA Workshop on Nuclear Hybrid Energy Systems. Joint Institute for Strategic Energy Analysis, U.S. National Renewable Energy Laboratory, Colorado.

[7] Bailey, R. W. (1982). Human Performance Engineering: A Guide to System Designers. Englewood Cliffs, NJ: Prentice Hall.

[8] Barnes, V. E., Moore, C. J., Wieringa, D. R., Isakson, C. S., Kono, B. K., and Gruel, R. L. (1989). Techniques for Preparing Flowchart Format Emergency Operating Procedures, Volumes 1 and 2 (NUREG/CR-5228). Washington, DC: U.S. Nuclear Regulatory Commission.

[9] Bibby, K. S., Marguiles, F., Rijnsdorp, J. E., and Withers, R. M. J. (1975). Man's role in control systems. Proceedings of IFAC 6th Triennial World Congress, Boston, MA.

[10] Bisantz, A. M., and Vicente, K. J. (1994). Making the abstraction hierarchy concrete. International Journal of Human-Computer Studies, 40, 83-117.

[11] Bolstad, C. A., Costello, A. M, and Endsley, M. R. (2006). Bad situation awareness designs: What went wrong and why. Presented at the International Ergonomics Association 16th World Congress, Maastricht, Netherlands.

[12] Boring, R. L. (2007). Meeting human reliability requirements through human factors design, testing, and modeling. Proceedings of the European Safety and Reliability Conference (ESREL 2007), pp. 3-8. London: Taylor \& Francis.

[13] Boring, R. L., and Agarwal, V. (2012). Resilience in Control Room Modernization: Ten Resilient Control Room Principles (INL/CON-12-25995).

[14] Bowers, J. M., and Benford, S. (Eds.) (1991). Studies in Computer-Supported Cooperative Work: Theory, Practice and Design. Amsterdam: North-Holland,

[15] Brown, W. S., O’Hara, J. M., and Higgins, J. C. (2000). Advance Alarm Systems: Guidance Development and Technical Basis (NUREG/CR-6684). Washington DC: U.S. Nuclear Regulatory Commission.

[16] Burgy, D., Lempges, C., Miller, A., Schroeder, L., VanCott, H., and Paramore, B. (1983). Task Analysis of Nuclear Power Plant Control Room Crews (NUREG/CR-3371). Washington DC: U.S. Nuclear Regulatory Commission. 
[17] Bye, A., Hollnagel, E., and Brendford, T. S. (1999). Human-machine function allocation: A functional modeling approach. Reliability Engineering and System Safety, 64, 291-300.

[18] Chapanis, A. (1996) Human Factors in Systems Engineering. New York: Wiley Interscience.

[19] Charny, L., Hornsby, M. E., and Sheridan, T. B. (1987). An interactive multi-objective decisionaiding system for tactical mission planning. Proceedings of the Human Factors and Ergonomics Society Annual Meeting, 31(4) 432-436.

[20] Clegg, C., Ravden, S. Corbett, M., and Johnson, S. (1989). Allocating functions in computer integrated manufacturing: A review and a new method. Behaviour \& Information Technology, 8(3), 175-190.

[21] Cook, C. A. (1999). Investigating dynamic functional allocation methods for Naval command and control. In Proceedings of the International conference on Human Interfaces in control rooms, cockpits, and command centers, Farnborough UK.

[22] de Winter, J. C. F., and Dodou, D. (2011). Why the Fitts' List has persisted throughout the history of function allocation. Cognition, Technology and Work. 25 August 2011, pp. 1-11.

[23] Endsley, M. R. (2000). Theoretical underpinnings of situation awareness: A critical review. In Endsley, M. R. and Garland, D. J. (Eds), Situation Awareness Analysis and Measurement. Mahwah, NJ: Lawrence Erlbaum Associates.

[24] Endsley, M. R., Bolte, B., and Jones, D. G. (2011). Designing for Situation Awareness: An Approach to User-Centered Design, $2^{\text {nd }}$ Ed. CRC Press.

[25] Fallon, E. F. (2006). Allocation of functions: Past, present and future perspective. In: Karwowski, W. (Ed.), Encyclopaedia of Ergonomics and Human Factors. Boca Raton, FL: Taylor \& Francis.

[26] Fitts, P. M. (1951). Human engineering for an effective air navigation and traffic control system. Columbus, OH: Ohio State University Foundation Report.

[27] Fitts, P. M. (1954). The information capacity of the human motor system in controlling the amplitude of movement. Journal of Experimental Psychology, 47(6) 381-391. (Reprinted in Journal of Experimental Psychology: General, 121(3), 262-269, 1992.)

[28] Fitts, P. M. (1962). Functions of man in complex systems. Aerospace Engineering, 21(1), 34-39.

[29] Fuld, R. B. (1993). The fiction of function allocation. Ergonomics in Design: The Quarterly of Human Factors Applications, 1(1), 20-24.

[30] Fuld, R. B. (2000). The fiction of function allocation, revisited. International Journal of HumanComputer Studies, 52(2), 217-233.

[31] General Electric (2006). ESBWR Allocation of Functions Implementation Plan (NEDO-33220). Licensing Topical Report. Wilmington, NC: General Electric Company. http://pbadupws.nrc.gov/docs/ML0603/ML060340058.pdf.

[32] Haight, J. (2007). Automated Control Systems: Do they reduce human error and incidents? Safety Engineering.

[33] Hancock, P. A., and Scallen, S. F. (1996). The future of function allocation. Ergonomics in Design: The Quarterly of Human Factors Applications, 4(4), 24-29.

[34] Higgins, J. C., and Nasta, K. (1996). HFE Insights For Advanced Reactors Based Upon Operating Experience (NUREG/CR-6400). Washington DC: U.S. Nuclear Regulatory Commission. 
[35] Higgins, J. C., O’Hara, J. M., Lewis, P. M., Persensky, J. J., Bongarra, J. P., Cooper, S. E., and Parry, G. W. (2007). Guidance for the Review of Changes to Human Actions (NUREG-1764, Rev. 1). Washington: DC: U.S. Nuclear Regulatory Commission.

[36] Hollnagel, E. (1997). Designing for complexity. In: Salvendy, G., Smith, M. J, and Koubek R. J. (Eds.), Seventh international conference on human- computer interaction, 217-220. San Francisco, August 24-29, 1997.

[37] Hollnagel, E. (2012). Coping with Complexity, past, present and future. Cognition, Technology and Work, 14, 199-205.

[38] Hollnagel, E., and Woods, D. D. (2005). Joint cognitive systems: Foundations of cognitive systems engineering. Boca Raton, FL: CRC Press.

[39] Hugo, J., Boring, R., Forester, J., Gertman, D., Joe, J, Medema, H., Persensky, J., and Whaley, A. (2012). Draft Framework for Advanced SMR Concepts of Operation Research (INL/EXT-1227299, SMR/ICHMI/INL/TR-12/01). Idaho Falls, ID: Idaho National Laboratory.

[40] Hugo, J. (2005). A Practical Function Allocation Method as part of the Human Factors Engineering Program for Nuclear Power Plants. Proceedings of CHI-SA 2005 Conference. Pretoria, South Africa.

[41] Hugo, J. (2006). A model-based approach to the integration of Human Factors in Systems Engineering. Proceedings of the 2006 Conference of the Ergonomics Society of South Africa. Pretoria, South Africa.

[42] Hugo, J. (2009). Design requirements for an Integrated Task Support System for Advanced HSIs. Proceedings of the 2009 Conference of the Ergonomics Society of South Africa. Port Elizabeth, South Africa.

[43] Hugo, J., and Engela, H., (2005). Function allocation for industrial human-system interfaces. Proceedings of CybErg 2005, the Fourth International Cyberspace Conference on Ergonomics. September 15-October 15, 2005.

[44] Human Factors and Engineering Society (2007). Human Factors Engineering of Computer Workstations (ANSI/HFES 100-2007). Washington DC: American National Standards Institute.

[45] Human Factors and Engineering Society (2008). Human Factors Engineering of Software User Interfaces (ANSI/HFES 200). Washington DC: American National Standards Institute.

[46] Hutchins, S., McDermott, P., and Barnes, M. (2010). A Comparison of Asset versus Criteria Allocation Decisions in Military Decision Making. In Proceedings of the Human Factors and Ergonomics Society Annual Meeting, 54(4), 344-348.

[47] IEEE Power and Energy Society (2011). IEEE Guide for Human Factors Applications of Computerized Operating Procedure Systems (COPS) at Nuclear Power Generating Stations and Other Nuclear Facilities (IEEE STD 1786-2011). New York: IEEE Standards Association.

[48] International Electrotechnical Commission (1995). Nuclear Power Plants Main Control RoomsVerification and Validation of Design (IEC 1771).

[49] International Electrotechnical Commission (2000a). Nuclear Power Plants - Control Rooms Design (IEC 60964).

[50] International Electrochemical Commission (2000b). Nuclear Power Plants - Design of Control Rooms - Functional Analysis and Assignment (IEC 61839).

[51] International Electrotechnical Commission (2009). Nuclear Power Plants - Instrumentation and Control: Guidance for the Decision on Modernization (IEC 62096). 
[52] Institute of Electrical and Electronics Engineers (1997). IEEE Guide for Incorporating Human Action Reliability Analysis for Nuclear Power Generating Stations (IEEE Std. 1082-1997). Piscataway NJ: IEEE.

[53] Institute for Electrical and Electronics Engineers (1998). Guide for Information Technology-System Definition - Concept of Operations (ConOps) Document (IEEE STD 1362). Piscataway NJ:IEEE.

[54] Institute of Electrical and Electronics Engineers (1999). IEEE Guide to the Evaluation of HumanSystem Performance in Nuclear Power Generating Stations (IEEE Std. 845-1999). Piscataway NJ: IEEE.

[55] Institute of Electrical and Electronics Engineers (2004). IEEE Recommended Practice for the Application of Human Factors Engineering to Systems, Equipment, and Facilities of Nuclear Power Generating Stations and Other Nuclear Facilities (IEEE STD. 1023-2004). Piscataway NJ: IEEE.

[56] International Council on Systems Engineering (2010). Systems Engineering Handbook - A Guide for System Life Cycle Processes and Activities, Version 3.2.2.

[57] International Standards Organization (1997). Guidance on usability (ISO 9241-11).

[58] International Standards Organization (2006). Ergonomic Design of Control Centres: Part 7: Principles for the Evaluation of Control Centres (ISO 11064-7).

[59] Jordan, N. (1963). Allocation of functions between man and machines in automated systems. Journal of Applied Psychology, 47(3), 161-165.

[60] Kim, S. Y. (2011). Model-based metrics of human-automation function allocation in complex work environments. PhD Dissertation, Georgia Institute of Technology, ProQuest.

[61] Kim, S. Y., Feigh, K. M., and Pritchett, A. (in press). Measuring human-automation function allocation.

[62] Kirwan, B. (2003). An overview of a nuclear reprocessing plant human factors programme. Applied Ergonomics, 34, 441-452. doi:10.1016/S0003-6870(03)00064-4.

[63] Kolaczkowski, A., Forester. J., Lois, E., and Cooper, S. (2005). Good Practices for Implementing Human Reliability Analysis (NUREG-1792). Washington DC: U.S. Nuclear Regulatory Commission.

[64] Kuznetsov, V. (2008). Options for small and medium sized reactors (SMRs) to overcome loss of economies of scale and incorporate increased proliferation resistance and energy security. Progress in Nuclear Energy, 50(2-6), 242-250.

[65] Lin, C. J., Yang, C. W., Yenn, T. C., and Cheng, L. Y. (2009). Allocating Human-System Interfaces Functions by Levels of Automation in an Advanced Control Room. In Human-Computer Interaction: Interacting in Various Application Domains, 741-750.

[66] Mallett, B. (2010). Presentation at the Commission Briefing on Reactor Issues - Design Certifications. April 6, 2010 (available at: http://www.nrc.gov/reading-rm/doccollections/commission/slides/2010/20100406/staff-20100406.pdf).

[67] Martinez-Pinna, H., Rejas, L.,and Ortega, F. (2012). HFE Analysis: A practical approach to the allocation of functions. Proceedings of the 8th International Topical Meeting on Nuclear Plant Instrumentation, Control and Human Machine Interface Technologies. San Diego, CA.

[68] Maslow, A. H. (1943). A theory of human motivation. Psychological Review, 50(4), 370-96.

[69] Masys, D. R., Hines, J. W., Saleem, J. J., Roth, E. M., McFarlane, D. C., and Agarwal, V. (2013). Diagnosis and Prognosis: Approaches to problem identification and prediction in healthcare and 
nuclear power. In Weinger, M.B., Hallbert, B.P. and Logan, M.K. (Eds), Risk and reliability in Healthcare and Nuclear Power: Learning from Each Other. Arlington VA: Association for the Advancement of Medical Instrumentation (AAMI) Monograph. ISBN 1057020-488-8.

[70] Matsumiya, H., (2009). The $4 S$ safety analysis (ADAMS ML092170507). Washington DC: U.S. Nuclear Regulatory Commission.

[71] Mays, G., and Williams, J.R. (2010). Key Technical Issues Associated with SMR Policy Issues. Regulatory Information Conference. Washington, DC: U.S. Nuclear Regulatory Commission. (http://www.nrc.gov/public-involve/conference-symposia/ric/slides/w12maysgpv.pdf).

[72] Mersiol, M. (2001). Répartition des fonctions entre les agents humains et les agents automatiques d'un système socio-technique: une methode et un util (Rapport LAAS No. 01107). Doctoral Dissertation, National Politechnic Institute of Toulouse, France.

[73] Mersiol, M., and Saidane, A. (2000). A tool to support function allocation. Proceedings of Safety and Usability Concerns in Aeronautics.

[74] Mumaw, R. J., Roth, E. M., Vicente, K. J., and Burns, C. M. (2000). There is more to monitoring a nuclear power plant than meets the eye. Human Factors, 42(1), 36-55.

[75] Nemeth, C. P. (2004). Human factors methods for design: Making systems human-centered. Boca Raton, FL: CRC Press

[76] Nof, S. Y., Knight Jr, J. L., and Salvendy, G. (1980). Effective utilization of industrial robots-A job and skills analysis approach. AIIE Transactions, 12(3), 216-225.

[77] Northey, E. (2013). Nuclear Energy: Obama admin placing big bet on small reactors. E\&E Publishing, Greenwire, Wednesday, March 13, 2013. http://www.eenews.net/public/Greenwire/2013/03/13/1, Accessed March 15, 2013.

[78] Nuclear Energy Agency, (2008). Market Competition in the Nuclear Industry (NEA\#6246). OECD Publishing.

[79] Nuclear Energy Agency (2010). Experimental Facilities for Sodium Fast Reactor Safety Studies (NEA/CSNI/R(2010)12). Task Group on Advanced Reactor Experimental Facilities (TAREF)..

[80] Nuclear Energy Institute (2000). Guidelines for 10 CFR 50.59 Implementation (NEI 96-01, Rev. 1).

[81] Nuclear Energy Institute (2010). License Structure for Multi-Module Small Modular Reactor Facilities. Position Paper.

[82] Nuclear Energy Institute (2011a). Control Room Staffing for Small Reactors. Position Paper. NEI Small Modular Reactor Licensing Task Force.

[83] Nuclear Energy Institute (2011b). Joyo. March 4, 2011. http://www.neimagazine.com/features/featurejoyo, Accessed March 2013.

[84] Nuclear Energy Institute (2011c). SMR Pre-Application Engagement. Position Paper.

[85] O’Hara, J. M., Brown, W. S., Lewis, P. M., and Persensky, J. J. (2002). Human-Systems Interface Design Review Guidance (NUREG-0700, Rev 2). Washington DC: U.S. Nuclear Regulatory Commission.

[86] O’Hara, J., and Higgins, J. (2010). Human-System Interfaces to Automatic Systems: Review Guidance and Technical Basis (BNL TR 91017-2010). Upton, NY: Brookhaven National Laboratory. 
[87] O’Hara, J., Higgins, J., Brown, W., and Fink, R. (2008). Human Factors Considerations with respect to Emerging Technology in Nuclear Power Plants (BNL Tech Report No. 79947-2008).

Washington DC: Brookhaven National Laboratory.

[88] O’Hara, J., Higgins, J., Brown, W., Kramer, J., and Persensky, J.J. (2004). Examining concept of operation in future plants. Proceedings of the Fourth American Nuclear Society International Topical Meeting on Nuclear Plant Instrumentation, Controls and Human-Machine Interface Technologies (NPIC\&HMIT 2004). Columbus, OH.

[89] O'Hara, J., Higgins, J, and D'Agostino, A. (2012). Multi-unit Operations in Non-nuclear Systems: Lessons Learned for Small Modular Reactors. Proceedings of the Eighth American Nuclear Society International Topical Meeting on Nuclear Plant Instrumentation, Control and Human-Machine Interface Technologies NPIC\&HMIT 2012, San Diego, CA, July 22-26, 2012.

[90] O'Hara, J., Higgins, J., Deem, R., Xing, J. and Agostino, A. (2010). Human Factors Aspects of Operating Small Reactors. Proceedings of the Seventh American Nuclear Society International Topical Meeting on Nuclear Plant Instrumentation, Control and Human-Machine Interface Technologies (NPIC \&HMIT 2010). Las Vegas, Nevada.

[91] O’Hara, J. M., Higgins, J. C., Fleger, S. A., and Pieringer, P. A. (2012). Human Factors Engineering Program Review Model (NUREG-0711, Rev 3). Washington DC: U.S. Nuclear Regulatory Commission.

[92] O’Hara, J., Higgins, J., and Kramer, J., (2000). Advanced information systems: Technical Basis and Human Factors Review Guidance (NUREG/CR-6633). Washington DC: U.S. Nuclear Regulatory Commission.

[93] O’Hara J., Higgins, J. and Pena M. (2011) Human-Performance Issues Related to the Design and Operation of Small Modular Reactors (NUREG/CR-7126). Washington DC: U.S. Nuclear Regulatory Commission.

[94] O’Hara, J. M., Higgins, J. C., Persensky, J. J., Lewis, P. M., and Bongarra, J. P. (2004). Human Factors Engineering Programme Review Model (NUREG-0711 Rev 2), Washington DC: U.S. Nuclear Regulatory Commission.

[95] O’Hara, J. M., Higgins, J. C., Stubler, W. F., and Kramer, J. (2000). Computer-Based Procedure Systems: Technical Basis and Human Factors Review Guidance (NUREG/CR-6634). Washington DC: U.S. Nuclear Regulatory Commission.

[96] O’Hara, J. M., Stubler, W., Brown, W., and Higgins, J. (1997). Integrated System Validation: Methodology and Review Criteria (NUREG/CR-6393). Washington DC: U.S. Nuclear Regulatory Commission.

[97] Papantonopoulos, S. A., and Salvendy, G. (1993). A Decision Model for Cognitive Task Allocation. In Human Factors and Ergonomics Society Annual Meeting Proceedings, 37(4), 392396.

[98] Papantonopoulos, S., and Salvendy, G. (2008). Analytic Cognitive Task Allocation: a decision model for cognitive task allocation. Theoretical Issues in Ergonomics Science, 9(2), 155-185.

[99] Parasuraman, R., Sheridan, T.B., and Wickens, C. (2000). A Model for Types and Levels of Human Interaction with Automation. IEEE Transactions on Systems, Man and Cybernetics - Part A: Systems and Humans, 30(3).

[100] Persensky, J., Szabo, A., Plott, C., Engh, T., and Barnes, V. (2005). Guidance for Assessing Exemption Requests from the Nuclear Power Plant Licensed Operator Staffing Requirements Specified in 10 CFR 50.54(m) (NUREG-1791). Washington, DC: U.S. Nuclear Regulatory Commission. 
[101] Plott, C., Engh, T., and Barnes, V. (2003). Technical Basis for Regulatory Guidance for Assessing Exemption Requests from the Nuclear Power Plant Licensed Operator Staffing Requirements Specified in 10 CFR 50.54(m) (NUREG/CR-6838). Washington DC: U.S. Nuclear Regulatory Commission.

[102] Price, H. E. (1985). The allocation of functions in systems. Human Factors: The Journal of the Human Factors and Ergonomics Society, 27(1), 33-45.

[103] Price, H. E., Maisano, R. E., and VanCott, H. P. (1982). The Allocation of Functions in ManMachine Systems: A Perspective and Literature Review (NUREG/CR-2623). Washington DC: U.S. Nuclear Regulatory Commission.

[104] Price, H.E., and Pulliam, R. (1988). Functional analysis and allocation of functions. In: Gael, S. (Ed.), The job analysis handbook for business, industry, and government, Volume 1 (pp. 639- 650). New York: John Wiley \& Sons.

[105] Pulliam, R., Price, H. E., Bongarra, J., Sawyer, C. R., and Kisner, R. A. (1983). A methodology for allocating nuclear power plant control functions to human or automatic control (NUREG/CR3331). Washington DC: U.S. Nuclear Regulatory Commission.

[106] Rasmussen, J., Pejtersen, A. M., and Goodstein, L. P. (1994). Cognitive systems engineering. New York: Wiley.

[107] Reason, J. (1987). Cognitive aids in process environments: prostheses or tools? International Journal of Man-Machine Studies, 27(5), 463-470.

[108] Roberts, N. and Edson, R. (2008). System Concept of Operations: Standards, Practices and Reality. In 11th Annual NDIA Systems Engineering Conference,

[109] Roth, E. M., Patterson, E.S. and Mumaw, R. J. (2002). Cognitive Engineering: Issues in UserCentered System Design. In J. J. Marciniak (Ed.), Encyclopedia of Software Engineering, 2nd Edition, 163-179. New York: Wiley-Interscience, John Wiley and Sons.

[110] Sarter, N. B., and Woods, D. D. (1995). How in the world did we ever get into that mode? Mode error and awareness in supervisory control. Human Factors: The Journal of the Human Factors and Ergonomics Society, 37(1), 5-19.

[111] Scallen, S.F., and Hancock, P.A. (2001). Implementing Adaptive Function Allocation. The International Journal of Aviation Psychology, 11(2), 197-221.

[112] Scerbo, M. W. (2006). Adaptive automation. In W. Karwowski (Ed.), International encyclopedia of ergonomics and human factors, Vol 1, 2nd Ed. Boca Raton, FL: Taylor \& Francis.

[113] Scerbo, M.W. (2006). Dynamic Function Allocation. In Karwowski, W., Ed., International Encyclopaedia of Ergonomics and Human Factors, Vol 1, 2nd Ed. Boca Raton, FL: Taylor and Francis.

[114] Sharit, J. (1996). Allocation of functions. In Salvendy, G. (Ed.), Handbook of Human Factors and Ergonomics. New York: Wiley.

[115] Sheridan, T. (2005). A brief history of normative models of human behavior. In Proceedings of the HFES - 49th Annual Meeting. Santa Monica, CA: Human Factors and Ergonomics Society.

[116] Sheridan, T. B. (2000). Function allocation: algorithm, alchemy or apostasy? International Journal of Human-Computer Studies, 52(2), 203-216.

[117] Sheridan, T. B. (2002). Humans and Automation: System Design and Research Issues. New York: John Wiley \& Sons, Inc. 
[118] Shraagen, J. M., Chipman, S. F., and Shalin, V. L., (Eds.) (2000). Cognitive Task Analysis. Mahwah, NJ: Lawrence Erlbaum Associates, Inc.

[119] Slovik, G. C., and Van Tuyle, G. J. (1990). Analysis of Unscrammed Events in PRISM (BNLNUREG-46344). Upton, NY: Brookhaven National Laboratory.

[120] Slovik, G. C. and Van Tuyle, G. J. (1991). Analysis of Postulated Events for the Revised ALMR/PRISM Design (BNL-NUREG-46429). Proceedings of the Nuclear Regulatory Commission Water Reactor Safety Information Meeting, Bethesda, Maryland, October 1991.

[121] Slovik, G. C., Van Tuyle, G.J., and Sands, S. (1992). Assessment of PRISM Response to Loss of Flow Events (BNL-NUREG-47818). Proceedings of the International Conference on the Design and Safety of Advanced Nuclear Power Plants, Tokyo, Japan, October 1992.

[122] Smith, J. (2011). Small Modular Reactor Issue Identification and Ranking Program: Control Room Staffing, Final Report. Washington, DC: U.S. Nuclear Regulatory Commission, Office of New Reactors.

[123] Stanton, N. A., Salmon, P., Jenkins, D., and Walker, G. (2010). Human factors in the design and evaluation of control room operations. Boca Raton: CRC Press, Taylor and Francis.

[124] Stubler, W., Higgins, J., and Kramer, J. (2000). Maintenance of Digital Systems: Technical Basis and Human Factors Review Guidance (NUREG/CR-6636). Washington DC: U.S. Nuclear Regulatory Commission.

[125] Stubler, W. and O'Hara, J. (1996a). Group-View Displays (BNL TR E2090-T4-4-12/94, Rev. 1). Upton, NY: Brookhaven National Laboratory.

[126] Stubler, W. and O'Hara, J. (1996b). Human-System Interface Design Process and Review Criteria (BNL TR E2090-T4-1-9/96). Upton, NY: Brookhaven National Laboratory.

[127] Stubler, W. F., O'Hara, J., Higgins, J., and Kramer, J. (2000). Human-System Interface and Plant Modernization Process: Technical Basis and Human Factors Review Guidance (NUREG/CR6637). Washington DC: U.S. Nuclear Regulatory Commission.

[128] Stubler, W. F., O'Hara, J., and Kramer, J. (2000). Soft Controls: Technical Basis and Human Factors Review Guidance (NUREG/CR-6635). Washington DC: U.S. Nuclear Regulatory Commission.

[129] Sun, K. (2012). Analysis of Advanced Sodium-cooled Fast Reactor Core Designs with Improved Safety Characteristics, Doctoral Dissertation, Thesis no 5480, Ecole Polytechnique Federale de Lausanne, SW.

[130] Triplett, B. S., Loewen, E. P., and Dooies, B. J. (2012). PRISM: A competitive small modular sodium cooled reactor. Nuclear Technology, 178, 186-200.

[131] U.S. Code of Federal Regulations (revised periodically). Part 26, "Fitness for Duty Programs," Title 10, "Energy" (10 CFR 26). Washington, DC: U.S. Government Printing Office.

[132] U.S. Code of Federal Regulations (revised periodically). Part 50, "Domestic Licensing of Production and Utilization Facilities," Title 10, "Energy" (10 CFR 50.13). Washington, DC: U.S. Government Printing Office.

[133] U.S. Code of Federal Regulations (revised periodically). Conditions of Licenses (10 CFR 50.54). Washington DC: U.S. Government Printing Office.

[134] U.S. Code of Federal Regulations (revised periodically). Part 52, "Early Site Permits; Standard Design Certifications; and Combined Licenses for Nuclear Power Plants," Title 10, "Energy" (10 CFR 52). Washington, DC: U.S. Government Printing Office. 
[135] U.S. Code of Federal Regulations (revised periodically). Part 55, "Operator's Licenses," Title 10, "Energy" (10 CFR 55). Washington, DC: U.S. Government Printing Office.

[136] U.S. Department of Energy (2003). Nuclear Energy Research Initiative: 2003 Annual Report (DOE/NE-0125). Washington DC: U.S. Department of Energy, Office of Nuclear Energy, Science and Technology. http://www.ne.doe.gov/pdfFiles/neri2003 annualreport.pdf.

[137] U.S. Department of Energy (2012a). Advanced Reactor Concepts. Technical Review Panel Report Evaluation and Identification of future R\&D on Eight Advanced Reactor Concepts. Washintgon DC.

[138] U.S. Department of Energy (2012b). Small Modular Reactors. Washington DC: Office of Nuclear Energy. http://energy.gov/ne/nuclear-reactor-technologies/small-modular-nuclear-reactors

[139] U.S. Nuclear Regulatory Commission (1980a). Clarification of TMI Action Plan Requirements (NUREG-0737). Washington, DC.

[140] U.S. Nuclear Regulatory Commission (1980b). NRC Action Plan Developed as a Result of the TMI2 Accident (NUREG-0660). Washington, DC.

[141] U.S. Nuclear Regulatory Commission (1981). Human Factors Acceptance Criteria for the Safety Parameter Display System (NUREG-0835). Washington, DC.

[142] U.S. Nuclear Regulatory Commission (1982a). Clarification of TMI Action Plan Requirements: Requirements for Emergency Response Capability (NUREG-0737, Supplement 1). Washington, DC.

[143] U.S. Nuclear Regulatory Commission (1982b). Guidelines for the Preparation of Emergency Operating Procedures (NUREG-0899). Washington, DC.

[144] U.S. Nuclear Regulatory Commission (1989). Lessons Learned From the Special Inspection Program for Emergency Operating Procedures (NUREG-1358). Washington, DC.

[145] U.S. Nuclear Regulatory Commission (1992). Lessons Learned From the Special Inspection Program for Emergency Operating Procedures (NUREG-1358, Supplement 1). Washington, DC.

[146] U.S. Nuclear Regulatory Commission (1997). Crediting of Operator Actions in Place of Automatic Actions and Modifications of Operator Actions, Including Response Times (Information Notice 9778). Washington, DC.

[147] U.S. Nuclear Regulatory Commission (2000). Technical Basis and Implementation Guidelines for a Technique for Human Event Analysis (ATHEANA) (NUREG-1624, Rev. 1). Washington, DC.

[148] U.S. Nuclear Regulatory Commission (2001). Inspection Manual: Chapter 0609, Significance Determination Process (CN Number 01-015). Washington, DC.

[149] U.S. Nuclear Regulatory Commission (2002). Inspection Manual: Chapter 2515, Light-water Reactor Inspection Program - Operations Phase (CN Number 02-001). Washington, DC.

[150] U.S. Nuclear Regulatory Commission (2004). Status of Staff's Proposed Regulatory Structure for New Plant Licensing and Potentially New Policy Issues (SECY-04-0157). Washington DC.

[151] U.S. Nuclear Regulatory Commission (2006). Reactor Oversight Process (NUREG-1649, Rev. 4). Washington, DC.

[152] U.S. Nuclear Regulatory Commission (2007a). Standard Review Plan: Conduct of Operations (NUREG-0800, Chapter 13). Washington, DC.

[153] U.S. Nuclear Regulatory Commission (2007b). Standard Review Plan: Human Factors Engineering (NUREG-0800, Chapter 18). Washington, DC. 
[154] U.S. Nuclear Regulatory Commission (2007c). Standard Review Plan: Use of Probabilistic Risk Assessment in Plant-Specific, Risk-Informed Decision Making: General Guidance (NUREG-0800, Chapter 19). Washington, DC.

[155] U.S. Nuclear Regulatory Commission (2008a). Guidance to Operators at the Controls and to Senior Operators in the Control Room of a Nuclear Power Unit (Regulatory Guide 1.114, Rev. 3). Washington DC. http://pbadupws.nrc.gov/docs/ML0823/ML082380236.pdf.

[156] U.S. Nuclear Regulatory Commission (2008b). Highly-Integrated Control Rooms-Human Factors Issues (DI\&C-ISG-05, Rev. 1). Washington, DC.

[157] U.S. Nuclear Regulatory Commission (2010). Potential Policy, Licensing, and Key Technical Issues for Small Modular Nuclear Reactor Designs (SECY-10-0034). Washington DC.

[158] U.S. Nuclear Regulatory Commission (2011a). An Approach for Plant-Specific, Risk-Informed Decision making: Technical Specifications (Regulatory Guide 1.177, Rev. 1). Washington, DC.

[159] U.S. Nuclear Regulatory Commission (2011b). An Approach for Using Probabilistic Risk Assessment in Risk-Informed Decisions on Plant-Specific Changes to the Licensing Basis (Regulatory Guide 1.174, Rev. 2). Washington, DC.

[160] U.S. Nuclear Regulatory Commission (2011c). Feasibility of Including Risk Information in Categorizing Structures, Systems, and Components as Safety-Related or Nonsafety-Related (SECY11-0156). Washington DC.

[161] U.S. Nuclear Regulatory Commission (2011d). Operator Staffing for Small or Multi-Module Nuclear Power Plant Facilities (SECY-11-0098). Washington DC.

[162] U.S. Nuclear Regulatory Commission (2011e). Staff Assessment of Selected Small Modular Reactor Issues Identified in SECY-10-0034 (SECY-11-0112). Washington DC.

[163] U.S. Nuclear Regulatory Commission (2011f). Use of Risk Insights to Enhance the Safety Focus of Small Modular Reactor Reviews (SECY-11-0024). Washington DC.

[164] U.S. Nuclear Regulatory Commission (2012). Report to Congress: Advanced Reactor Licensing. Washington DC.

[165] U.S. Nuclear Regulatory Commission (periodically updated). Emergency Operating Procedures (IP 42001), Washington, DC.

[166] U.S. Nuclear Regulatory Commission (periodically updated). Plant Procedures (IP 42700). Washington, DC.

[167] U.S. Nuclear Regulatory Commission (periodically updated). Sustained Control Room and Plant Observation (IP 71715). Washington DC.

[168] Vicente, K. J. (1999). Cognitive Work Analysis: Toward Safe, Productive, and Healthy ComputerBased Work. Mahwah, NJ: Lawrence Erlbaum Associates, Inc.

[169] Vicente, K. J., Moray, N., Lee, J. D., Hurecon, J. R., Jones, B. G., Brock, R., and Djemil, T. (1996). Evaluation of a Rankine cycle display for nuclear power plant monitoring and diagnosis. Human Factors, 38(3), 506-521.

[170] Wickens, C., Li, H., Santamaria, A., Sebok, A., and Sarter, N. (2010). Stages and Level of Automation: An integrated meta-analysis. Proceedings of the Human Factors and Ergonomics Society Annual Meeting, 54, 389.

[171] Wood, R. T. (2012). U.S. Department of Energy instrumentation and controls technology research for advanced small modular reactors. Nuclear Safety and Simulation, 3(4), 292-299. 
[172] Wood, R., Antonescu, C., Arndt, S., Britton, C., Brown-VanHoozer, S. Calvert, J. Damiano, B., Easter, J., Freer, M., Mullens, J., Neal, J., Protopopescu,V., Shaffer, R., Schryver, J., Smith, C. Tucker, R., Uhrig, R., Upadhyaya, B., Wetherington, G., Wilson, T., White, J., and Whitus, B.(2003). Emerging Technologies in Instrumentation and Controls (NUREG/CR-6812). Washington DC: U.S. Nuclear Regulatory Commission.

[173] Woods, D. D. (1985). Cognitive technologies: The design of joint human-machine cognitive systems. AI Magazine, 6(4), 86.

[174] Woods, D. D., and Hollnagel, E. (2006). Joint cognitive systems: Patterns in cognitive systems engineering. Boca Raton, FL: CRC Press.

[175] World Nuclear Association (2013). Small Nuclear Power Reactors. http://www.worldnuclear.org/info/Nuclear-Fuel-Cycle/Power-Reactors//Small-Nuclear-PowerReactors/\#.UVW3Yb-9-24, accessed March 2013.

[176] Yokoyama, K., and Shono, A. (2011). Japan's Experimental Fast Reactor JOYO Mk-I Core: Sodium-cooled Uranium-Plutonium Mixed Oxide Fueled Fast Core Surrounded by UO2 Blanket. International Handbook of Evaluated Reactor Physics Benchmark Experiments (IRPhE) (JOYOLMFR-RESR-001, NEA/NSC/DOC (2006) 1). OECD/NEA. 